\title{
Improving oxygenation in spontaneously breathing patients with atelectatic lung
}

\author{
András Lovas MD
}

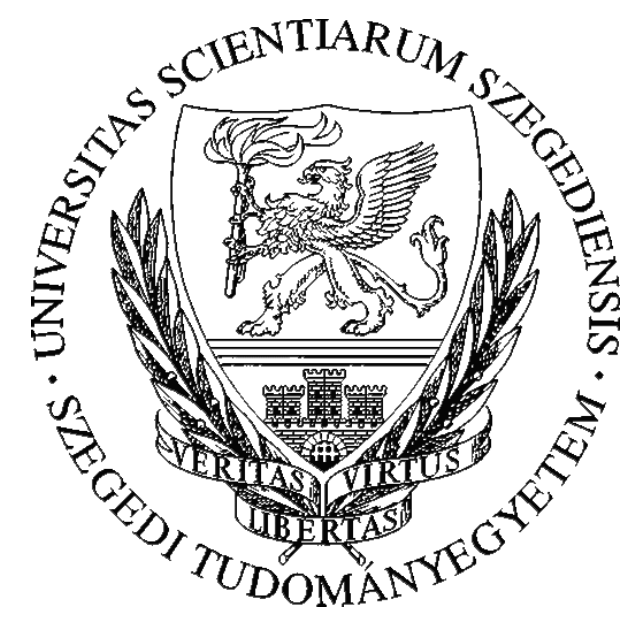

Department of Anaesthesiology and Intensive Therapy University of Szeged Supervisor: Prof. Zsolt Molnár MD PhD

$\mathrm{PhD}$ Thesis

Szeged

2015 



\section{Full paper publications related to the thesis}

I. Lovas A, Molnár Z. T-piece improves arterial and central venous oxygenation in trachestomized patients as compared to continuous positive airway pressure/pressure support ventilation. Minerva Anestesiol 2013;79(5):492-497.

\section{IF: 2.272}

II. Lovas A, Németh MF, Trásy D, Molnár Z. Lung recruitment can improve oxygenation in patients ventilated in continuous positive airway pressure/pressure support mode. Front Med (Lausanne) 2015;2:25. doi: 10.3389/fmed.2015.00025

\section{IF: pending}

III. Lovas A, Szakmány T. Haemodynamic effects of lung recruitment manoeuvres. Biomed Res Int 2015;Article ID 478970. doi:10.1155/2015/478970

\section{IF: 1.579}

\section{Book chapters related to the thesis}

IV. Lovas A. Alveolustoborzás in Molnár Z, Bede A (szerk.). A lélegeztetés gyakorlata. Medicina Könyvkiadó Zrt., Budapest, 2015:133-146.

V. Lovas A. Leszoktatás gépi lélegeztetésről in Molnár Z, Bede A (szerk.). A lélegeztetés gyakorlata. Medicina Könyvkiadó Zrt., Budapest, 2015:175-195.

\section{Presentations related to the thesis}

VI. Lovas A, Kószó R, Molnár Z. T-piece improves arterial and central venous oxygenation in tracheostomized patients as compared to pressure support (PS) ventilation. Intensive Care Med 2012;38 Supplement 1:S149-50.

\section{IF: $\mathbf{5 . 2 5 8}$}


VII. Lovas A, Trásy D, Németh M, Lászlo I, Molnár Z. Effect of lung recruitment on oxygenation in patients with acute lung injury ventilated in $\mathrm{CPAP} /$ pressure support mode. Critical Care 2015;19:P226

\section{IF: 4.48}

VIII. Lovas A, Kószó R, Molnár Z. A T-szár hatása az artériás oxigén tenzióra és centrális vénás szaturációra tracheosztomizált betegek gépi lélegeztetésröl történő leszoktatása során. MAITT 40. Kongresszus, Siófok, 2012. május 3.-5.

IX. Lovas A, Németh M, Molnár Z. Alveolus toborzás akut hipoxiás légzési elégtelenségben szenvedő, spontán nyomástámogatott üzemmódban lélegeztetett betegeknél. MAITT 40. Kongresszus, Siófok, 2013. május 23.-25.

X. Lovas A. Alveolus toborzás spontán légző betegnél. Szegedi Intenzív Terápiás Napok (SZINT), Szeged, 2013. november 14.-16.

XI. Lovas A. Leszoktatás: gép vagy ember vezérelje? SZINT, Szeged, 2015. november 12.-13.

XII. Lovas A. Mechanical ventilation in patients with COPD. 2nd SOS Team Days, Subotica-Palic, Serbia, 24-26 September 2015

XIII. Lovas A. Hemodynamic effects of lung recruitment. Third Congress of Intensive Care Medicine, Belgrade, Serbia, 26-28 November 2015 


\section{Table of contents}

1. Introduction 5

1.1. The open lung concept $\quad 5$

1.2. Benefits of maintaining spontaneous breathing $\quad 7$

1.3. Spontaneous breathing trial with T-piece 8

1.4. Our aims 10

2. Effects of alveolar recruitment in patients ventilated in continuous positive airway pressure/pressure support mode $\quad 11$

2.1. Materials and methods 11

2.1.1. Patients 11

2.1.2. Measurements and experimental protocol 11

2.1.3. Statistics 12

2.2. Results 13

3. Effects of T-piece on arterial and central venous oxygenation in trachestomized patients as compared to continuous positive airway pressure/pressure support ventilation

3.1. Materials and methods

3.1.1. Patients

3.1.2. Measurements and experimental protocol 18

3.1.3. Statistics 19

3.2. Results 
4.1. Effects of alveolar recruitment in patients ventilated in continuous positive airway pressure/pressure support mode

4.2. Effects of T-piece on arterial and central venous oxygenation in trachestomized patients as compared to continuous positive airway pressure/pressure support ventilation 


\section{Introduction}

Hypoxemic respiratory failure is one of the leading causes of the need for mechanical ventilation, in the most severe cases as the consequence of acute respiratory distress syndrome (ARDS), which still carries high risk of mortality. ${ }^{1}$ ARDS is a life threatening condition precipitated by disorders frequently resulting in critical care admissions like trauma, severe burns, sepsis, pancreatitis and pneumonia. ${ }^{2}$ All of these disorders, either causing direct (pulmonary) or indirect (extrapulmonary) tissue damage are featured by a systemic inflammatory response. The released cytokines like interleukin (IL)-1, IL-6, IL-8 and tumor necrosis factor activate neutrophils in the lung throughout the inflammatory cascade. ${ }^{3}$ The activated immune cells excrete injurious substances such as free oxygen radicals and proteolytic enzymes leading to alveolar endothelium and epithelium destruction. The latter pathophysiological mechanism induces impaired permeability in the lung resulting in alveolar immerging by the protein rich oedema fluid. ${ }^{4}$ Surfactant, which has a major role in modulating the surface tension of alveoli is also washed out. Furthermore, the surfactant production is also decreased due to the dysfunction of type II epithelial cells. As a consequence, pulmonary atelectasis develops due to alveolar collapse. ${ }^{5}$

Pulmonary atelectasis is accompanied by arterial hypoxemia due to increased intrapulmonary shunt (Fig. 1). ${ }^{6}$ As severe acute hypoxemia is a potential danger for all vital organs its resolution is of pivotal importance. There are several interventions, which may help improving oxygenation. In the most severe circumstances extracorporeal membrane oxygenation $^{7}$, high frequency oscillatory ventilation ${ }^{8}$, and prone positioning ${ }^{9}$ have been shown to reverse persistent hypoxemia. Some of these interventions require special equipment, demand extra manpower and may be time consuming to commence.

\subsection{The open lung concept}

In less severe cases of acute hypoxemia, especially when this is primarily caused by atelectasis, the collapsed lung areas can be opened up with the help of transient increment in 
transpulmonary pressure (TP) within a short time, hence decreasing shunt fraction and improving arterial oxygenation. ${ }^{10}$ This procedure is called the lung recruitment manoeuvre. It can be accompanied by the titration of the "optimal" positive end-expiratory pressure (PEEP), a process which is called on a broader term as the "open lung concept" described by Lachmann in 1992. ${ }^{11}$

Figure 1. Intrapulmonary shunt with the background of atelectasis in the alveolus
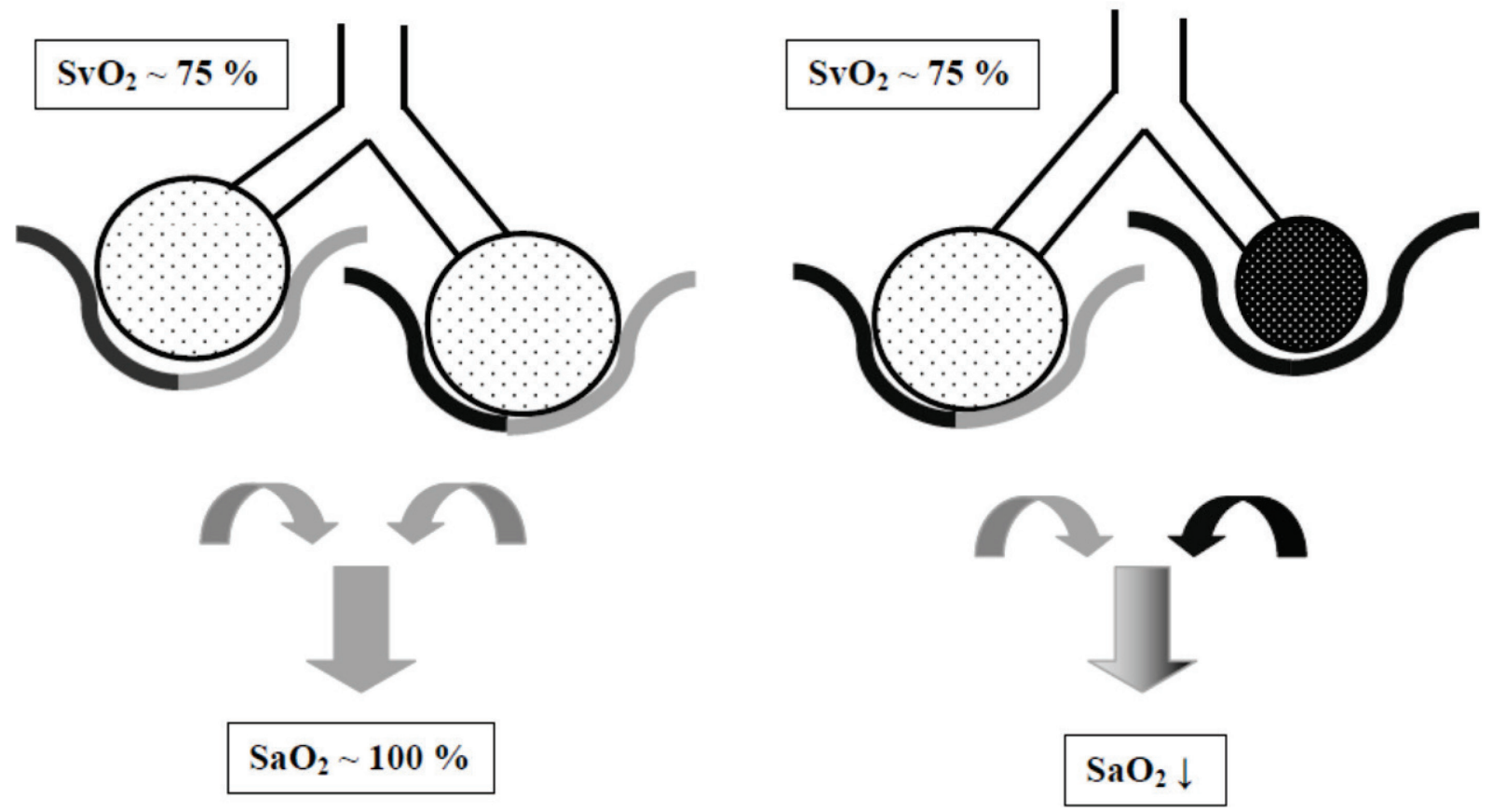

However, it is also well known that not every lung responds for recruitment manoeuvers. ${ }^{12}$ Although most recruitment strategies were tested under controlled mechanical ventilation $^{13}$, there is also increasing evidence that maintaining spontaneous breathing during mechanical ventilation may provide numerous advantages. ${ }^{14,15}$ Applying continuous positive airway pressure (CPAP) with or without pressure support (PS) and allowing the patient to breathe spontaneously is an often used ventilation mode, both during non-invasive and invasive ventilation. Although theoretically alveolar recruitment may also have a place in these patients ventilated invasively this has only been investigated during non-invasive ventilation. 


\subsection{Benefits of maintaining spontaneous breathing}

Maintaining spontaneous breathing on mechanical ventilation may provide several benefits. One of these advantages is the improvement of oxygenation in patients with acute lung injury by the recruitment of atelectatic lung areas in the juxtadiaphragmatic regions. Diaphragmatic contractions evoked by spontaneous breathing efforts may facilitate the recruitment of collapsed, dependent lung regions. As the collapse of alveoli is more pronounced in the dorsal regions where the muscle contraction induced diaphragm excursion is the most remarkable the redistribution of ventilation-perfusion ratio may improve oxygenation (Fig 2). ${ }^{15}$

Beyond amelioration in gas exchange maintaining spontaneous breathing offers the prevention of cyclic alveolar atelectasis in the basal pulmonary regions. The undesirable alveolar shearing generated by the cyclic collapse and re-opening can be reduced by this advantageous phenomenon. ${ }^{15}$ Henceforward spontaneous breathing movements can amend the protective ventilation strategy by attenuating the mechanical distress. Reducing the inflammatory response at the level of alveoli may provide advances in the regeneration of pulmonary function.

Figure 2. Diaphragm excursion and ventilation/perfusion $\left(\mathrm{V}_{\mathrm{A}} / \mathrm{Q}\right)$ distribution during spontaneous breathing and mechanical ventilation

\section{anterior}

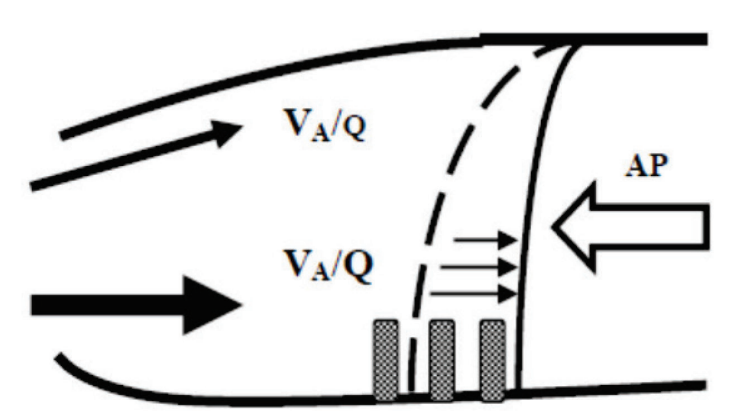

posterior

SPONTANEOUS BREATHING

MECHANICAL VENTILATION

AP, abdominal pressure 
Prolonged respiratory support, especially controlled mechanical ventilation (CMV), induces diaphragm muscle atrophy and dysfunction. The inability of diaphragm contraction precipitated by CMV leads to neural deactivation and molecular changes in the muscle cells. ${ }^{13}$ Maintaining spontaneous breathing is advantageous in the prevention of losing force generated by diaphragm contractility. Furthermore, reserving spontaneous breathing during mechanical ventilation offers a lower level of sedation target and improved patient-ventilator interaction. This has a major impact on respiratory weaning. The reduced requirement of sedatives attenuates the duration of respiratory support, decreases the length of stay in the intensive care unit and the overall cost of care giving. ${ }^{15}$

\subsection{Spontaneous breathing trial with T-piece}

Weaning from mechanical ventilation is a challenging process for critical care physicians. Over the last decades many respiratory strategies were investigated to identify the most suitable method of successful weaning. ${ }^{16}$ Conducting spontaneous breathing trial (SBT) with T-piece to identify patients ready for extubation has been a common practice, but it may also be used as a weaning tool by alternating periods of ventilatory support and SBT on Tpiece.

Ayre's T-piece is a simple, non-rebreathing circuit first used in paediatric anaesthesia. ${ }^{17}$ Its potential advantages in the critical care setting are the minimal dead space, the low airway resistance and the activation of the breathing muscles. The inspired fraction of oxygen $\left(\mathrm{FiO}_{2}\right)$ can be adjusted with high flow oxygen/air mixers or by the application of a Venturi injector on the inspiratory limb. PEEP can also be applied with the help of a PEEPvalve at the end of the expiratory limb hereby establishing a high flow CPAP circuit (Fig. $3) .{ }^{18}$ Comparing with mechanical ventilation disadvantages are the lack of pressure support, monitoring airway pressure and tidal volume.

Spontaneous ventilation can be facilitated by new generation of ventilators, by applying CPAP with pressure support (PS) and automatic tube compensation (ATC). The purpose of the latter is the automatic regulation of the airway pressure in proportion to the ventilator's flow rate in order to compensate for the resistance of artificial airways. ${ }^{19}$ However, T-piece is applied widespread in everyday practice its effect on gas exchange has not been investigated yet. 
Figure 3. Scheme of the T-piece circuit.

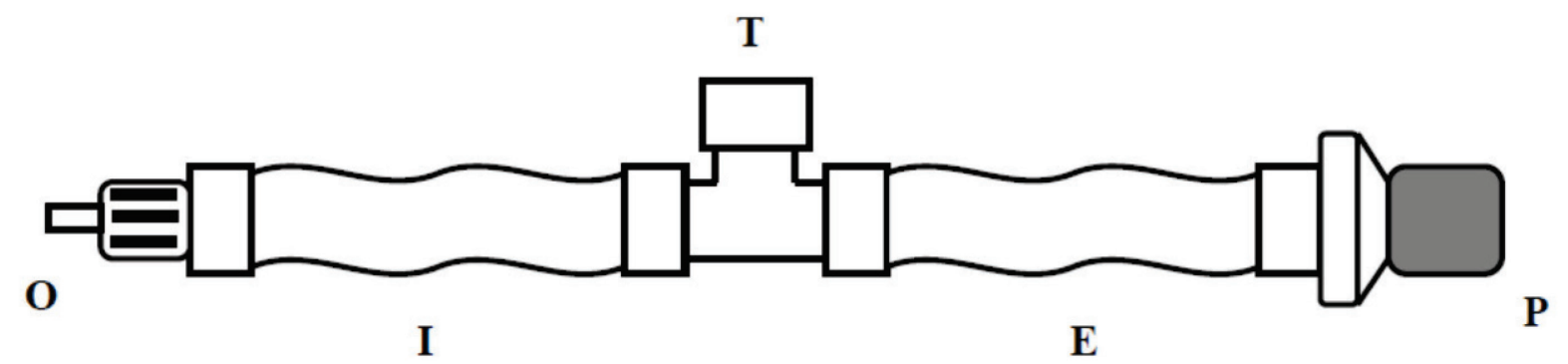

O, oxygen connector with Venturi injector; I, inspiratory limb corrugated tube; T, T-piece; E, expiratory limb corrugated tube; P, PEEP valve 
1.4. Our aims

1. To investigate the effects of recruitment on the $\mathrm{PaO}_{2} / \mathrm{FiO}_{2}$ ratio in patients ventilated in CPAP/PS mode suffering from moderate and severe hypoxemic respiratory failure.

2. To assess recruitability in patients ventilated in CPAP/PS mode suffering from moderate and severe hypoxemic respiratory failure.

3. To investigate the effects of T-piece on gas exchange as compared to CPAP/PS and CPAP/automatic tube compensation (ATC) modes in tracheostomized patients during respiratory weaning.

4. To investigate alteration in central venous oxygen saturation $\left(\mathrm{ScvO}_{2}\right)$ after recruitment manoeuver in spontaneously breathing patients ventilated in CPAP/PS mode suffering from moderate and severe hypoxemic respiratory failure and throughout T-piece trial in tracheostomized patients during respiratory weaning. 


\section{Effects of alveolar recruitment in patients ventilated in continuous positive airway pressure/pressure support mode}

\subsection{Materials and methods}

\subsubsection{Patients}

Following ethics committee approval of the Human Investigation Review Board of University of Szeged, informed consent was obtained from the patients' next of kin. All mechanically ventilated patients with maintained spontaneous breathing, ventilated in CPAP/PS mode with a PEEP $\geq 5 \mathrm{cmH}_{2} \mathrm{O}$, were enrolled in this prospective, observational study if their $\mathrm{PaO}_{2} / \mathrm{FiO}_{2}$ ratio $<300 \mathrm{mmHg}$ or required an $\mathrm{FiO}_{2}>0.5$, regardless of the etiology of respiratory failure. ${ }^{20,21}$ Exclusion criteria were: age $<18$, pregnancy, pulmonectomy/lobectomy or spontaneous pneumothorax in past medical history, emphysematous bullae, clinically diagnosed end stage chronic obstructive pulmonary disease and vasopressor refractory hemodynamic instability.

\subsubsection{Measurements and experimental protocol}

All patients who were eligible for the study had a radial arterial and an internal jugular or subclavian central venous catheter inserted on admission to the intensive care unit as part of our standard care. Patients were sedated with continuous infusion of propofol and fentanyl reaching a Richmond Agitation Sedation Scale score of -1 to -2. Electrocardiogram, invasive blood pressure and $\mathrm{SpO}_{2}$ were continuously monitored by Dräger Infinity Gamma XL Monitor (Telford, PA, USA). Patients were ventilated with Dräger Evita ${ }^{\circledR}$ XL respirators (Lübeck, Germany). The level of pressure support was adjusted to achieve adequate arterial $\mathrm{pCO}_{2}$ level to maintain $\mathrm{pH} \geq 7.30$. Respiratory parameters, airway pressures, dynamic respiratory compliance, airway resistance, end-tidal carbon dioxide $\left(\mathrm{EtCO}_{2}\right)$, dead space $(\mathrm{Vds})$ and dead space to exhaled tidal volume ratio (Vds/Vte) were all continuously monitored by the respirator and its own volumetric capnography.

Once inclusion criteria were fulfilled respirator settings, cardio-respiratory and airway parameters were recorded at baseline. Then PEEP was increased by $5 \mathrm{cmH}_{2} \mathrm{O}$ and after 5 
minutes measurements were repeated to investigate the effect of any PEEP-induced recruitment. For alveolar recruitment pressure support was increased to $40 \mathrm{cmH}_{2} \mathrm{O}$ for 40 seconds to limit the undesirable side effects of volutrauma. After which peak inspiratory pressure was reduced to the initial value as at baseline while maintaining the increased level of PEEP (by $5 \mathrm{cmH}_{2} \mathrm{O}$ ) according to the open lung concept. ${ }^{11}$ Measurements were repeated immediately after recruitment then 15 and 30 minutes later with constant respirator settings as at baseline. Arterial blood gas samples were analyzed by a Roche cobas b 221 (Mannheim, Germany) blood gas system at each measurement points and central venous samples were taken at baseline and at the final time point to determine $\mathrm{ScvO}_{2}$.

Primary outcome parameter was the change in oxygenation $\left(\mathrm{PaO}_{2} / \mathrm{FiO}_{2}\right)$ after the recruitment manoeuver. Patients were considered as non-responders (NR) if difference of $\mathrm{PaO}_{2} / \mathrm{FiO}_{2}<20 \%$ and responders $(\mathrm{R})$ if difference of $\mathrm{PaO}_{2} / \mathrm{FiO}_{2} \geq 20 \%$ between baseline and following recruitment measurements.

\subsubsection{Statistics}

Based on a preliminary analysis of our data ${ }^{22}$, the mean $\mathrm{PaO}_{2} / \mathrm{FiO}_{2}$ ratio before recruitment was $156 \mathrm{mmHg}$ with a standard deviation of $43 \mathrm{mmHg}$. In order the study to have an $80 \%$ power with a $\mathrm{P}<0.05$ and to observe an increase in the $\mathrm{PaO}_{2} / \mathrm{FiO}_{2}$ of 10 or $20 \%$ (which corresponds to a $\mathrm{PaO}_{2} / \mathrm{FiO}_{2}$ of 171 and $186 \mathrm{mmHg}$ respectively) after recruitment, the required minimal sample size was calculated to be 51 or 13 . Therefore we decided that a sample size of 30 should be feasible and provide adequate statistical power.

All data in the tables are presented as median [interquartile range]. Figures are presented as boxplots: $5^{\text {th }}-95^{\text {th }}$ percentile, interquartile range and median. After testing for normality with Shapiro-Wilk test data were analyzed between groups with Mann-Whitney U test or Kruskal-Wallis test as suitable. Matched pairs were investigated with Wilcoxon signed rank test and relationship was analyzed with Spearman's correlation coefficient. For evaluating goodness of fit and independence Pearson's chi-square test was used. The "P" value was considered significant if $<0.05$. For statistical analysis IBM SPSS Statistics Version 20 (Armonk, NY, USA) software was used. 


\subsection{Results}

Over the study period 30 patients were enrolled, of whom $15(50 \%)$ patients turned out to be non-responders and $15(50 \%)$ responders. There was no significant difference between groups in baseline respirator settings and demographic characteristics except of age. Out of the 19 patients with admission diagnosis of cardiac origin 13 (68\%) were responders (Table 1). Serious adverse effects of recruitment manoeuver like pneumothorax and worsening hemodynamic instability were not detected.

Table 1. Demographic data

\begin{tabular}{lccc}
\hline & $\begin{array}{c}\text { Non-responders } \\
(\mathrm{n}=15)\end{array}$ & $\begin{array}{c}\text { Responders } \\
(\mathrm{n}=15)\end{array}$ & $\mathrm{P}$ \\
\hline Age $-\mathrm{yr}$ & $63[55-58]$ & $74[59-76]$ & .045 \\
Male/female $-\mathrm{N}$. & $11 / 4$ & $9 / 6$ & \\
Body-mass index $-\mathrm{kg} / \mathrm{m}^{2}$ & $27[24-31]$ & $29[25-34]$ & .389 \\
APACHE II score & $21[18-25]$ & $23[19-33]$ & .851 \\
Baseline PEEP $-\mathrm{cmH}_{2} \mathrm{O}$ & $10[8-12]$ & $10[10-12]$ & .389 \\
Baseline $\mathrm{FiO}{ }_{2}-\%$ & $60[50-62]$ & $60[60-80]$ & .126 \\
Baseline $\mathrm{PS}-\mathrm{cmH}_{2} \mathrm{O}$ & $12[8-16]$ & $10[10-16]$ & .935 \\
Ventilated days $-\mathrm{N}$. & $4[2-6]$ & $2[1-4]$ & .202 \\
Lung injury score & $2.3[1.7-2.7]$ & $2.3[2.0-2.8]$ & .461 \\
Orotracheal tube ID $-\mathrm{mm}$ & $8[8-8.5]$ & $8[8-8]$ & .567 \\
\hline Cause of admission $(\%)$ & & & \\
Heart failure & $4(13)$ & $6(20)$ & \\
Ischemic heart disease & $2(8)$ & $7(24)$ & \\
Pneumonia & $3(10)$ & $1(3)$ & \\
Sepsis & $3(10)$ & 0 & \\
Pulmonary contusion & $1(3)$ & 0 & \\
Stroke & $1(3)$ & 0 & \\
Other & $1(3)$ & $1(3)$ & \\
\hline
\end{tabular}

APACHE II, acute physiology and chronic health evaluation II; PEEP, positive end-expiratory pressure; PS, Pressure Support; ID, internal diameter 
There was a non-significant decrease in $\mathrm{PaO}_{2} / \mathrm{FiO}_{2}$ from baseline to 30 minutes following recruitment in the NR-group. In the R-group $\mathrm{PaO}_{2} / \mathrm{FiO}_{2}$ significantly improved after the recruitment manoeuver as compared to baseline results and remained elevated throughout the observation period. There was significant improvement in $\mathrm{SaO}_{2}$ among responders, while there was no significant change in the NR-group. Bicarbonate and base excess levels showed significant difference between groups at all time points. Hemodynamic parameters and $\mathrm{ScvO}_{2}$ did not show any significant change over time (Table 2, Fig 4).

Table 2. Hemodynamic variables and blood gas results

\begin{tabular}{|c|c|c|c|c|c|c|}
\hline & \multirow[b]{2}{*}{ Group } & \multicolumn{5}{|c|}{ Time point } \\
\hline & & Baseline & $\begin{array}{c}\text { PEEP } \\
\text { increment }\end{array}$ & After RM & $\begin{array}{c}15 \text { min } \\
\text { following } R M\end{array}$ & $\begin{array}{c}30 \text { min } \\
\text { following } R M\end{array}$ \\
\hline \multirow{2}{*}{$\begin{array}{l}\text { heart rate - } \\
1 / \mathrm{min}\end{array}$} & NR & 88 [64-99] & 89 [68-102] & 87 [66-100] & 91 [67-99] & 90 [67-99] \\
\hline & $\mathrm{R}$ & 95 [70-100] & 95 [72-115] & $93[70-106]$ & $92[70-101]$ & 99 [70-119] \\
\hline \multirow{2}{*}{$\mathrm{MAP}-\mathrm{mmHg}$} & NR & $75[68-92]$ & $80[70-83]$ & $79[68-88]$ & $79[69-83]$ & $80[70-86]$ \\
\hline & $\mathrm{R}$ & $75[69-88]$ & $75[71-87]$ & $78[66-87]$ & $76[68-85]$ & $74[69-86]$ \\
\hline \multirow{2}{*}{$\mathrm{SaO}_{2}-\%$} & NR & 96 [93-99] & 97 [94-99] & 97 [94-99] & 97 [95-98] & 97 [95-99] \\
\hline & $\mathrm{R}$ & $95[94-97]$ & $96[95-98]^{\mathrm{a}}$ & $98[96-99]^{\mathrm{a}}$ & $98[96-99]^{\mathrm{a}}$ & $97[96-99]^{\mathrm{a}}$ \\
\hline \multirow{2}{*}{$\begin{array}{l}\mathrm{PaCO}_{2}- \\
\mathrm{mmHg}\end{array}$} & NR & $47[44-50]$ & $50[44-52]$ & $48[43-50]$ & $48[45-53]$ & $48[43-52]$ \\
\hline & $\mathrm{R}$ & $39[37-49]$ & $41[37-50]$ & $42[37-51]$ & $40[37-52]$ & $39[37-53]$ \\
\hline \multirow{2}{*}{$\mathrm{ScvO}_{2}-\%$} & NR & $74[70-82]$ & & & & $77[69-83]$ \\
\hline & $\mathrm{R}$ & $76[69-79]$ & & & & $77[72-81]$ \\
\hline \multirow{2}{*}{$\mathrm{pH}$} & NR & $7.4[7.3-7.4]$ & $7.4[7.3-7.4]$ & $7.4[7.3-7.4]$ & $7.4[7.3-7.4]$ & $7.4[7.3-7.4]$ \\
\hline & $\mathrm{R}$ & $7.4[7.3-7.4]$ & $7.4[7.3-7.4]$ & $7.4[7.3-7.4]$ & $7.4[7.3-7.4]$ & $7.4[7.3-7.4]$ \\
\hline \multirow{2}{*}{$\begin{array}{l}\mathrm{HCO}_{3}{ }^{-}- \\
\mathrm{mmol} / \mathrm{L}\end{array}$} & NR & $28[24-31]$ & $29[24-31]$ & $28[24-31]$ & $29[24-31]$ & $28[23-31]$ \\
\hline & $\mathrm{R}$ & $23[20-28]^{b}$ & $23[21-27]^{\mathrm{b}}$ & $23[21-28]^{b}$ & $23[21-28]^{b}$ & $23[20-28]^{b}$ \\
\hline \multirow{2}{*}{$\mathrm{BE}$} & NR & $2.7[-0.3-4.5]$ & $3.2[-0.7-5.1]$ & $2.9[-0.6-5.0]$ & $3.2[-1.3-5.3]$ & $3.0[-2.4-5.0]$ \\
\hline & $\mathrm{R}$ & $-1.4[-4.2-2.5]^{\mathrm{b}}$ & $-1.6[-4.2-2.5]^{b}$ & $-1.8[-4.2-2.1]^{b}$ & $-1.9[-4.2-1.9]^{b}$ & $-1.9[-4.2-1.8]^{b}$ \\
\hline \multirow{2}{*}{$\begin{array}{l}\text { lactate - } \\
\mathrm{mmol} / \mathrm{L}\end{array}$} & NR & $0.9[0.7-1.1]$ & $0.9[0.7-1.0]$ & $0.9[0.7-1.1]$ & 0.9 [0.6-1.0] & $0.9[0.6-1.0]$ \\
\hline & $\mathrm{R}$ & $1.1[0.8-1.6]$ & $1.1[0.8-1.5]$ & $1.1[0.8-1.5]$ & $1.1[0.9-1.5]$ & $1.0[0.7-1.5]$ \\
\hline
\end{tabular}

PEEP, positive end-expiratory pressure; RM, recruitment manoeuver; NR, Non-responder; R, Responder; MAP, Mean Arterial Pressure; $\mathrm{ScvO}_{2}$, central venous oxygen saturation; $\mathrm{BE}$, Base Excess

${ }^{a}$ significant difference as compared to baseline measurements, $\mathrm{P}<.05$

${ }^{\mathrm{b}}$ significant difference between groups, $\mathrm{P}<.05$ 
Figure 4. Changes in $\mathrm{PaO}_{2} / \mathrm{FiO}_{2}$

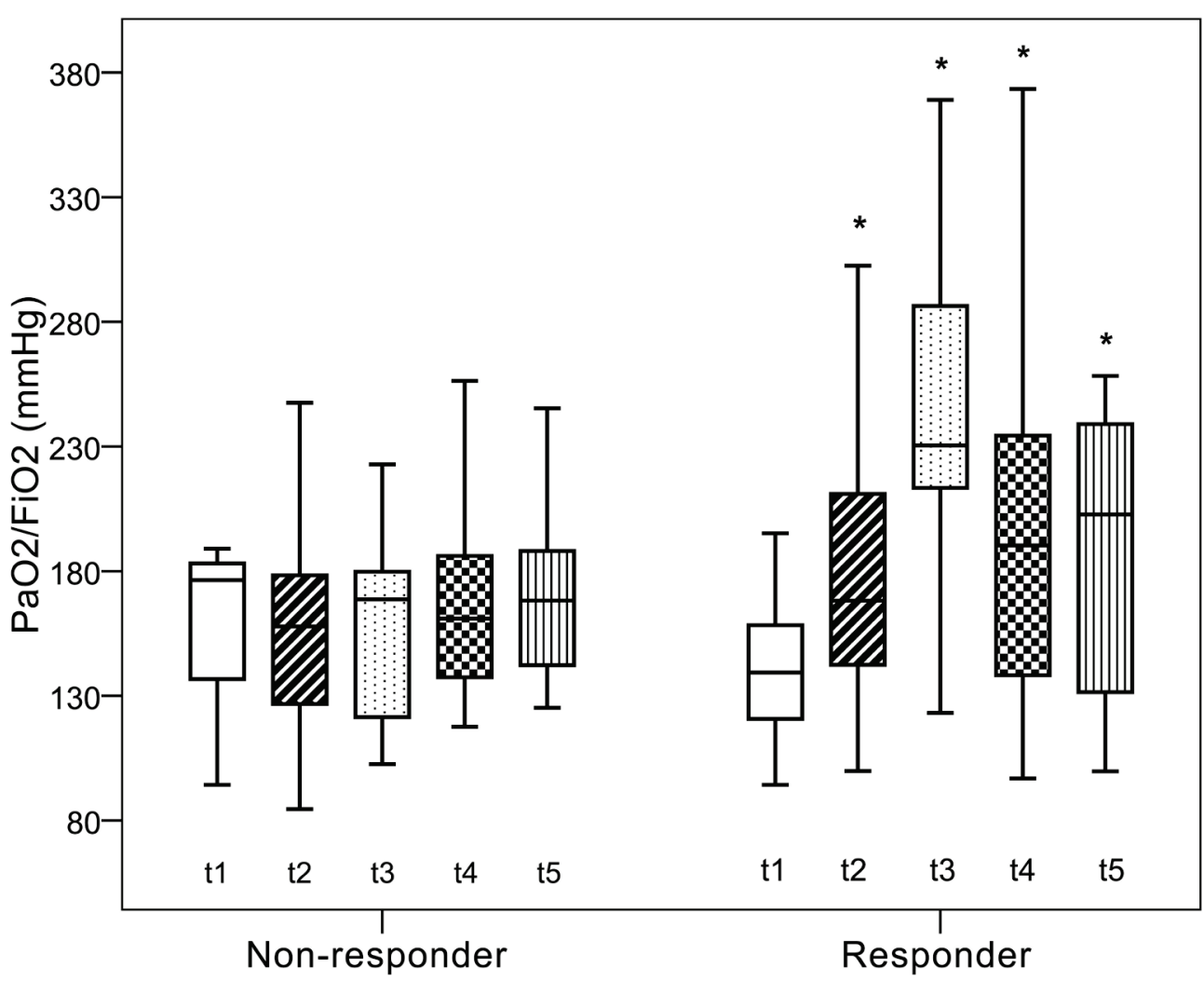

$\mathrm{t}_{0}$, baseline measurements; $\mathrm{t}_{1}$, increasing PEEP by $5 \mathrm{cmH}_{2} \mathrm{O} ; \mathrm{t}_{2}$, after recruitment; $t_{3}$ and $t_{4}, 15$ and 30 minutes after recruitment. *significant difference as compared to baseline measurements, $\mathrm{P}<.05$

There was no significant change in tidal volume, Vte indexed for predicted bodyweight, respiratory rate and minute ventilation between groups and throughout the study as compared to baseline parameters. In the NR-group dynamic compliance, a parameter indicated on the ventilator dropped non-significantly after the recruitment manoeuver but there was a significant increase in $\mathrm{Vds} / \mathrm{Vte}$ following recruitment and 15 minutes later as compared to baseline in the same group. There was no other significant change in the examined respiratory and airway parameters in the NR- and R-group. (Table 3). 
Table 3. Respiratory and airway parameters complemented with arterial to end-tidal $\mathrm{CO}_{2}$ results

\begin{tabular}{|c|c|c|c|c|c|c|}
\hline & \multirow[b]{2}{*}{ Group } & \multicolumn{5}{|c|}{ Time point } \\
\hline & & Baseline & $\begin{array}{c}\text { PEEP } \\
\text { increment }\end{array}$ & After RM & $\begin{array}{c}15 \mathrm{~min} \\
\text { following } \mathrm{RM}\end{array}$ & $\begin{array}{c}30 \text { min } \\
\text { following } R M\end{array}$ \\
\hline \multirow{2}{*}{ Vte $-\mathrm{ml}$} & NR & 473 [398-612] & 479 [397-588] & 447 [393-615] & 506 [378-597] & $471[453-663]$ \\
\hline & $\mathrm{R}$ & 513 [406-667] & $489[385-702]$ & $492[398-602]$ & 510 [354-698] & $520[402-741]$ \\
\hline \multirow{2}{*}{$\begin{array}{l}\text { Vte/PBW - } \\
\mathrm{ml} / \mathrm{kg}\end{array}$} & NR & $8[6-8]$ & 7 [6-9] & $7[5-8]$ & 7 [6-9] & 7 [6-9] \\
\hline & $\mathrm{R}$ & 7 [7-9] & 7 [6-10] & 7 [6-10] & 8 [6-10] & 8 [7-10] \\
\hline \multirow{2}{*}{$\mathrm{RR}-1 / \mathrm{min}$} & NR & 17 [13-22] & 18 [13-20] & 18 [13-20] & 18 [13-20] & 17 [14-22] \\
\hline & $\mathrm{R}$ & 19 [13-24] & 19 [14-26] & 17 [14-26] & $19[15-24]$ & 18 [14-24] \\
\hline \multirow{2}{*}{$\mathrm{MV}-\mathrm{ml}$} & NR & $\begin{array}{l}7896[7011- \\
11016]\end{array}$ & $\begin{array}{l}8040[6300- \\
11020]\end{array}$ & $\begin{array}{l}7524 \text { [7152- } \\
9825]\end{array}$ & $\begin{array}{l}7809[6230- \\
10380]\end{array}$ & $\begin{array}{l}8208 \text { [7260- } \\
10296]\end{array}$ \\
\hline & $\mathrm{R}$ & $\begin{array}{l}9744 \text { [8037- } \\
11687]\end{array}$ & $\begin{array}{l}9741[8220- \\
10875]\end{array}$ & $\begin{array}{l}9798[7700- \\
11808]\end{array}$ & $\begin{array}{l}10101 \text { [8328- } \\
11328]\end{array}$ & $\begin{array}{l}10116 \text { [8788- } \\
11625]\end{array}$ \\
\hline \multirow{2}{*}{$\begin{array}{l}\mathrm{R}_{\mathrm{aw}}- \\
\mathrm{cmH}_{2} \mathrm{O} / \mathrm{L} / \mathrm{s}\end{array}$} & NR & 13 [9-14] & 13 [9-18] & 14 [10-17] & 13 [9-18] & 14 [9-18] \\
\hline & $\mathrm{R}$ & $11[9-16]$ & $11[9-16]$ & 11 [9-16] & $11[9-15]$ & 11 [9-15] \\
\hline \multirow{2}{*}{$\begin{array}{l}\mathrm{C}_{\mathrm{rs}}- \\
\mathrm{ml} / \mathrm{cmH}_{2} \mathrm{O}\end{array}$} & NR & 68 [47-83] & $65[41-85]$ & $64[42-75]$ & 69 [43-95] & 68 [46-85] \\
\hline & $\mathrm{R}$ & 52 [34-98] & 53 [31-106] & $56[36-90]$ & 58 [39-98] & 58 [39-99] \\
\hline \multirow{2}{*}{$\begin{array}{l}\mathrm{EtCO}_{2}- \\
\mathrm{mmHg}\end{array}$} & NR & $42[34-45]$ & $41[35-47]$ & $40[34-45]$ & $41[36-47]$ & $41[37-45]$ \\
\hline & $\mathrm{R}$ & 36 [30-47] & 37 [31-47] & 39 [31-47] & $38[30-48]$ & $39[30-48]$ \\
\hline \multirow{2}{*}{$\begin{array}{l}\mathrm{P}_{(\mathrm{a}-\mathrm{ET})} \mathrm{CO}_{2}- \\
\mathrm{mmHg}\end{array}$} & NR & 7 [4-13] & 8 [4-10] & $8[5-13]$ & 7 [4-11] & 7 [4-13] \\
\hline & $\mathrm{R}$ & 5 [1-9] & 6 [2-9] & $6[3-11]$ & $5[1-10]$ & 6 [1-9] \\
\hline \multirow{2}{*}{$\mathrm{Vds}-\mathrm{ml}$} & NR & 146 [128-191] & 148 [135-201] & 153 [133-198] & 150 [127-198] & 150 [127-198] \\
\hline & $\mathrm{R}$ & $153[118-172]$ & $166[126-180]$ & 144 [118-180] & $153[125-177]$ & $158[125-183]$ \\
\hline \multirow{2}{*}{$\begin{array}{l}\text { Vds/Vte - } \\
\%\end{array}$} & NR & 32 [27-37] & $35[30-42]$ & $36[25-42]^{\mathrm{a}}$ & $35[29-41]^{\mathrm{a}}$ & 32 [29-40] \\
\hline & $\mathrm{R}$ & $26[22-34]$ & 28 [24-38] & 27 [24-33] & 27 [24-34] & $28[25-36]$ \\
\hline
\end{tabular}

PEEP, positive end-expiratory pressure; RM, recruitment manoeuver; NR, Non-responder; R, Responder; Vte, exhaled tidal volume; Vte/PBW, exhaled tidal volume indexed to Predicted Body Weight; RR, Respiratory Rate; MV, Minute Ventilation; $\mathrm{R}_{\mathrm{aw}}$, airway resistance; $\mathrm{C}_{\mathrm{rs}}$, dynamic compliance; $\mathrm{EtCO}_{2}$, end-tidal $\mathrm{CO}_{2} ; \mathrm{P}_{(\mathrm{a}-\mathrm{ET})} \mathrm{CO}_{2}$, arterial minus end-tidal $\mathrm{CO}_{2} ; \mathrm{Vds}$, dead space; Vds/Vte, dead space to exhaled tidal volume ratio

${ }^{a}$ significant difference as compared to baseline measurements, $\mathrm{P}<.05$

Improvement in oxygenation was detected in $74 \%$ of all patients, and in $26 \%$ arterial oxygenation did not improve or even deteriorated. Testing in a contingency table the change in $\mathrm{PaO}_{2} / \mathrm{FiO}_{2}$ and dynamic compliance after the recruitment manoeuver is shown in Fig. 5. Improvement $(\geq 0)$ or deterioration $(<0)$ of dynamic compliance gave high sensitivity and specificity with a positive predictive value of 0.89 to differentiate patients with worsening as compared to those with improved $\mathrm{PaO}_{2} / \mathrm{FiO}_{2}$. 
Figure 5. Changes in $\mathrm{PaO}_{2} / \mathrm{FiO}_{2}$ and dynamic compliance after recruitment manoeuver as compared to baseline parameters

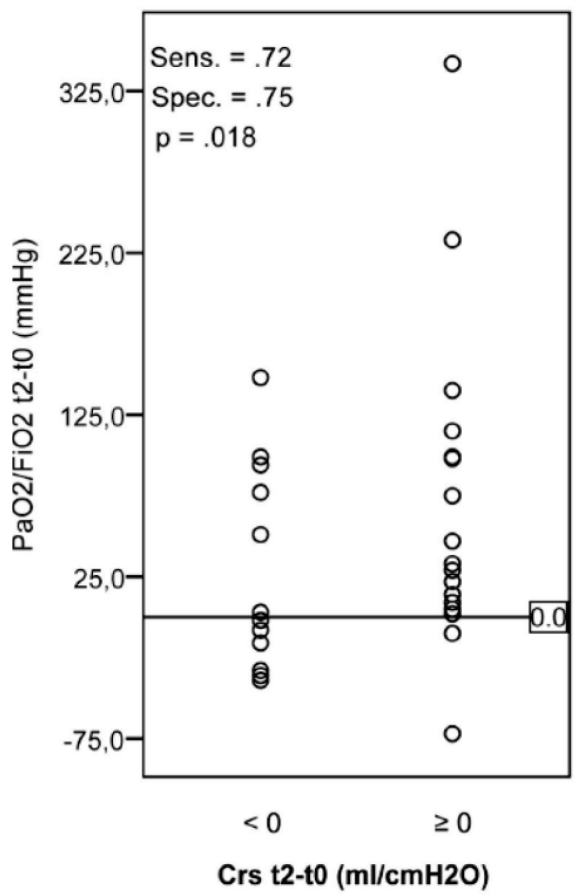

$\mathrm{C}_{\mathrm{rs}}$, dynamic compliance, Sens., Sensitivity; Spec., Specificity 


\section{Effects of T-piece on arterial and central venous oxygenation in trachestomized patients as compared to continuous positive airway pressure/pressure support ventilation}

\subsection{Materials and methods}

\subsubsection{Patients}

The study was approved by the Human Investigation Review Board of University of Szeged. Due to the prospective observational design of the study, and because T-piece weaning has long tradition in the department and the protocol included no other intervention that regular monitoring, the need for informed consent was waived. All patients ventilated in CPAP/PS mode via a tracheostomy tube and fulfilling the criteria of the department's weaning protocol of SBT were enrolled. Weaning criteria were defined as: $\mathrm{SpO}_{2}>94 \%$, respiratory rate $(\mathrm{RR})<35 \mathrm{~min}^{-1}$, hemodynamic stability with heart rate $(\mathrm{HR})<100 \mathrm{~min}^{-1}$, mean arterial pressure (MAP) $>60 \mathrm{mmHg}$ on PEEP $<10 \mathrm{cmH}_{2} \mathrm{O}, \mathrm{FiO}_{2}<50 \%$ and PS $\leq 10$ $\mathrm{cmH}_{2} \mathrm{O}$. Exclusion criteria were: pregnancy, age under 18, coexisting ventilator associated pneumonia and pulmonectomy or lobectomy in past medical history. Electrocardiogram, invasive blood pressure, $\mathrm{SpO}_{2}$ and $\mathrm{RR}$ were continuously monitored by Dräger Infinity Gamma XL Monitor (Telford, PA, USA) and central venous catheters were in situ in all cases. Patients were ventilated by Dräger Evita ${ }^{\circledR}$ XL respirator (Lübeck, Germany) at all times.

\subsubsection{Measurements and experimental protocol}

Once patients fulfilled the criteria for weaning, baseline $\left(\mathrm{t}_{0}\right)$ respirator settings, cardiorespiratory parameters and arterial and central venous blood gas results were recorded while the patients were ventilated in CPAP/PS mode. Then PS was decreased to $0 \mathrm{cmH}_{2} \mathrm{O}$ when just ATC was applied for 15 minutes and the respiratory parameters were recorded again $\left(t_{1}\right)$. ATC was set to $100 \%$ compensation, artificial airway was marked as tracheostomy tube with the exact internal diameter. After that patients were placed on T-piece with constant $\mathrm{FiO}_{2}$ and PEEP according to the respirator settings. T-piece was assembled from: a) T-tube 
(Intersurgical, Wokingham, United Kingdom), b) $1500 \mathrm{~mm}$ long corrugated tube as inspiratory limb, with a c) Venturi injector (Intersurgical, Wokingham, United Kingdom) to provide adequate fresh gas flow $(30-50 \mathrm{~L} / \mathrm{min})$, d) a $500 \mathrm{~mm}$ long corrugated tube as expiratory limb, with e) a pre-calibrated, adjustable PEEP valve (Ambu, Baltorpbakken, Denmark). $\mathrm{FiO}_{2}$ was monitored throughout with an Ohmeda 5100 Oxygen Monitor (Madison, WI, USA) connected between the Venturi injector and the inspiratory limb of the T-piece. Repeated measurements were taken at $15\left(\mathrm{t}_{2}\right), 30\left(\mathrm{t}_{3}\right)$ and 60 minutes $\left(\mathrm{t}_{4}\right)$ on the T-piece trial. Vital parameters were recorded and arterial blood gas samples were analysed by a Roche cobas b 221 (Mannheim, Germany) blood gas system at each measurement points and central venous samples were taken at $t_{0}$ and $t_{4}$ to determine $\mathrm{ScvO}_{2}$. The trial was interrupted if $\mathrm{RR}$ increased $>35 \mathrm{~min}^{-1}, \mathrm{SpO}_{2}$ decreased permanently under $90 \%$, HR $>120 \mathrm{~min}^{-1}$, blood pressure $>160 / 90 \mathrm{mmHg}$ or patient indicated shortness of breath.

\subsubsection{Statistics}

After testing for normality with the Kolgomorov-Smirnov test with Lilliefor's modification, matched pairs were tested by nonparametric Friedman's ANOVA test. The "P" value was considered significant if $<0.05$. For statistical analysis PASW Statistics 18 (Chichago, IL, USA) software was used.

\subsection{Results}

Over the study period 25 tracheostomized patients were enrolled. The trial was interrupted in four cases $(16 \%)$ after $t_{2}$, because of pulmonary oedema, hypertension and on two occasions because of fatigue with $\mathrm{CO}_{2}$ retention. As data was analysed on an intention-totreat basis, we included those 4 patients who failed the T-piece trial in the final analysis. Demographic characteristics of the patients is summarised in Table 4. 
Table 4. Patient characteristics

\begin{tabular}{lc}
\hline \multicolumn{1}{c}{ Characteristics } & Mean \pm SD \\
\hline Age - yr & $60 \pm 14$ \\
Male/female - no. & $14 / 7$ \\
Body-mass index & $31 \pm 9$ \\
APACHE II score & $23 \pm 7$ \\
$\mathrm{PEEP}_{-} \mathrm{cmH}_{2} \mathrm{O}$ & $7 \pm 2$ \\
$\mathrm{FiO}_{2}$ & $44 \pm 7$ \\
$\mathrm{PS}-\mathrm{cmH}_{2} \mathrm{O}$ & $8 \pm 3$ \\
$\mathrm{Ventilated} \mathrm{days}-$ no. & $10 \pm 6$ \\
Days since tracheostomy - no. & $4 \pm 4$ \\
\hline Cause of admission & No. (\%) \\
Trauma & $5(24)$ \\
$\quad$ Heart failure & $4(19)$ \\
Sepsis & $4(19)$ \\
Intracerebral haemorrhage & $3(14)$ \\
Other & $5(24)$ \\
\hline
\end{tabular}

APACHE II, acute physiology and chronic health evaluation II; PEEP, positive end-expiratory pressure; PS, pressure support

\subsubsection{CPAP/PS versus $C P A P / A T C$}

$\mathrm{PaO}_{2} / \mathrm{FiO}_{2}$ and $\mathrm{SaO}_{2}$ did not show any significant change on CPAP/ATC as compared to CPAP/PS mode (Fig 6). Tidal volume (Vte) did not decrease significantly with a significant increase in RR at the same time. There was no significant change in arterial carbon dioxide $\left(\mathrm{PaCO}_{2}\right), \mathrm{pH}$, base excess $(\mathrm{BE})$, bicarbonate $\left(\mathrm{HCO}_{3}{ }^{-}\right)$and lactate. Switching from CPAP/PS to CPAP/ATC had no effect on haemodynamic parameters, as indicated by MAP and HR values (Table 5). 
Table 5. Blood gas results and vital parameters. Data are presented as median [interquartile range]

\begin{tabular}{|c|c|c|c|c|c|}
\hline & $\begin{array}{c}\mathrm{t}_{0} \\
(\mathrm{n}=25)\end{array}$ & $\begin{array}{c}\mathrm{t}_{1} \\
(\mathrm{n}=25)\end{array}$ & $\begin{array}{c}\mathrm{t}_{2} \\
(\mathrm{n}=25)\end{array}$ & $\begin{array}{c}\mathrm{t}_{3} \\
(\mathrm{n}=21)\end{array}$ & $\begin{array}{c}\mathrm{t}_{4} \\
(\mathrm{n}=21)\end{array}$ \\
\hline Vte-ml & $450[365-530]$ & $407[335-500]$ & & & \\
\hline $\mathrm{RR}-\min ^{-1}$ & 23 [18-30] & $27[20-30]^{\mathrm{c}}$ & $30[26-33]^{\mathrm{c}, \mathrm{d}}$ & $28[24-35]^{\mathrm{c}, \mathrm{d}}$ & $29[25-35]^{\mathrm{c}, \mathrm{d}}$ \\
\hline $\mathrm{SaO}_{2}-\%$ & 97 [96-98] & 97 [95-98] & $99[97-99]^{\mathrm{c}, \mathrm{d}}$ & $99[97-99]^{\mathrm{c}, \mathrm{d}}$ & $99[97-99]^{\mathrm{c}, \mathrm{d}}$ \\
\hline $\mathrm{PaO}_{2}-\mathrm{mmHg}$ & 89 [78-111] & 96 [82-113] & $119[98-138]^{c}$ & $\begin{array}{c}127[101- \\
149]^{\mathrm{c}, \mathrm{d}}\end{array}$ & $122[98-144]^{\mathrm{c}, \mathrm{d}}$ \\
\hline $\begin{array}{l}\mathrm{PaO}_{2} / \mathrm{FiO}_{2}- \\
\mathrm{mmHg}\end{array}$ & 208 [175-266] & 223 [186-290] & $262[207-339]^{\mathrm{c}}$ & $\begin{array}{c}270[208- \\
373]^{\mathrm{c}, \mathrm{d}}\end{array}$ & $\begin{array}{c}249[215- \\
325]^{\mathrm{c}, \mathrm{d}}\end{array}$ \\
\hline $\mathrm{PaCO}_{2}-\mathrm{mmHg}$ & $41[37-47]$ & $41[38-48]$ & $47[43-55]^{\mathrm{c}, \mathrm{d}}$ & $49[43-58]^{\mathrm{c}, \mathrm{d}}$ & $50[43-58]^{\mathrm{c}, \mathrm{d}}$ \\
\hline $\mathrm{ScvO}_{2}-\%$ & 73 [71-78] & & & & $80[75-82]^{\mathrm{c}}$ \\
\hline $\mathrm{pH}$ & $\begin{array}{c}7.41[7.39- \\
7.43]\end{array}$ & $\begin{array}{c}7.41[7.38- \\
7.43]\end{array}$ & $\begin{array}{c}7.36[7.33- \\
7.40]^{\mathrm{a}, \mathrm{b}}\end{array}$ & $\begin{array}{c}7.37[7.33- \\
7.41]^{\mathrm{a}, \mathrm{b}}\end{array}$ & $\begin{array}{c}7.38[7.33- \\
7.41]^{\mathrm{a}, \mathrm{b}}\end{array}$ \\
\hline $\mathrm{HCO}_{3}^{-}-\mathrm{mmol} / 1$ & $\begin{array}{c}25.9[23.7- \\
27.9]\end{array}$ & $\begin{array}{c}26.1[24.4- \\
27.6]\end{array}$ & $\begin{array}{c}26.9[25.8- \\
29.2]^{\mathrm{c}, \mathrm{d}}\end{array}$ & $\begin{array}{c}27.1[25.7- \\
30.6]^{\mathrm{c}, \mathrm{d}}\end{array}$ & $\begin{array}{c}27.0[25.9- \\
29.6]^{\mathrm{c}, \mathrm{d}}\end{array}$ \\
\hline $\mathrm{BE}$ & $1.3[-0.2-2.8]$ & $1.4[0.0-2.3]$ & $1.2[0.3-3.0]$ & $1.6[0.1-4.3]$ & $1.9[0.2-3.4]$ \\
\hline Lactate-mmol/1 & $1.0[0.5-1.2]$ & $0.9[0.5-1.2]$ & $1.0[0.6-1.1]$ & $0.9[0.6-1.0]^{\mathrm{a}, \mathrm{b}}$ & $0.8[0.5-1.0]^{\mathrm{a}}$ \\
\hline $\mathrm{HR}-\mathrm{min}^{-1}$ & 79 [71-86] & 78 [71-87] & 83 [72-93] & 83 [73-93] & $85[74-96]^{\mathrm{d}}$ \\
\hline MAP-mmHg & 82 [73-95] & 83 [73-95] & $90[80-106]^{\mathrm{c}, \mathrm{d}}$ & $91[79-105]^{\mathrm{c}, \mathrm{d}}$ & $93[78-101]^{\mathrm{d}}$ \\
\hline
\end{tabular}

Vte, tidal volume; RR, respiratory rate; $\mathrm{BE}$, base excess; $\mathrm{HR}$, heart rate; MAP, mean arterial pressure

\footnotetext{
${ }^{a}$ significant decrease as compared to $t_{0}, p<0.05$

${ }^{b}$ significant decrease as compared to $t_{1}, p<0.05$

${ }^{c}$ significant increase as compared to $t_{0}, p<0.05$

${ }^{d}$ significant increase as compared to $t_{1}, p<0.05$
} 
Figure 6. Arterial oxygen tension/fraction of inspired oxygen $\left(\mathrm{PaO}_{2} / \mathrm{FiO}_{2}\right)$. Data are presented as $5^{\text {th }}-95^{\text {th }}$ percentile, interquartile range and median

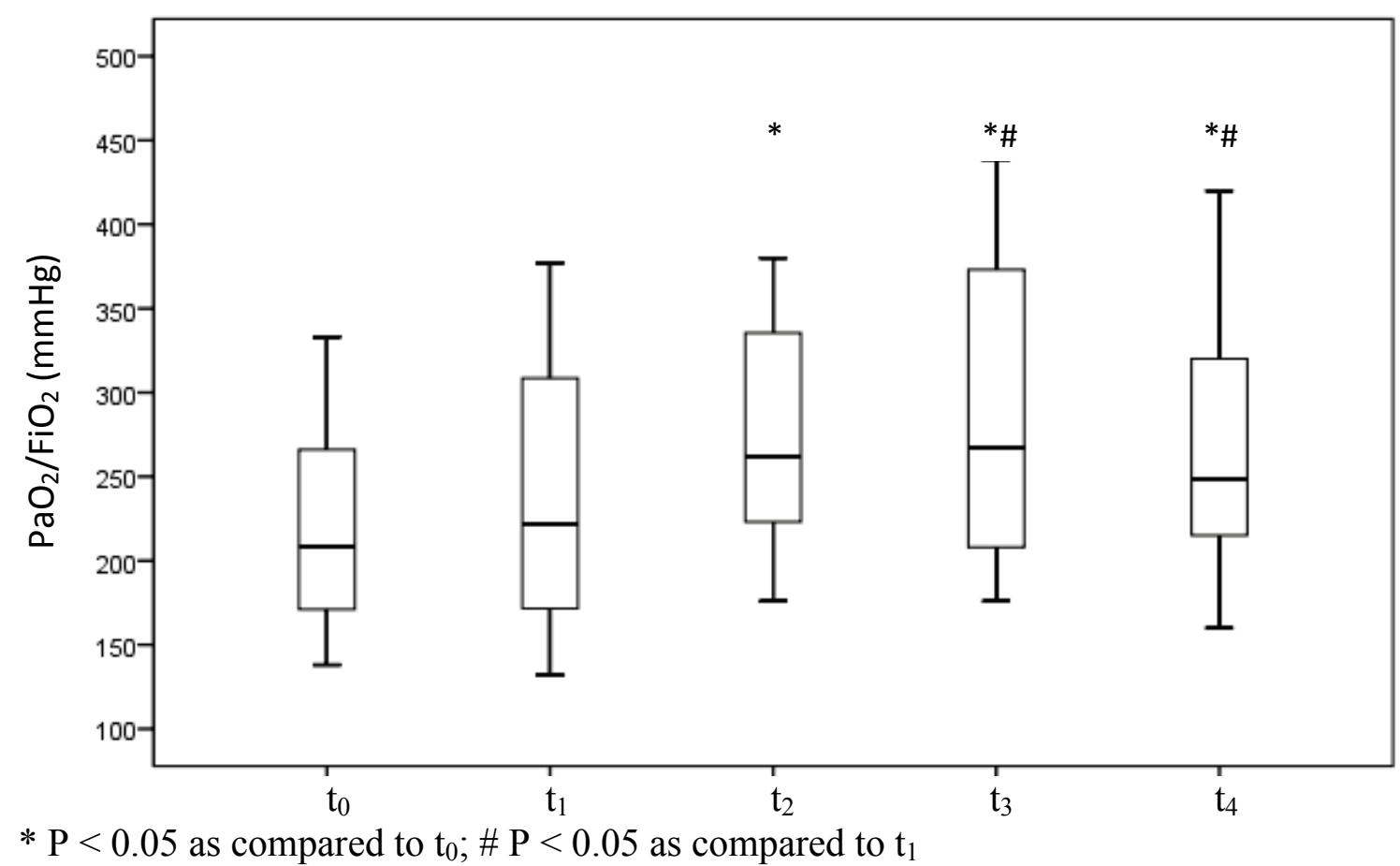

\subsection{2. $C P A P / P S$ and $C P A P / A T C$ versus T-piece}

Regarding oxygenation, $\mathrm{PaO}_{2} / \mathrm{FiO}_{2}$ and $\mathrm{SaO}_{2}$ showed significant improvement almost at all measurement points on T-piece trial as compared to CPAP/PS and CPAP/ATC modes except of results at $t_{2}$ as compared to $t_{1}$ when $\mathrm{PaO}_{2} / \mathrm{FiO}_{2}$ did not change significantly. There was also a significant increase in $\mathrm{ScvO}_{2}$ at $\mathrm{t}_{4}$ as compared to baseline measurements (Fig 6, Fig 7, Table 5). 
Figure 7. Central venous oxygen saturation. Data are presented as $5^{\text {th }}-95^{\text {th }}$ percentile, interquartile range and median

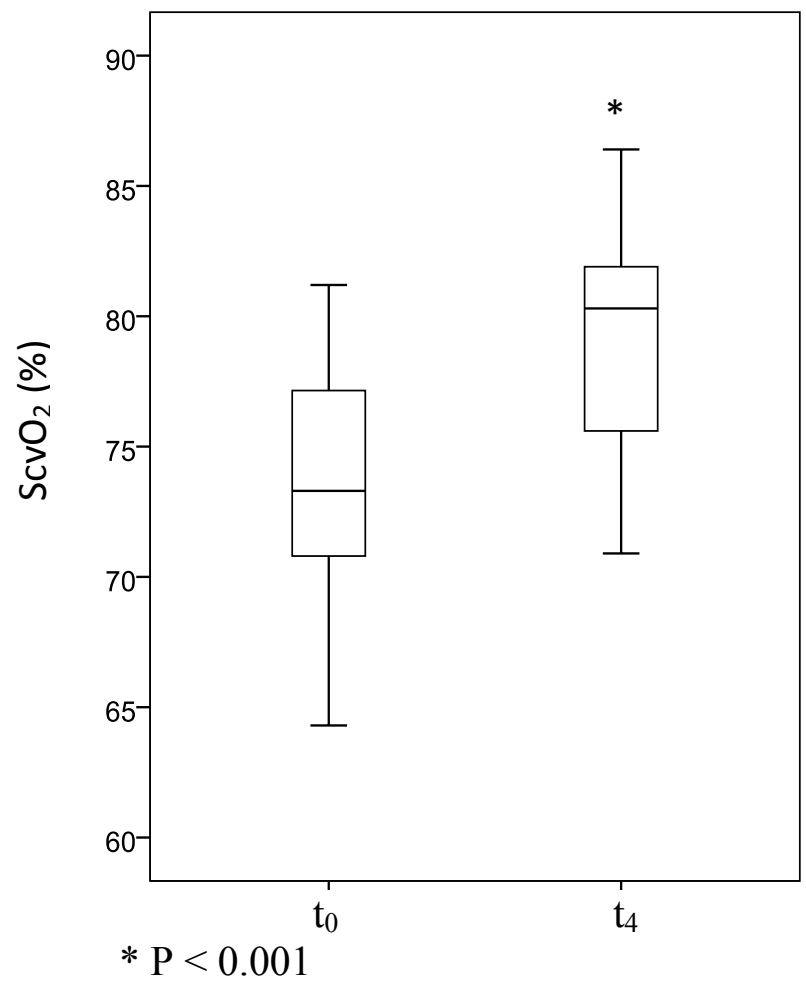

$\mathrm{RR}$ and $\mathrm{PaCO}_{2}$ were significantly higher at all time-points with a significant decrease in $\mathrm{pH}$. There was a tendency of significantly elevated $\mathrm{HCO}_{3}{ }^{-}$levels at $\mathrm{t}_{2-4}$ with no significant increase in $\mathrm{BE}$ and lactate levels showed minimal change. Regarding haemodynamic parameters MAP was significantly higher on T-piece at all time points and HR increased significantly but only by $\mathrm{t}_{4}$ as compared to $\mathrm{t}_{1}$ (Table 5 ). 


\section{Discussion}

\subsection{Effects of alveolar recruitment in patients ventilated in continuous positive airway pressure/pressure support mode}

The most important finding of the study is that recruitment manoeuver improved oxygenation by more than $20 \%$ in half of the patients with moderate and severe hypoxemic respiratory failure ventilated in CPAP/PS mode. We also found that patients in whom hypoxemia was due to cardiac origin seemed to benefit the most, as nearly $70 \%$ of these patients were found to be responders.

Patients, according to the change in the $\mathrm{PaO}_{2} / \mathrm{FiO}_{2}$ ratio after recruitment, were divided to non-responder and responder groups. Regarding the demographic data, it is an interesting finding that patients in the NR-group were significantly younger than those in the other responder group. There were also more patients with ischemic heart disease and heart failure in the R-group, while there were only four patients with heart failure in the NR-group. One of the possible explanations is that although lung compliance decreases with age in general but success of recruitment depends on other factors like co-morbidities and it may be more successful in patients with heart disease as compared to patients with pneumonia. The beneficial effects of PEEP induced alveolar recruitment with improved compliance and oxygenation are well known phenomenon in patients with ischaemic heart disease. ${ }^{23}$ PEEP can also decrease intrapulmonary shunt such as hypoxic pulmonary vasoconstriction with a reduced pulmonary artery pressure among patients with heart failure. ${ }^{24}$ Therefore it is not the age per se but the accompanying higher number of patients with heart condition that caused the observed difference in the current study. Our results draw the attention of the importance of the etiology of acute lung injury and co-morbidities, at least as far as improvement in oxygenation is concerned after the recruitment manoeuver. These results are also in accord with those reported in patients on controlled mechanical ventilation ${ }^{25}$ but it also contradicts those in which etiology did not seem to matter. ${ }^{26}$ However, in this recent study by Grasso et $a l$, the sample size was small (11 per group) and none of the patients were admitted due to acute heart failure. Nevertheless, the success of recruitment as far as oxygenation is concerned 
in spontaneously breathing patients having developed hypoxemic respiratory failure due to acute heart failure is an important finding and should be investigated further.

Although it is not the most accurate way to assess lung recruitment, but measuring changes in arterial oxygenation is one of the commonly used methods to detect the efficacy of recruitment. ${ }^{27,28}$ Furthermore, there is no consensus on how to define responders and nonresponders based on the $\mathrm{PaO}_{2} / \mathrm{FiO}_{2}$ values which vary between 30 to $50 \%$ in the literature. ${ }^{26,29}$ Due to the lack of well-defined values we have chosen an arbitrary threshold of difference in $\mathrm{PaO}_{2} / \mathrm{FiO}_{2} \geq 20 \%$ to define as responders and $<20 \%$ as non-responders following recruitment. Nevertheless, we detected an improvement of oxygenation in $74 \%$ of all patients, and in $26 \%$ arterial oxygenation did not improve or even deteriorated. Taking the $20 \%$ improvement in oxygenation as a clinically significant change, $50 \%$ of patients still responded which is similar to that of reported in recently published studies. ${ }^{30,31}$ However, it is important to note that the ratio of responders is highly dependent on the defined threshold. Furthermore, the improvement in arterial oxygenation among responders lasted longer than in studies where controlled ventilation was applied. In the investigation by Oczenski et al, after the initial improvement, $\mathrm{PaO}_{2} / \mathrm{FiO}_{2}$ returned to the baseline values after 30 minutes ${ }^{32}$ while in our trial the significant improvement in oxygenation persisted throughout, suggesting that the effects of recruitment may last longer in spontaneous assisted modes as compared to controlled modes of ventilation in hypoxemic respiratory failure. Although the sample size is too small for an outcome study, which holds true for all of the above mentioned investigations, but our data suggests that CPAP/PS ventilation and lung recruitment may have benefits in patients suffering from moderate to severe acute lung injury especially due to acute heart failure which should be investigated further.

It may also be important to note, that prior to intervention patients were ventilated for a median of 4 days in the NR-group while it was only 2 days in the R-group. Although it was not statistically significant, but these results are similar to that of reported by Grasso et al, where the length of mechanical ventilation was significantly shorter in those patients who responded for recruitment manoeuvers. ${ }^{26}$

It is well known that not every lung responds for recruitment and unnecessary manoeuvers may lead to adverse effects. ${ }^{12,33}$ Several methods had been evaluated of which chest CT scan remains the gold standard warranting the direct visualization of the recruitable 
lung tissue. ${ }^{12}$ However, this method requires the transport of the critically ill patients to the CT scanner and exposes them to radiation. ${ }^{34}$ Other bed-side measurements to assess recruitability are pressure-volume curve assessment and end-expiratory lung volume/functional residual capacity ratio measurement. ${ }^{35,36}$ Unfortunately, due to financial and ethical reasons these methods were not applied in our study therefore we only have limited proof on the change in lung volume after the recruitment.

We did not observe any significant change neither in the $\mathrm{PaCO}_{2}$ nor in any other blood gas variables throughout the study. However, there was a significant difference in bicarbonate and base excess levels between groups this observation had no effect on the investigation of recruitment. One of the potential alternatives for assessing alveolar recruitment may be the change in the difference between the arterial and end tidal $\mathrm{CO}_{2}\left(\mathrm{P}_{\mathrm{a}-\mathrm{ETCO}}\right) .{ }^{37}$ In our study $\mathrm{P}_{\mathrm{a}-}$ ${ }_{\mathrm{ET}} \mathrm{CO}_{2}$ although did not change significantly over time in neither of the groups but in the Rgroup its value was lower than in the NR-group. Therefore it may be a promising parameter but its relevance requires further studies.

Another important parameter is compliance, which is determined by volume/pressure relationships. Theoretically, in recruitable patients increasing pressures will increase volume hence compliance should improve or remain unchanged. While in non-recruitable patients increased pressures during recruitment can lead to the overdistension without gaining lung volumes, hence result in a consecutive fall in respiratory compliance. ${ }^{38}$ Although, in a recent study by Oczenski et al, in patients with ARDS who were ventilated in controlled mode and underwent recruitment after a PEEP trial there was no significant change in compliance 3 minutes after the manoeuver what was accompanied by a significant improvement in oxygenation $^{32}$, This approach cannot be evaluated in our study as the value of the ventilator indicated compliance in spontaneously breathing patients has not been validated yet.

Finally, hemodynamic changes during the recruitment manoeuver have been widely investigated. ${ }^{39,40}$ Although we did not apply advanced hemodynamic monitoring in this study but as far as heart rate, mean arterial pressure, lactate and $\mathrm{ScvO}_{2}$ are concerned there was no significant change after the recruitment procedure as compared to baseline therefore it is likely that patients remained hemodynamically stable, suggesting that performing recruitment manoeuver in CPAP/PS ventilation is a safe strategy in patients with severe acute respiratory failure 
There are several limitations of our study. In the absence of lung CT scans, recruitment and the degree of the recruited lung area cannot be estimated. Although the investigation of Gattinoni et al still remains the reference method to assess lung recruitment ${ }^{12}$ we considered it difficult to be accepted ethically because of the potential dangers of transport and radiation. Furthermore, esophageal and herewith transpulmonary pressures were not monitored therefore we could not conclude if pleural pressure was swinging in spontaneously breathing patients hereby producing different recruitment effects during the time course of the manoeuver. Finally, neither the sample size which was too small nor the protocol (with one single recruitment manoeuver only) allowed us to draw any conclusion regarding hard clinical end-points such as ventilator free days, length of stay or outcome. However, based on the current findings, a study designed to answer these questions is certainly warranted. Nevertheless, the significant tendency what we observed has never been reported before and these preliminary results may provide important information for those who are interested in applying spontaneous assisted/supported modes of ventilation for patients with severe acute respiratory failure.

\subsection{Effects of T-piece on arterial and central venous oxygenation in trachestomized patients as compared to continuous positive airway pressure/pressure support ventilation}

The major finding of this study is that breathing via a T-piece improved arterial and central venous oxygenation in tracheostomized patients as compared to CPAP/PS and CPAP/ATC ventilatory modes.

In this investigation $84 \%$ of the patients completed the T-piece trial, and in 4 cases we had to interrupt the trial. Unfortunately we cannot compare our failure rate directly with international results as according to our best knowledge there is no literature data on the effect of T-piece on gas exchange and weaning in tracheostomized patients. In general, failure rate after SBT is reported around $26-42 \%$ within the first 60 minutes ${ }^{16}$, which was only $16 \%$ in our study. Michalopoulos et al., investigated the effect of different arrangements of T-piece parts on oxygenation ${ }^{41}$ and Hoffman et al., analysed the impact of tracheal gas insufflation on 
ventilatory demand ${ }^{42}$ in patients with tracheostomy but the termination rate was not mentioned in these trials. In two out of four cases when the trial had to be interrupted in our study patients suffered from chronic cardiac conditions such as ischaemic heart disease and cardiac failure which is in accord with previous results that cardiac dysfunction can limit respiratory weaning during $\mathrm{SBT}^{43}$

Varelman et al., found no significant change in $\mathrm{PaO}_{2}$ when ATC was compared with PS ventilation in intubated patients. ${ }^{44}$ This is in accord with our findings in tracheostomized patients. Regarding the effects of T-piece trial on gas exchange, in a recent clinical study on intubated patients it was found that $\mathrm{PaO}_{2}$ did not change significantly as compared to PS ventilation $^{45}$, which is in contrast with our findings of improved oxygenation on T-piece.

There are several mechanisms which could explain this significant increase in arterial oxygenation. First, the activation of breathing muscles without the interference of the ventilator may have a significant impact. Mechanical ventilation, controlled as well as PS modes, induce diaphragm dysfunction. ${ }^{46}$ In patients who fulfill the "ready to be weaned" criteria, breathing via a T-piece may be beneficial as compared to several ventilation modes, in which the patient has to trigger the ventilator by either flow or pressure. During T-piece trials respiratory muscle movements may promote immediate alveolar recruitment ${ }^{47}$ with a prompt benefit on gas exchange. It has also been shown in a recent article that different arrangements of the T-piece system can affect $\mathrm{PaO}_{2}$. Second, when a long inspiratory corrugated tube was inserted between the Venturi injector and the T-piece as an inspiratory limb, just like in our investigation, it resulted in significantly improved arterial oxygenation as compared to assembling the Venturi injector directly to the T-piece ${ }^{41}$ Finally, the PEEP valve might have had some effect on the observed changes. Comparing adjustable PEEP valves, the same as we used on our study, to precalibrated fixed PEEP valves during helmet CPAP, the adjustable ones showed a variable degree flow dependency producing higher end expiratory pressures on higher flow rates. ${ }^{48}$ Increased PEEP level is associated with alveolar recruitment and improved arterial oxygenation. ${ }^{49}$ As we did not measure the actual PEEP level on Tpiece, one cannot exclude its effect on the results.

Regarding ventilation on T-piece there was a significant and gradual increase in $\mathrm{PaCO}_{2}$ and a decrease in $\mathrm{pH}$ values over time. Although this change was statistically significant, but even the last median $\mathrm{pH}$ value remained in the normal range of $>7.35$. 
Nevertheless, one has to bear in mind that with the lack of pressure support on T-piece, and this holds true for all SBT methods, patients are prone to $\mathrm{CO}_{2}$ retention which per se is an important sign of weaning failure. ${ }^{16}$ Although assessment of the success of weaning was beyond the aim of this study, 4 patients out of the 25 had to go back on mechanical ventilation during the study period of 75 minutes due to fatigue (and consequent hypoventilation) and signs of acute heart failure. Future studies may be warranted to investigate the predictive value of $\mathrm{PaCO}_{2}$ changes on T-piece as a predictor of weaning failure/success in tracheostomized patients.

In the current study we measured significantly higher $\mathrm{ScvO}_{2}$ values on T-piece as compared to CPAP/PS and CPAP/ATC ventilation. Increased $\mathrm{ScvO}_{2}$ can be the result of increased oxygen delivery (cardiac output, $\mathrm{CO}$ and arterial oxygen content, $\mathrm{CaO}_{2}$ ) and/or when oxygen consumption is decreased. ${ }^{50}$ Unfortunately, we are unable to give an exact explanation for this phenomenon as we did not measure $\mathrm{CO}$ and work of breathing (WOB). However, Jiao et al., found in an in vitro investigation that Dräger Evita ${ }^{\circledR}$ XL respirator, the one we used in our study, had the highest expiratory resistance among four newer generation ventilators with active expiratory valve ${ }^{51}$ what can significantly affect WOB. Therefore, it can be that the increase in $\mathrm{ScvO}_{2}$ was in indeed an improvement as a result of the less WOB on T-piece. This hypothesis is also supported by the fact, that there was no sign of inadequate oxygen uptake as indicated by normal lactate, bicarbonate and $\mathrm{pH}$ levels. All 21 patients remained haemodynamically stable throughout as indicated by MAP, HR and lactate values. However, as there was a significant increase of $2 \%$ in $\mathrm{SaO}_{2}$ on $\mathrm{T}$-piece it might have also had some contribution in improved oxygen delivery hence on the observed increase in $\mathrm{ScvO}_{2}$.

The main limitation of this study is that detailed cardio-respiratory monitoring on Tpiece such as airway pressure, PEEP, tidal volume, $\mathrm{CO}$, WOB, was not available it is difficult to explain the observed findings. However, the primary aim of this study was to observe if there was any difference in oxygenation on T-piece. Having found the current results a detailed investigation may be warranted. 


\subsection{Haemodynamic effects of lung recruitment manoeuvres}

The anatomical proximity of the lungs and heart within the chest means that transiently increased intrathoracic pressures have major effect on systemic cardiovascular function. Undesired side effects of the recruitment process mainly arise from the increased airway pressures which can cause overdistension of alveoli in well ventilated lung areas, marked increase in ventilation-perfusion mismatch, barotrauma, pneumothorax and new air leak around an existing chest tube. ${ }^{52}$ These effects may be even more pronounced in patients with ARDS in whom hemodynamic instability is a common feature. ${ }^{53}$ It has strong pathophysiological rationale supported by clinical data that routine ICU monitoring, such as invasive blood pressure and central venous pressure monitoring may not be adequate to follow hemodynamic changes encountered during lung recruitment. ${ }^{39}$

\subsubsection{Effects on right heart and pulmonary circulation}

Distending lung volume evoked by applied raised airway pressure leads to an increase in TP. TP can be estimated from the difference between alveolar and intrathoracic pressures. The transmission of TP to the pleural space impedes venous return and the filling of the right ventricle. Meanwhile, the increased TP is transposed to vessels interlacing the lung tissue hereby elevating pulmonary vascular resistance (PVR) and right ventricular afterload.

\subsubsection{Systemic venous return and right ventricle preload}

The increase of intrathoracic pressure compresses the right atrium and caval veins carrying the systemic venous return to the heart. The generated retrograde pressure results in elevation in the central venous pressure (CVP) and could impede right ventricular filling. Due to this mechanism the assessment of cardiac preload by CVP during lung recruitment manoeuvre is misleading, as the transmission of the intrathoracic pressure to the intravascular 
compartment $^{39}$ does not represent the true preload component. Restricted right ventricular preload is a dominant but not solitary mechanism in the fall of the right ventricular ejection fraction.

\subsubsection{Right ventricular afterload}

Right ventricular afterload represents the resistance, quantified by the pulmonary artery pressure, which the right ventricle should overcome to eject the blood through the pulmonary valve. During the lung recruitment manoeuvre the interposed TP further increases the area where the intraluminal pressure of the juxtaalveolar capillaries is lower than the intraalveolar pressure. This results in a significant increase in the pulmonary vascular resistance, parallel to an increase in the pulmonary artery pressure. Thus right ventricular afterload is augmented by transitionally elevated TP.

Hypoxic pulmonary vasoconstriction, which developed to attenuate the ventilationperfusion mismatch caused by alveolar hypoventilation, is another important determinant of the right ventricular afterload. ${ }^{54}$ During significant hypoxaemia the atelectatic lung regions are served with only marginal circulation. The hypoxic pulmonary vasoconstriction contributes to the overall pulmonary vascular resistance, however there is only limited data about it's role and the changes occurred during lung recruitment.

These mechanisms can impair right ventricular function and decrease right ventricular stroke volume. ${ }^{55}$ Iannuzzi et al. found that pressure controlled ventilation (PCV) with peak inspiratory pressure of $45 \mathrm{cmH}_{2} \mathrm{O}$ for 2 minutes generated a higher grade of lung opening and resulted a major and significant increase in $\mathrm{PaO}_{2} / \mathrm{FiO}_{2}$ ratio compared to sustained inflation (SI) (Figure 8). They found that hypoxic pulmonary vasoconstriction and pulmonary vascular resistance index (PVRI) were also reduced, with smaller degree of hyperinflation in the PCV group (figure 8). 
Figure 8. Pressure-time product and main characteristics of sustained inflation (SI) and pressure control ventilation $(\mathrm{PCV})$ recruitment manoeuvres

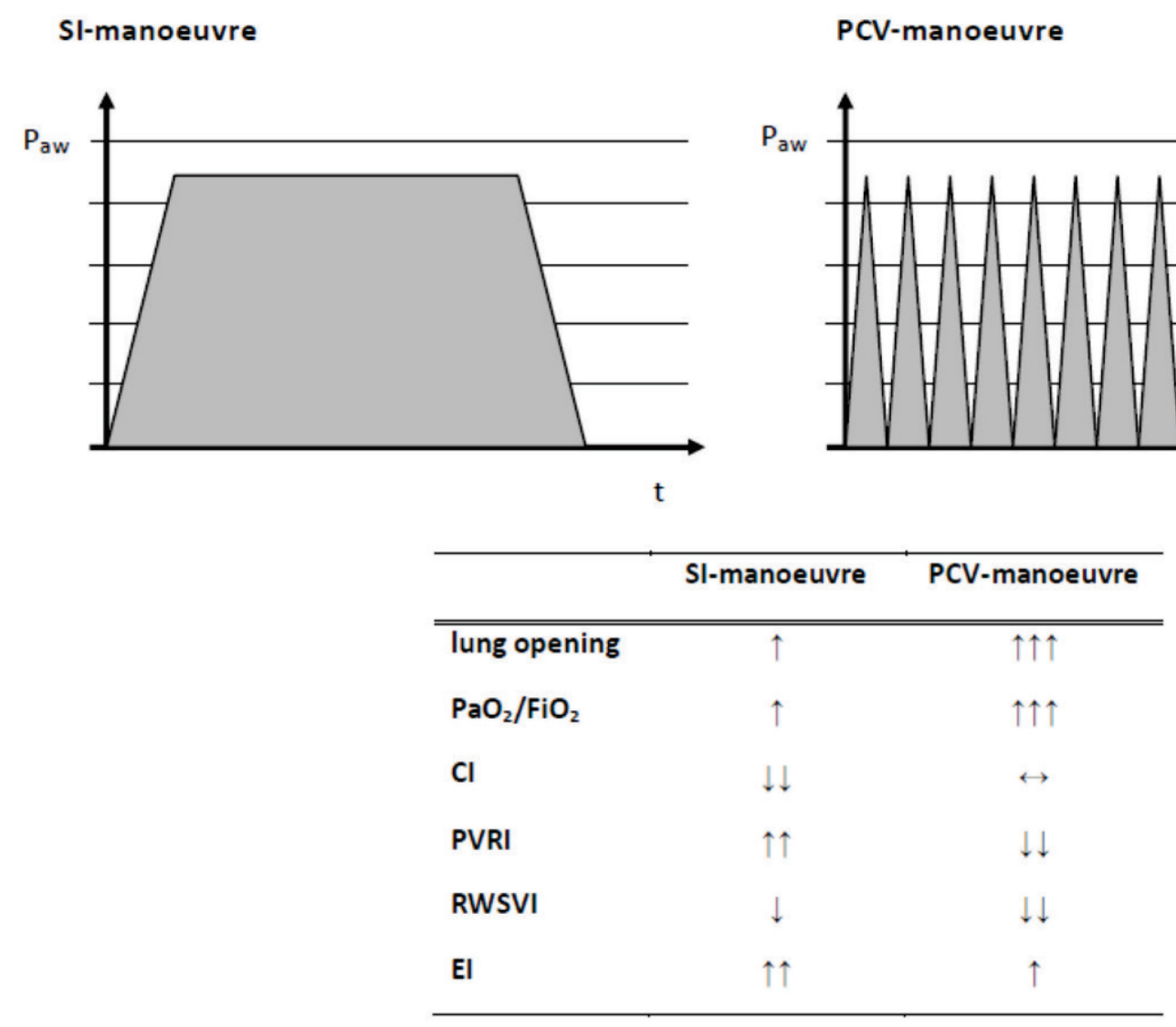

$\mathrm{P}_{\mathrm{aw}}$, airway pressure; $\mathrm{t}$, time; $\mathrm{CI}$, cardiac index; PVRI, pulmonary vascular resistance index; RWSVI, right ventricle stroke work index; EI, eccentricity index

On the other hand Reis Miranda et al. could not detect any significant impairment in right heart function comparing conventional mechanical ventilation to the open lung concept in patients after cardiac surgery. ${ }^{56}$ This disagreement between the two observations may arise from the different methods applied, especially the different timing of measurements. Whereas Iannuzzi et al. investigated the immediate effects ${ }^{55}$ in the other study cardiovascular measurements were taken in every 30 minutes for 3 hours. ${ }^{56}$

Similar results were reported by Celebi et al. ${ }^{57}$ where pulmonary and haemodynamic effects of two different recruitment manoeuvres were investigated in patients after open heart surgery. During the study period there was no significant change of PVR between the groups, 
measured after 15 minutes. One may suggest from these observations that the effect of the recruitment manoeuvre on the right ventricular afterload is transient, lasting for seconds only. Relieving high airway pressures after recruitment helps in the normalization of haemodynamic changes in the pulmonary circulation.

Apart from the different methods employed in the studies, controversial results may arise from the different patient inclusion criteria. In the study of Iannuzzi et al. patients with

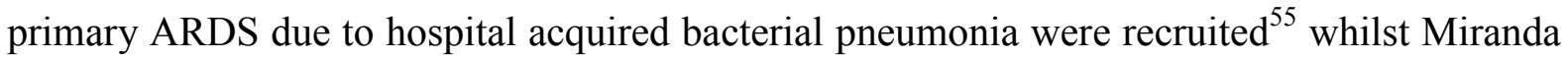
Reis et al. investigated patients following cardiac surgery without significant lung injury. ${ }^{56}$ It has been demonstrated in a murine model of acute lung injury induced by Escherichia coli lipopolysaccharide, that dynamic inflation applied during lung recruitment produced increased right ventricular pressure and total PVR. It also resulted in sustained inflammation and vascular dysfunction whilst no similar changes were reported in healthy lungs. ${ }^{58}$

\subsubsection{Right ventricular ejection fraction}

The primary role of the right ventricle is to receive systemic venous blood and to forward it via a high volume and low-pressure system, the pulmonary circulation, to the left heart chambers. ${ }^{59}$ Right ventricular ejection fraction is affected by preload, contractility and afterload. During the recruitment manoeuvre, the raised intrathoracic and right atrial pressures, as discussed previously, could affect both venous return and afterload significantly $^{57}$ (Figure 9 and 10). Both mechanisms can result in impaired right ventricular contractility. 
Figure 9. The effects of increased transpulmonary pressure (TPP)

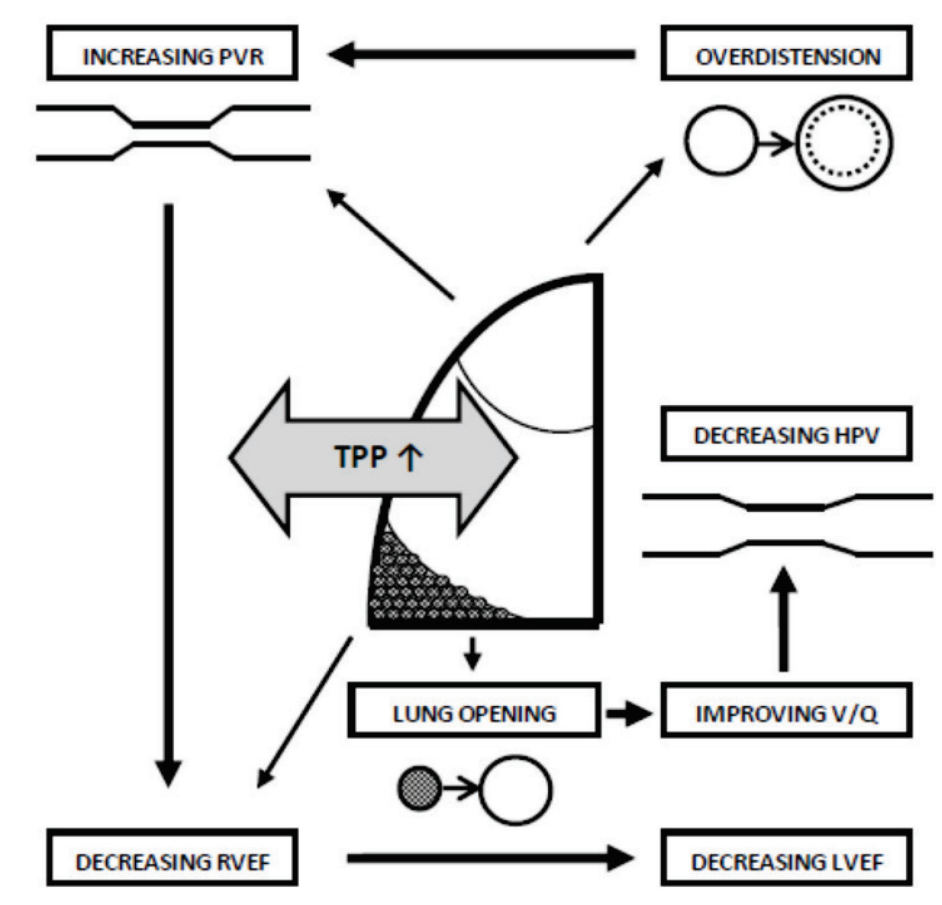

PVR, pulmonary vascular resistance; RVEF, right ventricular ejection fraction; LVEF, left ventricular ejection fraction; V/Q, ventilation/perfusion; HPV, hypoxic pulmonary vasoconstriction

Right ventricular ejection fraction is inversely related to the ventricle's afterload. In the study by Reis Miranda et al. ${ }^{56}$ PVRI and right ventricular ejection fraction showed no significant changes following recruitment within the first 3 hours, neither within nor between groups at any measurement points. However, if immediate effects on right ventricular function were investigated, then significant increase in right ventricular stroke work index was reported during the recruitment manoeuvre and 2 minutes following the intervention. ${ }^{31}$ These results call for further attention on the immediate effects of the recruitment manoeuvre on right heart function. There is also lack of data, whether it has any clinically relevant longterm effects. 


\subsubsection{Ventricular interdependence}

It is important to note that the end-diastolic right ventricular volume has a direct effect on the left ventricle, which holds true vica versa. This is called the ventricular diastolic interdependence. ${ }^{60}$ The two chambers are coupled within a common pericardial sac and share joint intraventricular septa as a traverse wall. Thus, their volumes are limited by the pericardium, hence any change in the right ventricular end-diastolic volume has an effect on the left ventricular end-diastolic volume (Figure 10).

During sigh recruitment, the right ventricle can have a marked effect on the adjacent heart chamber. When lung recruitment manoeuvre is applied by a sustained inspiration, left ventricular end-diastolic area can be reduced by as much as $45 \%$. ${ }^{61} \mathrm{PVR}$ is also increasing with the transposed intrathoracic pressure, leading to an acute right ventricular pressure overload with dilation, leftward septal shift and left ventricular collapse resulting in low cardiac output (CO) and marked systemic haemodynamic changes (Figure 10). These changes are transient and only seen during the manoeuvre, with almost instant normalisation of haemodynamics once the intrathoracic pressure returns to the baseline. ${ }^{55}$

There is a special scenario when this interdependence is questioned and this is the postoperative period after cardiac surgery when the pericardial sac is kept open. ${ }^{56}$ Theoretically, due to the missing pericardial sac, interaction between the two adjacent ventricles should be impaired and in these patients the diastolic interdependence is not fully present. However, in an animal experiment on dogs it was found that artificially increasing the pulmonary artery resistance and the right ventricular load had a profound effect on the left ventricular filling dynamics. This was explained by the prolonged relaxation and altered pressure-volume chamber relations. ${ }^{62}$ 
Figure 10. Ventricular interdependence before (A) and during alveolar recruitment manoeuvre (B)

A

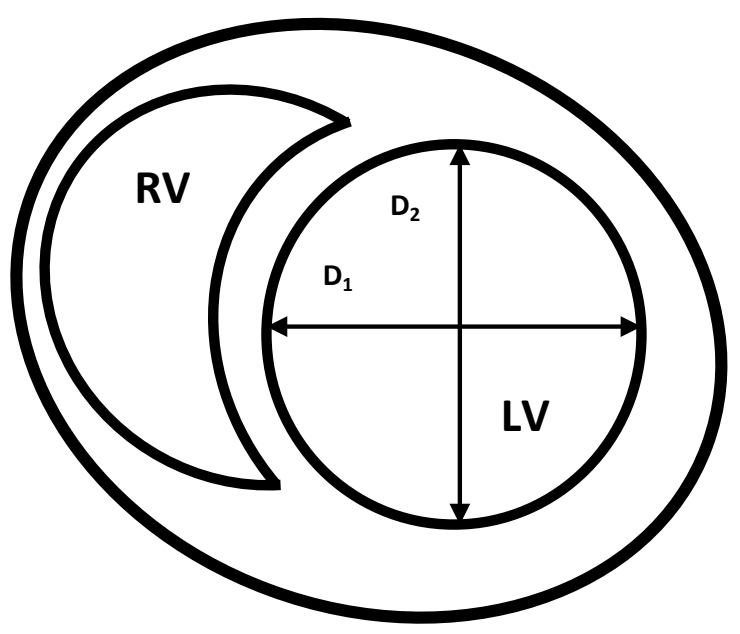

B

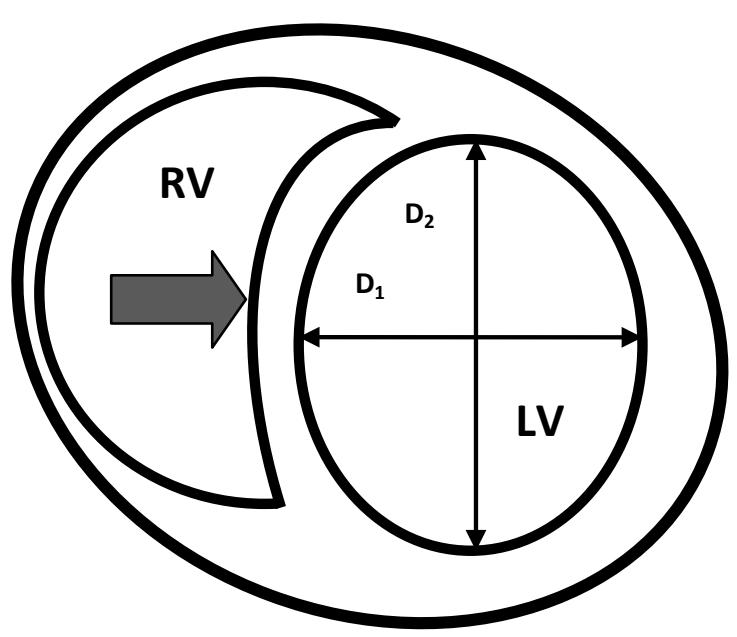

\section{$\mathrm{El}_{\mathrm{A}}<\mathrm{El}_{\mathrm{B}}$}

$\mathrm{D}_{1}$, midmitral diamether; $\mathrm{D}_{2}$, diameter orthogonal to $\mathrm{D}_{1}$. Eccentricity index (EI) is calculated as $\mathrm{D}_{2} / \mathrm{D}_{1}$. RV, right ventricle; $\mathrm{LV}$, left ventricle.

\subsubsection{Effects on left heart and systemic circulation}

The cardiopulmonary system is described by Pinsky as a pressure chamber inside a pressure chamber. ${ }^{63}$ Any increment in the intrathoracic pressure increases the right atrial pressure, decreases the venous return and the transmural left ventricular systolic pressure hence attenuating the left ventricular ejection fraction (Figure 11). If haemodynamic changes 
are solely monitored by mean arterial pressure (MAP) during lung recruitment manoeuvre one can theoretically miss relevant alterations in the systemic circulation. Recent investigations concluded that simple haemodynamic parameters like MAP or heart rate did not show any significant change during and after various recruitment interventions. ${ }^{31,56,64}$ However, applying advanced invasive haemodynamic monitoring, relevant changes in the systemic circulation can be observed. ${ }^{39}$

Figure 11. Pressure chamber (heart) in a pressure chamber (thorax)

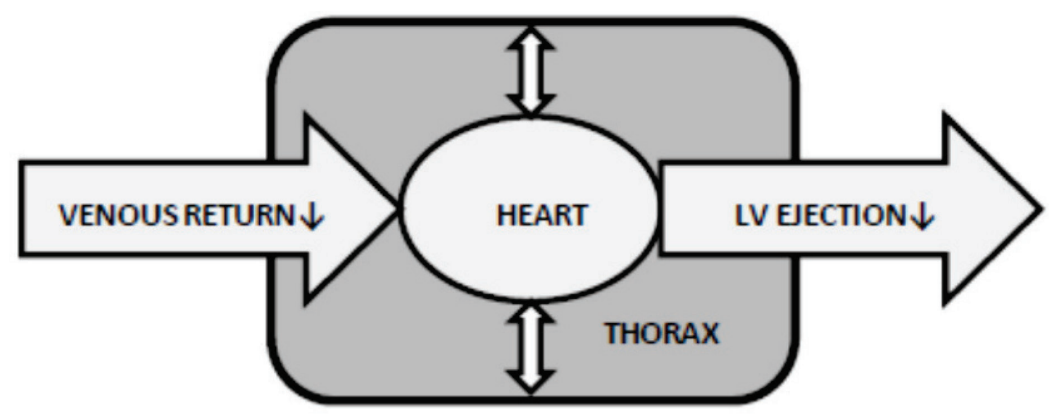

LV ejection, left ventricular ejection

\subsubsection{Left ventricle preload and afterload}

As described above, ventricular interdependence plays a significant role during lung recruitment manoeuvre in determining the left ventricular preload. The increased TP compresses the right atrium and increases the CVP by the transmission of pressure to the intraluminal compartment of the caval veins. Echocardiographic investigations identify this mechanism as partial cause of the impaired left ventricular preload and consecutive decrease of CO. ${ }^{55}$

Left ventricular afterload is defined as the pressure of the wall in the left ventricle during ejection. Following Laplace's law, if there is no significant alteration in the systolic arterial pressure, as seen throughout most of the studies investigating recruitment manoeuvre, left ventricle afterload decreases along with the fall of the transmural pressure of the left 
ventricle. ${ }^{65}$ Measuring these pressure fluctuations requires sophisticated methods at the bedside therefore correlation between left ventricle afterload and lung recruitment has not been investigated thoroughly in human subjects.

\subsubsection{Cardiac output and left ventricular end-diastolic volume}

The increased availability of sophisticated continuous CO monitoring using pulse pressure analysis like pulse contour cardiac output $\left(\mathrm{PiCCO}^{\mathrm{TM}}\right)$, lithium dilution cardiac output $\left(\mathrm{LiDCO}^{\mathrm{TM}}\right)$ or FloTrac ${ }^{\mathrm{TM}} /$ Vigileo $^{\mathrm{TM}}$ techniques and Doppler cardiac output devices enabled the clinicians to follow alterations in the systemic haemodynamics during each cardiac cycle. ${ }^{66}$ Utilising these advanced monitoring techniques, profound and significant decrease in CO was observed during lung recruitment manoeuvres. ${ }^{39,55,61}$ This decline in left ventricular performance can be explained by interconnected fluctuations within the "chamber in the chamber" system discussed previously. ${ }^{63}$ Increased intrathoracic pressure, decreased right ventricular filling, increased right ventricular outflow impedance with leftward intraventricular septal shift are all precipitating reduced CO (Figure 10). However, rapid recovery of the baseline $\mathrm{CO}$ was described when the effects were measured in a temporal study, so the depression is only transient correlating with the temporarily increased TP. ${ }^{67}$

The absolute reduction in $\mathrm{CO}$ is influenced by the technique of the lung recruitment and also by the nature of the lung injury. As discussed previously, sustained inflation manoeuvre can significantly change left ventricle eccentricity index (Figure 8) indicating a significant reduction in left ventricular end-diastolic volume compared to PCV-recruitment, which was accompanied by a less profound effect.

The importance of the underlying pathology of the lung injury has been emphasised by Lim et al. ${ }^{67}$ They investigated three different types of lung injury models during recruitment: oleic acid injury depicting acute surfactant loss, ventilator-induced lung injury and finally an injury caused by infection. Animals in all three models underwent a PCV, a sigh and a PEEP incremental recruitment. Regardless of the way the manoeuvres were executed, a significant but interim drop of $\mathrm{CO}$ was observed in each model. However, in the pneumonia model the $\mathrm{CO}$ decreased to a greater extent and the recovery of systemic 
haemodynamics also showed a moderate pattern as compared the two other. It is possible, that in septic shock induced inflammatory response, a more profound depression of myocardial function and compensatory vasomotor reflexes takes place. ${ }^{68}$ Out of the three recruitment techniques, the sigh manoeuvre resulted in the most significant reduction in $\mathrm{CO}$ in accordance with previous investigations. ${ }^{55,67}$

One of the available methods to prevent the undesired decrease in $\mathrm{CO}$ during lung recruitment is the selective lung opening technique described by Hansen et al. in an elegant animal model. ${ }^{69}$ In their experiment pigs were randomized into two groups of lung recruitment manoeuvres (by applying $40 \mathrm{cmH}_{2} \mathrm{O}$ airway pressure for 30 seconds), either a selective lung recruitment manoeuvre such as using the inner lumen of the bronchial blocker followed by a whole lung recruitment manoeuvre or vice versa. Whilst there was no significant difference in the improvement of oxygenation and the end-expiratory lung volume between the two groups, there were no circulatory changes during the selective technique. On the other hand, the whole lung recruitment caused a significant drop in $\mathrm{CO}$ and left ventricular end-diastolic volume. This suggests that selective lung recruitment technique might be advantageous in patients with lobar atelectasis prone to haemodynamic instability. However, this new method requires further investigations in humans.

\subsubsection{Alterations in heart rate}

Along with stroke volume, heart rate is the other determinant of CO. Through the recruitment manoeuvre one may expect the development of reflex tachycardia along the drop in CO. Many investigations failed to observe such an increase in heart rate, principally no significant alteration of pulse rate was found. ${ }^{31,56,57,64}$ However, in the investigation of Nielsen et al. the significant reduction in heart rate was suspected as the major component of the declining CO during the sigh manoeuvre. ${ }^{61}$ One of the explanations is that the inflated lung tissue can activate vagal tone causing bradycardia. ${ }^{70}$ Another assumption is that the sigh manoeuvre may precipitate a similar pattern in intrathoracic pressure as the Valsalva manoeuvre, hence producing reduction in heart rate. As opposed to the previous findings Lim 
et al. reported an increased heart rate, perhaps reflecting just a sympathetic response to the lengthy recruitment procedure they used. ${ }^{71}$

\subsubsection{The effect of volemic state on left heart function}

One of the main patient exclusion criteria in the lung recruitment studies is hemodynamic instability and/or signs of intravascular volume depletion. ${ }^{39,57,61,64,71}$ Hypovolemia can amplify the undesirable haemodynamic effects of lung recruitment manoeuvre as demonstrated by Nielsen et al. ${ }^{72}$ In their animal experiment the impact of recruitment manoeuvre on central haemodynamics was investigated in pigs with different volemic states. The animals were randomized to a 10 second long recruitment followed by lung opening lasting 30 seconds by applying $40 \mathrm{cmH}_{2} \mathrm{O}$ airway pressure or vice versa, performed under hypo-, normo- and hypervolemia. Volemic states were controlled either by removing $15 \%$ of the estimated blood volume or by infusion of a volume equal to $15 \%$ of the estimated blood volume with 3\% dextran in Ringer's solution. The study focused on the immediate circulatory effects. They found a significant reduction in left ventricular enddiastolic volume, which could explain the depleted $\mathrm{CO}$ during lung recruitment manoeuvre in pigs with acute lung-injury. As expected, the impact of this effect was significantly exaggerated by hypovolemia. On the other hand hypervolemic conditions prevented the reduction of $\mathrm{CO}$ during the extended sigh manoeuvre.

Fougères et al. suggested that some microvessels of the lungs may be collapsed by PEEP and were recruiteable by the increased left ventricular preload. ${ }^{73}$ In their recent investigation in patients with ARDS recruitment was accomplished by increasing PEEP for reaching a plateau pressure of $30 \mathrm{cmH}_{2} \mathrm{O}$. During the manoeuvre $\mathrm{CO}$ was decreased along with increasing right ventricular afterload. Importantly, passive leg raising restored the $\mathrm{CO}$ and reduced the PVR. These important observations reinforce the need of appropriate intravascular volume assessment prior to the alveolar opening procedure. 


\section{Conclusions}

1. Alveolar recruitment manoeuver can improve oxygenation in patients suffering from moderate and severe acute hypoxemic respiratory failure and ventilated in CPAP/PS mode as indicated by the significant improvement in oxygenation after recruitment in $74 \%$ of all patients.

2. The decrease in dynamic compliance as displayed on the ventilator after the recruitment manoeuver proved to be a simple bed-side indicator of failure in improving oxygenation in spontaneously breathing patients.

3. Ayre's T-piece significantly improves arterial oxygenation as compared to CPAP/PS and CPAP/ATC ventilation.

4. Ayre's T-piece resulted in significantly higher $\mathrm{ScvO}_{2}$ as compared to CPAP/PS and CPAP/ATC ventilation. Our results suggest a potential role of T-piece trials during respiratory weaning in tracheostomized patients. 


\section{References}

1. Eastwood G, Bellomo R, Bailey $\mathrm{M}$ et al. Arterial oxygen tension and mortality in mechanically ventilated patients. Intensive Care Med. 2012;38(1):91-98.

2. Cortés I, Peñuelas O, Esteban A. Acute respiratory distress syndrome: evaluation and management. Minerva Anestesiol. 2012;78(3):343-375.

3. Lee WL, Downey GP. Neutrophil activation and acute lung injury. Curr Opin Crit Care. $2001 ; 7(1): 1-7$.

4. Han S, Mallampalli RK. The acute respiratory distress syndrome: from mechanism to translation. J Immunol. 2015;194(3):855-860.

5. Ware LB, Matthay MA. The acute respiratory distress syndrome. $N$ Engl J Med. 2000;342(18):1334-1349.

6. Pelosi P, de Abreu MG. Acute respiratory distress syndrome: we can't miss regional lung perfusion!. BMC Anesthesiol. 2015;15(35)

7. Leligdowicz A, Fan E. Extracorporeal life support for severe acute respiratory distress syndrome. Curr Opin Crit Care. 2015;21(1):13-19.

8. Ferguson ND, Cook DJ, Guyatt GH et al. High-frequency oscillation in early acute respiratory distress syndrome. $N$ Engl J Med. 2013;368(9):795-805.

9. Guérin C, Reignier J, Richard JC, et al. Prone positioning in severe acute respiratory distress syndrome. N Engl J Med. 2013;368(23):2159-2168.

10. Keenan JC, Formenti P, Marini JJ. Lung recruitment in acute respiratory distress syndrome: what is the best strategy?. Curr Opin Crit Care. 2014;20(1):63-68.

11. Lachmann B. Open up the lung and keep the lung open. Intensive Care Med. 1992;18(6):319-321.

12. Gattinoni L, Caironi P, Cressoni M. et al. Lung recruitment in patients with the acute respiratory distress syndrome. $N$ Engl J Med 2006;354(17):1775-1786.

13. Catherine S, Sassoon CS, Zhu E et al. Assist-control mechanical ventilation attenuates ventilator-induced diaphragmatic dysfunction. Am $J$ Respir Crit Care Med. 2004;170(6):626-632. 
14. Vimlati L, Kawati R, Hedenstierna G, et al. Spontaneous breathing improves shunt fraction and oxygenation in comparison with controlled ventilation at a similar amount of lung collapse. Anesth Analg. 2011;113(5)1089-1095.

15. Putensen C, Muders T, Varelmann D, et al. The impact of spontaneous breathing during mechanical ventilation. Curr Opin Crit Care. 2006;12(1):13-18.

16. Boles JM, Bion J, Connors A, et al. Weaning from mechanical ventilation. Eur Respir J. 2007;29(5):1033-1056.

17. Ayre P. Anaesthesia for intracranial operations: A new technique. Lancet. 1937; 229(5923):561-563.

18. Lawrence JC. PEEP and the Ayre's T-Piece System. Anaesth Intensive Care. 1978; 6(4):359.

19. Fabry B, Haberthür C, Zappe D, et al. Breathing pattern and additional work of breathing in spontaneously breathing patients with different ventilatory demands during inspiratory pressure support and automatic tube compensation. Intensive Care Med. 1997;23(5):545-552.

20. Murray JF, Matthay MA, Luce JM, et al. An expanded definition of the adult respiratory distress syndrome. Am Rev Respir Dis. 1988;138(3):720-723.

21. Ferguson ND, Fan E, Camporota L, et al. (2012). The Berlin definition of ARDS: an expanded rationale, justification, and supplementary material. Intensive Care Med. 2012;38(10):1573-1582.

22. Lovas A, Trasy D, Nemeth M, et al. Effect of lung recruitment on oxygenation in patients with acute lung injury ventilated in CPAP/pressure support mode. Crit Care. 2015; 19(Suppl 1):P226.

23. Wiesen J, Ornstein M, Tonelli AR, et al. State of the evidence: mechanical ventilation with PEEP in patients with cardiogenic shock. Heart. 2013;99(24):1812-1817.

24. Pinsky MR. Cardiovascular issues in respiratory care. Chest. 2005;128(5 Suppl 2):592S-597S.

25. Rocco PR, Pelosi P. Pulmonary and extrapulmonary acute respiratory distress syndrome: myth or reality? Curr Opin Crit Care. 2008;14(1):50-55.

26. Grasso S, Mascia L, Del Turco M, et al. Effects of recruiting maneuvers in patients with acute respiratory distress syndrome ventilated with protective ventilator strategy. Anesthesiology. 2002;96(4):795-802. 
27. Esan A, Hess DR, Raoof S, et al. Severe hypoxemic respiratory failure: part 1ventilator strategies. Chest. 2010;137(5):1203-1216.

28. Schreiter D, Reske A, Stichert B, et al. Alveolar recruitment in combination with sufficient positive end-expiratory pressure increases oxygenation and lung aeration in patients with severe chest trauma. Crit Care Med. 2004;32(4):968-975.

29. Reutershan J, Schmitt A, Dietz K, et al. Alveolar recruitment during prone position: time matters. Clin Sci (Lond). 2006;110(6):655-663.

30. Di Marco F, Devaquet J, Lyazidi A, et al. Positive end-expiratory pressure-induced functional recruitment in patients with acute respiratory distress syndrome. Crit Care Med. 2010;38(1):127-132.

31. Huh JW, Hong SB, Lim CM, et al. Effect of the alveolar recruitment manoeuvre on haemodynamic parameters in patients with acute respiratory distress syndrome: relationship with oxygenation. Respirology. 2010;15(8):1220-1225.

32. Oczenski W, Hörmann C, Keller C, et al. Recruitment maneuvers after a positive endexpiratory pressure trial do not induce sustained effects in early adult respiratory distress syndrome. Anesthesiology 2004;101(3):620-625.

33. Dueck R. Alveolar recruitment versus hyperinflation: a balancing act. Curr Opin Anaesthesiol. 2006;19(6):650-654.

34. Waydhas C. Intrahospital transport of critically ill patients. Crit Care. 1999;3(5):R8389.

35. Patroniti N, Bellani G, Cortinovis B, et al. Role of absolute lung volume to assess alveolar recruitment in acuterespiratory distress syndrome patients. Crit Care Med. 2010;38(5):1300-1307.

36. Dellamonica J, Lerolle N, Sargentini C, et al. PEEP-induced changes in lung volume in acute respiratory distress syndrome. Two methods to estimate alveolar recruitment. Intensive Care Med. 2011;37(10):1595-1604.

37. Blanch L, Fernández R, Benito S, et al. Effect of PEEP on the arterial minus end-tidal carbon dioxide gradient. Chest. 1978;92(3):451-454.

38. Schumann S, Vimlati L, Kawati R, et al. Analysis of dynamic intratidal compliance in a lung collapse model. Anesthesiology. 2011;114(5):1111-1117.

39. Toth I, Leiner T, Mikor A, et al. Hemodynamic and respiratory changes during lung recruitment and descending optimal positive end-expiratory pressure titration in 
patients with acute respiratory distress syndrome. Crit Care Med. 2007;35(3):787793.

40. Villagrá A, Ochagavía A, Vatua S, et al. Recruitment maneuvers during lung protective ventilation in acute respiratory distress syndrome. Am J Respir Crit Care Med. 2002;165(2):165-170.

41. Michalopoulos AS, Gregoriades K, Falagas ME. The effect of different arrangements of T-piece parts on oxygenation of patients with tracheostomy. Anesth Analg. 2006;103(4):1054-1055.

42. Hoffman LA, Tasota FJ, Delgado E, et al. Effect of tracheal gas insufflation during weaning from prolonged mechanical ventilation: a preliminary study. Am J Crit Care. 2003;12(1):31-39.

43. Moschietto S, Doyen D, Grech L, et al. Transthoracic echocardiography with doppler tissue imaging predicts weaning failure from mechanical ventilation: evolution of the left ventricle relaxation rate during a spontaneous breathing trial is the key factor in weaning outcome. Crit Care. 2012;16(3):R81.

44. Varelmann D, Wrigge $\mathrm{H}$, Zinserling $\mathrm{J}$, et al. Proportional assist versus pressure support ventilation in patients with acute respiratory failure: cardiorespiratory responses to artificially increased ventilatory demand. Crit Care Med. 2005;33(9):1968-1975.

45. Cabello B, Thille AW, Roche-Campo F, et al. Physiological comparison of three spontaneous breathing trials in difficult-to-wean patients. Intensive Care Med. 2010;36(7):1171-1179.

46. Hudson MB, Smuder AJ, Nelson WB, et al. Both high level pressure support ventilation and controlled mechanical ventilation induce diaphragm dysfunction and atrophy. Crit Care Med. 2012;40(4):1254-1260.

47. Westerdahl E, Lindmark B, Eriksson T, et al. The immediate effects of deep breathing exercises on atelectasis and oxygenation after cardiac surgery. Scand Cardiovasc $J$. 2003;37(6):363-367.

48. Isgrò S, Zanella A, Giani M, et al. Performance of different PEEP valves and helmet outlets at increasing gas flow rates: a bench top study. Minerva Anestesiol. 2012;78(10):1095-1100.

49. Villar J. The use of positive end-expiratory pressure in the management of the acute respiratory distress syndrome. Minerva Anestesiol. 2005;71(6):265-272. 
50. Bloos F, Reinhart K. Venous oximetry. Intensive Care Med. 2005;31(7):911-913.

51. Jiao GY, Newhart JW. Bench study on active exhalation valve performance. Respir Care. 2008;53(12):1697-1702.

52. Fan E, Checkley W, Stewart TE, et al. Complications from recruitment maneuvers in patients with acute lung injury: secondary analysis from the lung open ventilation study. Respir. Care. 2012;57(11):1842-1849.

53. Fuller BM, Mohr NM, Graetz TJ, et al. The impact of cardiac dysfunction on acute respiratory distress syndrome and mortality in mechanically ventilated patients with severe sepsis and septic shock: an observational study. J Crit Care. 2015;30(1):65-70.

54. Orchard CH, Sanchez de Leon R, Sykes MK. The relationship between hypoxic pulmonary vasoconstriction and arterial oxygen tension in the intact dog. J Physiol. 1983;338:61-74.

55. Iannuzzi M, De Sio A, De Robertis E, et al. Different patterns of lung recruitment maneuvers in primary acute respiratory distress syndrome: effects on oxygenation and central hemodynamics. Minerva Anestesiol. 2010;76(9):692-698.

56. Reis Miranda D, Gommers D, Struijs A, et al. The open lung concept: effects on right ventricular afterload after cardiac surgery. Br J Anaesth. 2004;93(3):327-332.

57. Celebi S, Köner O, Menda F, et al. The pulmonary and hemodynamic effects of two different recruitment maneuvers after cardiac surgery. Anesth Analg. 2007;104(2):384-390.

58. Mekontso Dessap A, Voiriot G, Zhou T, et al. Conflicting physiological and genomic cardiopulmonary effects of recruitment maneuvers in murine acute lung injury. $A m \mathrm{~J}$ Respir Cell Mol Biol. 2012;46(4):541-550.

59. Haddad F, Hunt SA, Rosenthal DN, et al. Right ventricular function in cardiovascular disease, part I: Anatomy, physiology, aging, and functional assessment of the right ventricle. Circulation. 2008;117(11):1436-1448.

60. Janicki JS, Weber KT. The pericardium and ventricular interaction, distensibility, and function. Am J Physiol. 1980;238(4):H494-503.

61. Nielsen J, Østergaard M, Kjaergaard J, et al. Lung recruitment maneuver depresses central hemodynamics in patients following cardiac surgery. Intensive Care Med. 2005;31(9):1189-1194. 
62. Fragata JI, Areias JC. Acute loads applied to the right ventricle: effect on left ventricular filling dynamics in the presence of an open pericardium. Pediatr Cardiol. 1996;17(2):77-81.

63. Pinsky MR. Recent advances in the clinical application of heart-lung interactions. Curr Opin Crit Care. 2002;8(1):26-31.

64. Lovas A, Németh MF, Trásy D, et al. Lung recruitment can improve oxygenation in patients ventilated in continuous positive airway pressure/pressure support mode. Front Med (Lausanne). 2015;2:article 25.

65. Katzenberg C, Olajos M, Morkin E, et al. Effects of changes in airway pressure on the left ventricle and left atrium of dogs. Cardiovasc Res. 1986;20(11):853-862.

66. Alhashemi JA, Cecconi M, Hofer CK. Cardiac output monitoring: an integrative perspective. Crit Care. 2011;15(2):214.

67. Lim SC, Adams AB, Simonson DA, et al. Transient hemodynamic effects of recruitment maneuvers in three experimental models of acute lung injury. Crit Care Med. 2004;32(12):2378-2384.

68. Walley KR. Deeper understanding of mechanisms contributing to sepsis-induced myocardial dysfunction. Crit Care. 2014;18(3):137.

69. Hansen LK, Sloth E, Nielsen J, et al. "Selective recruitment maneuvers for lobar atelectasis: effects on lung function and central hemodynamics: an experimental study in pigs," Anesth Analg. 2006;102(5):1504-1510.

70. Campagna JA, Carter C. Clinical relevance of the Bezold-Jarisch reflex. Anesthesiology. 2003;98(5):1250-1260.

71. Lim CM, Koh Y, Park W, et al. Mechanistic scheme and effect of "extended sigh" as a recruitment maneuver in patients with acute respiratory distress syndrome: a preliminary study. Crit Care Med. 2001;29(6):1255-1260.

72. Nielsen J, Nilsson M, Fredén F, et al. Central hemodynamics during lung recruitment maneuvers at hypovolemia, normovolemia and hypervolemia. A study by echocardiography and continuous pulmonary artery flow measurements in lunginjured pigs. Intensive Care Med. 2006;32(4):585-594.

73. Fougères E, Teboul JL, Richard C, et al. Hemodynamic impact of a positive endexpiratory pressure setting in acute respiratory distress syndrome: importance of the volume status," Crit. Care Med. 2010;38(3)802-807. 


\section{Acknowledgment}

I would like to thank for the help of my supervisor, Professor Zsolt Molnár who was always ready for consultation and who guided the investigations thoroughly. This work could not have been completed with the selfless assistance of Márton Németh, Domonkos Trásy and Tamás Szakmány. I would like to render thanks for all of the employees from the Department of Anaesthesiology and Intensive Therapy of University of Szeged. Special thanks for my family members for their patience and constant support throughout the past years. 


\section{Appendix}



I 



\title{
T-piece improves arterial and central venous oxygenation in trachestomized patients as compared to continuous positive airway pressure/pressure support ventilation
}

\author{
A. LOVAS, Z. MOLNÁR
}

Department of Anaesthesiology and Intensive Therapy, Faculty of Medicine, University of Szeged, Szeged, Hungary

\section{A B S T R A C T}

Background. T-piece has been widely used as T-piece trial to identify patients who are ready for extubation but it is seldom used as a weaning tool. Our objective was to investigate the effects of breathing via T-piece on gas exchange as compared to continuous positive airway pressure with pressure support (CPAP+PS) and CPAP with automatic tube compensation (CPAP+ATC) as it has not been evaluated yet.

Methods. Tracheostomized, "ready to be weaned" critically ill patients were enrolled in this prospective, auto-control clinical trial. Arterial oxygen tension $\left(\mathrm{PaO}_{2}\right)$ was determined on CPAP+PS $\left(\mathrm{t}_{0}\right), 15$ minutes later on CPAP+ATC $\left(t_{1}\right)$, then on T-piece at 15, 30 and 60 minutes $\left(t_{2-4}\right)$. ScvO $\mathrm{S}_{2}$ was measured at $\mathrm{t}_{0}$ and $\mathrm{t}_{4}$. Settings of fraction of inspired oxygen $\left(\mathrm{FiO}_{2}\right)$ and positive end-expiratory pressure (PEEP) were kept constant throughout the investigation.

Results. Twenty-five patients were enrolled. T-piece trial was interrupted in 4 cases after $t_{2}$, due to pulmonary oedema, hypertension or fatigue. $\mathrm{PaO}_{2} / \mathrm{FiO}_{2}$ was significantly higher on T-piece $\left(\mathrm{t}_{3,4}\right)$ then on CPAP $\left(\mathrm{t}_{0,1}\right), \mathrm{P}<0.05$, $\mathrm{PaO}_{2} / \mathrm{FiO}_{2}$ did not change significantly on CPAP+PS $\left(\mathrm{t}_{0}\right)$ vs. CPAP $+\mathrm{ATC}\left(\mathrm{t}_{1}\right)$ modes: median $=208$ (interquartile range: 175-266) vs. 223 (186-290) $\mathrm{mmHg}, \mathrm{P}=0.102$, but significantly increased from $\mathrm{t}_{0}-\mathrm{t}_{4}: 208$ (175-266) vs. 249 (215-325) $\mathrm{mmHg}, \mathrm{P}=0.003$, respectively. $\mathrm{ScvO}_{2}$ was significantly higher on T-piece at $\mathrm{t}_{4}: 80 \%$ (75-82\%) than on $\mathrm{CPAP}+\mathrm{PS}$ at $\mathrm{t}_{0}: 73 \%(71-78 \%), \mathrm{P}<0.001$.

Conclusion: $\mathrm{On}$ the same $\mathrm{FiO}_{2}$ and PEEP setting, breathing via T-piece improved oxygenation and resulted in increased $\mathrm{ScvO}_{2}$ as compared to breathing on CPAP with PS. Our observations suggest a potential role of T-piece during weaning from mechanical ventilation. (Minerva Anestesiol 2013;79:492-7)

Key words: Continuous positive airway pressure - Positive-pressure respiration - Ventilator weaning - Tracheostomy.

$\mathrm{W}$ eaning from mechanical ventilation is a challenging process for critical care physicians. Over the last decades many respiratory strategies were investigated to indentify the most suitable method of successful weaning. ${ }^{1}$ Conducting spontaneous breathing trial (SBT) with T-piece to identify patients ready for extubation has been a common practice, but it may also be used as a weaning tool by alternating periods of

Comment in p. 474. ventilatory support and SBT on T-piece. ${ }^{2}$ Ayre's T-piece is a simple, non-rebreathing circuit first used in paediatric anaesthesia. ${ }^{3}$ Its potential advantages in the critical care setting are the minimal dead space, the low airway resistance and the activation of the breathing muscles. The inspired fraction of oxygen $\left(\mathrm{FiO}_{2}\right)$ can be adjusted with high flow oxygen/air mixers or by the application of a Venturi injector on the inspiratory limb. Positive end-expiratory pressure (PEEP) can also be applied with the help of a PEEP-valve at the 
end of the expiratory limb. ${ }^{4}$ Comparing with mechanical ventilation disadvantages are the lack of pressure support, monitoring airway pressure and tidal volume. Spontaneous ventilation can be facilitated by new generation of ventilators, by applying continuous positive airway pressure (CPAP) with pressure support (PS) and automatic tube compensation (ATC). The purpose of the latter is the automatic regulation of the airway pressure in proportion to the ventilator's flow rate in order to compensate for the resistance of artificial airways. 5 Our objective was to investigate the effects of T-piece on gas exchange as compared to $\mathrm{CPAP}+\mathrm{PS}$ and CPAP+ATC modes in tracheostomized patients during respiratory weaning.

\section{Materials and methods}

\section{Study population}

The study was approved by the Human Investigation Review Board of University of Szeged. Due to the prospective observational design of the study, and because T-piece weaning has long tradition in the department and the protocol included no other intervention that regular monitoring, the need for informed consent was waived. All patients ventilated in $\mathrm{CPAP}+\mathrm{PS}$ mode via a tracheostomy tube and fulfilling the criteria of the department's weaning protocol of SBT were enrolled. Weaning criteria were defined as: $\mathrm{SpO}_{2}>94 \%$, respiratory rate $(\mathrm{RR})<35 \mathrm{~min}^{-1}$, hemodynamic stability with heart rate $(\mathrm{HR})<100 \mathrm{~min}^{-1}$, mean arterial pressure (MAP) $>60 \mathrm{mmHg}$ on $\mathrm{PEEP}<10 \mathrm{cmH}_{2} \mathrm{O}$, $\mathrm{FiO}_{2}<50 \%$ and $\mathrm{PS} \leq 10 \mathrm{cmH}_{2} \mathrm{O}$. Exclusion criteria were: pregnancy, age under 18 , coexisting ventilator associated pneumonia and pulmonectomy or lobectomy in past medical history. Electrocardiogram, invasive blood pressure, $\mathrm{SpO}_{2}$ and $\mathrm{RR}$ were continuously monitored by Dräger Infinity Gamma XL Monitor (Telford, PA, USA) and central venous catheters were in situ in all cases. Patients were ventilated by Dräger Evita $\mathrm{XL}$ respirator (Lübeck, Germany) at all times.

\section{Experimental protocol}

Once patients fulfilled the criteria for weaning, baseline $\left(\mathrm{t}_{0}\right)$ respirator settings, cardio-respiratory parameters and arterial and central venous blood gas results were recorded while the patients were ventilated in $\mathrm{CPAP}+\mathrm{PS}$ mode. Then PS was decreased to $0 \mathrm{cmH}_{2} \mathrm{O}$ when just ATC was applied for 15 minutes and the respiratory parameters were recorded again $\left(t_{1}\right)$. ATC was set to $100 \%$ compensation, artificial airway was marked as tracheostomy tube with the exact internal diameter. After that patients were placed on T-piece with constant $\mathrm{FiO}_{2}$ and PEEP according to the respirator settings. Tpiece was assembled from: 1) T-tube (Intersurgical, Wokingham, United Kingdom); 2) 1500 mm long corrugated tube as inspiratory limb; with a 3) Venturi injector (Intersurgical, Wokingham, United Kingdom) to provide adequate fresh gas flow (30$50 \mathrm{~L} / \mathrm{min}$ ); 4) a $500 \mathrm{~mm}$ long corrugated tube as expiratory limb; with 5) a precalibrated, adjustable PEEP valve (Ambu, Baltorpbakken, Denmark). $\mathrm{FiO}_{2}$ was monitored throughout with an Ohmeda 5100 Oxygen Monitor (Madison, WI, USA) connected between the Venturi injector and the inspiratory limb of the T-piece. Repeated measurements were taken at $15\left(t_{2}\right), 30\left(t_{3}\right)$ and 60 minutes $\left(t_{4}\right)$ on the T-piece trial. Vital parameters were recorded and arterial blood gas samples were analyzed by a Roche cobas b 221 (Mannheim, Germany) blood gas system at each measurement points and central venous samples were taken at $t_{0}$ and $t_{4}$ to determine central venous oxygen saturation $\left(\mathrm{ScvO}_{2}\right)$. The trial was interrupted if $\mathrm{RR}$ increased $>35 \mathrm{~min}^{-1}, \mathrm{SpO}_{2}$ decreased permanently under $90 \%, \mathrm{HR}>120 \mathrm{~min}^{-}$ 1, blood pressure $>160 / 90 \mathrm{mmHg}$ or patient indicated shortness of breath.

\section{Statistical analysis}

After testing for normality with the Kolgomorov-Smirnov test with Lilliefor's modification, matched pairs were tested by nonparametric Friedman's ANOVA test. The $\mathrm{P}$ value was considered significant if $<0.05$. For statistical analysis PASW Statistics 18 (Chichago, IL, USA) software was used.

\section{Results}

Over the study period 25 tracheostomized patients were enrolled. The trial was interrupted in four cases $(16 \%)$ after $t_{2}$, because of pulmonary 


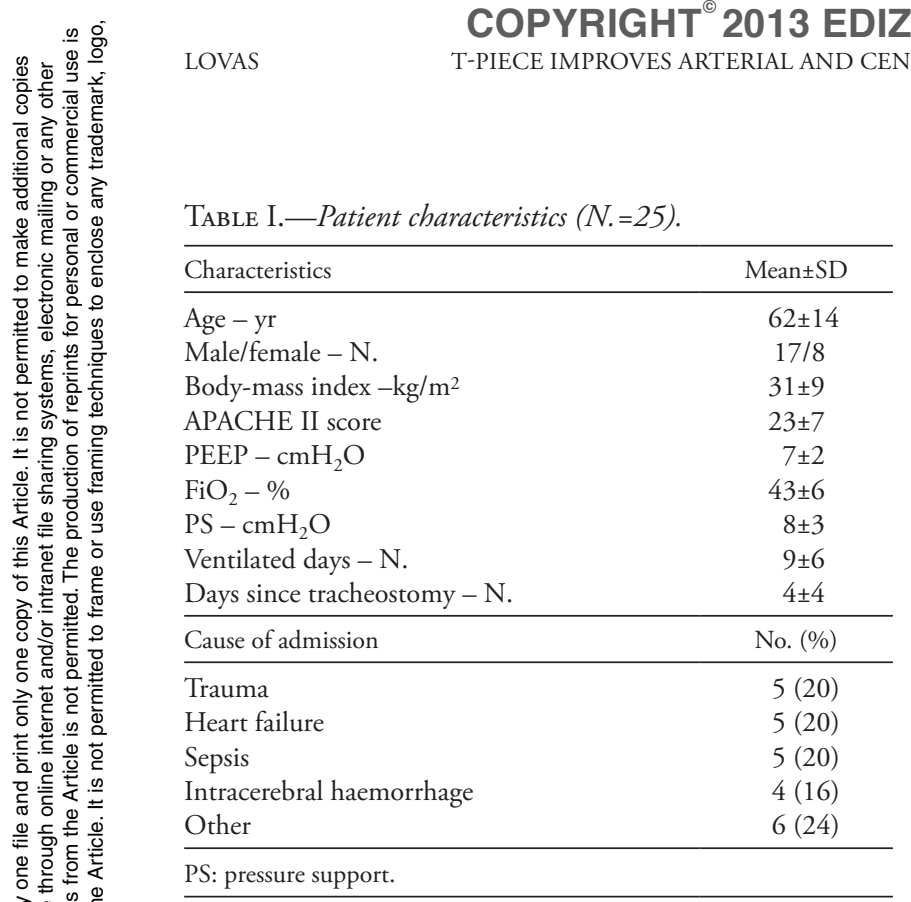

oedema, hypertension and on two occasion because of fatigue with $\mathrm{CO}_{2}$ retention. As data was analyzed on an intention-to-treat basis, we included those 4 patients who failed the T-piece trial in the final analysis. Demographic characteristics of the patients is summarised in Table I. tile range and median. ${ }^{*} \mathrm{P}<0.05$ as compared to t $0 ; \# \mathrm{P}<0.05$ as compared to $t 1$

\section{$C P A P+P S$ versus $C P A P+A T C$}

Arterial oxygen tension $\mathrm{PaO}_{2} / \mathrm{FiO}_{2}$ and $\mathrm{SaO}_{2}$ did not show any significant change on $\mathrm{CPAP}+\mathrm{ATC}$ as compared to $\mathrm{CPAP}+\mathrm{PS}$ mode (Figure 1). Tidal volume (Vte) did not decrease significantly with a significant increase in RR at the same time. There was no significant change in arterial carbon dioxide $\left(\mathrm{PaCO}_{2}\right), \mathrm{pH}$, base excess $(\mathrm{BE})$, bicarbonate $\left(\mathrm{HCO}_{3}^{-}\right)$and lactate. Switching from CPAP+PS to CPAP+ATC had no effect on haemodynamic parameters, as indicated by MAP and HR values (Table II).

\section{$C P A P+P S / C P A P+A T C$ versus T-piece}

Regarding oxygenation, $\mathrm{PaO}_{2} / \mathrm{FiO}_{2}$ and $\mathrm{SaO}_{2}$ showed significant improvement almost at all measurement points on T-piece trial as compared to $\mathrm{CPAP}+\mathrm{PS}$ and $\mathrm{CPAP}+\mathrm{ATC}$ modes except of results at $t_{2}$ as compared to $t_{1}$ when $\mathrm{PaO}_{2} / \mathrm{FiO}_{2}$ did not change significantly. There was also a significant increase in $\mathrm{ScvO}_{2}$ at $\mathrm{t}_{4}$ as compared to baseline measurements (Figures 1, 2, Table II).

$\mathrm{RR}$ and $\mathrm{PaCO}_{2}$ were significantly higher at all

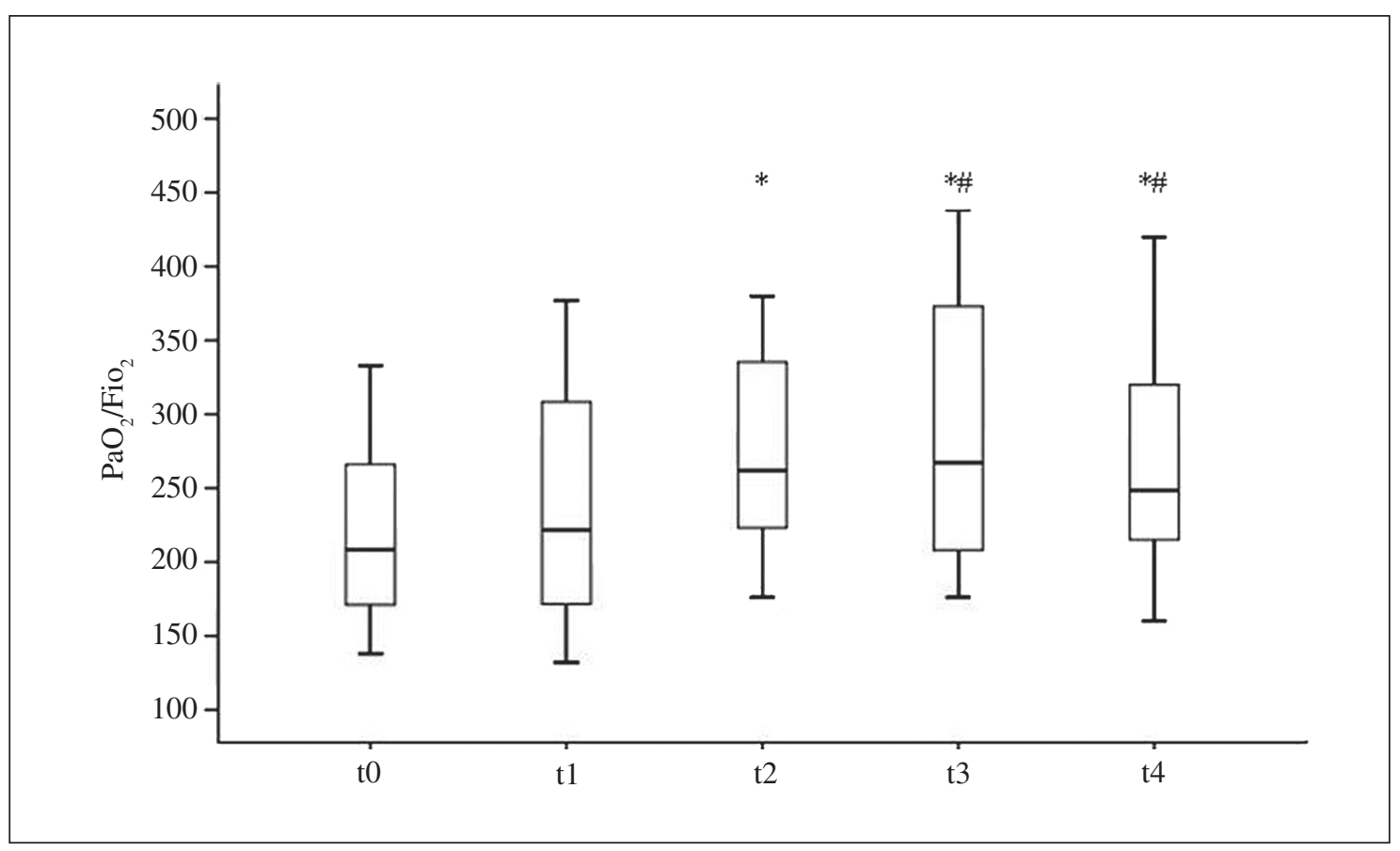

Figure 1.-Arterial oxygen tension/fraction of inspired oxygen $\left(\mathrm{PaO}_{2} / \mathrm{FiO}_{2}\right)$. Data are presented as 5 th- 95 th percentile, interquar- 
TABLE II.-Blood gas results and vital paramters. Data are presented as median [interquartile range].

\begin{tabular}{|c|c|c|c|c|c|}
\hline & $\begin{array}{c}\mathrm{t}_{0} \\
(\mathrm{~N} .=25)\end{array}$ & $\begin{array}{c}\quad \begin{array}{c}\mathrm{t}_{1} \\
\mathrm{~N} .=25)\end{array} \\
\end{array}$ & $\begin{array}{c}\left.\stackrel{\mathrm{t}_{2}}{(\mathrm{~N} .}=25\right) \\
\end{array}$ & $\begin{array}{c}\left.\stackrel{\mathrm{t}_{3}}{(\mathrm{~N} .}=21\right) \\
\end{array}$ & $\left(\begin{array}{c}\mathrm{t}_{4} \\
(\mathrm{~N} .=21)\end{array}\right.$ \\
\hline Vte-ml & $450[365-530]$ & $407[335-500]$ & & & \\
\hline $\mathrm{RR}-\mathrm{min}^{-1}$ & 23 [18-30] & $27[20-30] c$ & $30[26-33] c, d$ & $28[24-35] c, d$ & $29[25-35] c, d$ \\
\hline $\mathrm{SaO}_{2}-\%$ & 97 [96-98] & 97 [95-98] & $99[97-99] \mathrm{cdd}$ & $99[97-99] \mathrm{cd}$ & $99[97-99] \mathrm{cd}$ \\
\hline $\mathrm{PaO}_{2}-\mathrm{mmHg}$ & 89 [78-111] & 96 [82-113] & 119 [98-138]c & $127[101-149]^{\mathrm{cdd}}$ & $122[98-144]^{\mathrm{c}, \mathrm{d}}$ \\
\hline $\mathrm{PaO}_{2} / \mathrm{FiO}_{2}$ & 208 [175-266] & 223 [186-290] & $262[207-339]^{\mathrm{c}}$ & $270[208-373]^{\mathrm{cd}}$ & $249[215-325]^{c, d}$ \\
\hline $\mathrm{PaCO}_{2}-\mathrm{mmHg}$ & $41[37-47]$ & $41[38-48]$ & $47[43-55]^{c, d}$ & $49[43-58] c, d$ & $50[43-58] c, d$ \\
\hline $\mathrm{ScvO}_{2}-\%$ & $73[71-78]$ & & & & $80[75-82]^{\mathrm{c}}$ \\
\hline $\mathrm{pH}$ & $7.41[7.39-7.43]$ & $7.41[7.38-7.43]$ & $7.36[7.33-7.40]^{\mathrm{a}, \mathrm{b}}$ & $7.37[7.33-7.41]^{\mathrm{a}, \mathrm{b}}$ & $7.38[7.33-7.41] \mathrm{a}, \mathrm{b}$ \\
\hline $\mathrm{HCO}_{3}-\mathrm{mmol} / \mathrm{L}$ & $25.9[23.7-27.9]$ & 26.1 [24.4-27.6] & $26.9[25.8-29.2]^{c, d}$ & $27.1[25.7-30.6]^{c, d}$ & $27.0[25.9-29.6]^{\mathrm{c}, \mathrm{d}}$ \\
\hline $\mathrm{BE}$ & $1.3[-0.2-2.8]$ & $1.4[0.0-2.3]$ & $1.2[0.3-3.0]$ & $1.6[0.1-4.3]$ & $1.9[0.2-3.4]$ \\
\hline Lactate- $\mathrm{mmol} / \mathrm{L}$ & $1.0[0.5-1.2]$ & $0.9[0.5-1.2]$ & $1.0[0.6-1.1]$ & $0.9[0.6-1.0]^{\mathrm{a}, \mathrm{b}}$ & $0.8[0.5-1.0]^{a}$ \\
\hline HR-min ${ }^{-1}$ & $79[71-86]$ & 78 [71-87] & 83 [72-93] & 83 [73-93] & $85[74-96]^{\mathrm{d}}$ \\
\hline MAP-mmHg & 82 [73-95] & 83 [73-95] & $90[80-106]^{\mathrm{c}, \mathrm{d}}$ & $91[79-105]^{c, d}$ & $93[78-101]^{\mathrm{d}}$ \\
\hline
\end{tabular}

asignificant decrease as compared to $t 0, \mathrm{P}<0.05$; bsignificant decrease as compared to $\mathrm{t} 1, \mathrm{P}<0.05$; csignificant increase as compared to t0, $\mathrm{P}<0.05$; ${ }^{d}$ significant increase as compared to $t 1, \mathrm{P}<0.05$

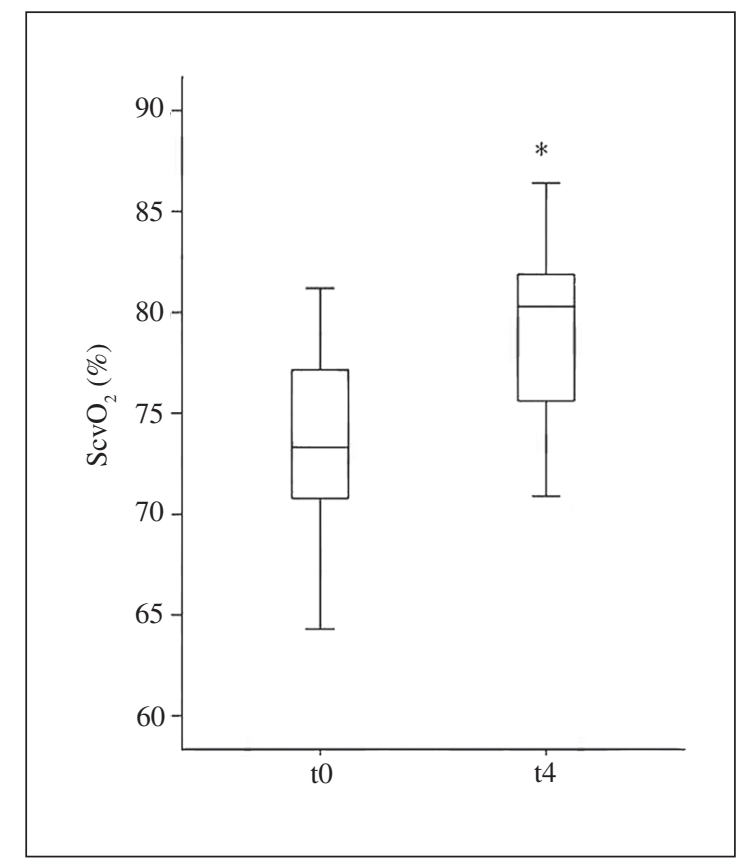

Figure 2.-Central venous oxygen saturation. Data are presented as 5th-95th percentile, interquartile range and median. ${ }^{*} \mathrm{P}<0.001$

time-points with a significant decrease in $\mathrm{pH}$. There was a tendency of significantly elevated $\mathrm{HCO}_{3}{ }^{-}$levels at $\mathrm{t}_{2-4}$ with no significant increase in $\mathrm{BE}$ and lactate levels showed minimal change. Regarding haemodynamic parameters MAP was significantly higher on T-piece at all time points and HR increased significantly but only by $\mathrm{t}_{4}$ as compared to $t_{1}$ (Table II).

\section{Discussion}

The major finding of this study is that breathing via a T-piece improved arterial and central venous oxygenation in tracheostomized patients as compared to $\mathrm{CPAP}+\mathrm{PS}$ and $\mathrm{CPAP}+\mathrm{ATC}$ ventilatory modes.

\section{Weaning with T-piece}

In this investigation $84 \%$ of the patients completed the T-piece trial, and in 4 cases we had to interrupt the trial. Unfortunately we cannot compare our failure rate directly with international results as according to our best knowledge there is no literature data on the effect of T-piece on gas exchange and weaning in tracheostomized patients. In general, failure rate after SBT is reported around $26-42 \%$ within the first 60 minutes ${ }^{1}$, which was only $16 \%$ in our study. Michalopoulos et al., investigated the effect of different arrangements of T-piece parts on oxygenation ${ }^{6}$ and Hoffman et al., analyzed the impact of tracheal gas insufflation on ventilatory demand 7 in patients with tracheostomy but the termination rate was not mentioned in these trials. In two out of four cases when the trial had to be interrupted in our study patients 
suffered from chronic cardiac conditions such as ischemic heart disease and cardiac failure which is in accord with previous results that cardiac dysfunction can limit respiratory weaning during SBT. ${ }^{8}$

\section{Effects on gas exchange}

Varelman et al., found no significant change in $\mathrm{PaO}_{2}$ when ATC was compared with PS ventilation in intubated patients. ${ }^{9}$ This is in accord with our findings in tracheostomized patients. Regarding the effects of T-piece trial on gas exchange, in a recent clinical study on intubated patients it was found that $\mathrm{PaO}_{2}$ did not change significantly as compared to PS ventilation, 10 which is in contrast with our findings of improved oxygenation on T-piece.

There are several mechanisms which could explain this significant increase in arterial oxygenation. First, the activation of breathing muscles without the interference of the ventilator may have a significant impact. Mechanical ventilation, controlled as well as PS modes, induce diaphragm dysfunction. ${ }^{11}$ In patients who fulfill the "ready to be weaned" criteria, breathing via a T-piece may be beneficial as compared to several ventilation modes, in which the patient has to trigger the ventilator by either flow or pressure. During T-piece trials respiratory muscle movements may promote immediate alveolar recruitment ${ }^{12}$ with a prompt benefit on gas exchange. It has also been shown in a recent article that different arrangements of the T-piece system can affect $\mathrm{PaO}_{2}$. Second, when a long inspiratory corrugated tube was inserted between the Venturi injector and the T-piece as an inspiratory limb, just like in our investigation, it resulted in significantly improved arterial oxygenation as compared to assembling the Venturi injector directly to the T-piece. ${ }^{6}$ Finally, the PEEP valve might have had some effect on the observed changes. Comparing adjustable PEEP valves, the same as we used on our study, to precalibrated fixed PEEP valves during helmet CPAP, the adjustable ones showed a variable degree flow dependency producing higher end expiratory pressures on higher flow rates. ${ }^{13}$ Increased PEEP level is associated with alveolar recruitment and improved arterial oxygenation. ${ }^{14}$ As we did not measure the actual PEEP level on T-piece, one cannot exclude its effect on the results.

Regarding ventilation on T-piece there was a significant and gradual increase in $\mathrm{PaCO}_{2}$ and a decrease in $\mathrm{pH}$ values over time. Although this change was statistically significant, but even the last median $\mathrm{pH}$ value remained in the normal range of $>7.35$. Nevertheless, one has to bear in mind that with the lack of pressure support on T-piece, and this holds true for all SBT methods, patients are prone to $\mathrm{CO}_{2}$ retention which per se is an important sign of weaning failure. ${ }^{1}$ Although assessment of the success of weaning was beyond the aim of this study, 4 patients out of the $25 \mathrm{had}$ to go back on mechanical ventilation during the study period of 75 minutes due to fatigue (and consequent hypoventilation) and signs of acute heart failure. Future studies may be warranted to investigate the predictive value of $\mathrm{PaCO}_{2}$ changes on T-piece as a predictor of weaning failure/success in tracheostomized patients.

\section{Effects on $\mathrm{ScvO}_{2}$}

In the current study we measured significantly higher $\mathrm{ScvO}_{2}$ values on T-piece as compared to $\mathrm{CPAP}+\mathrm{PS} / \mathrm{CPAP}+\mathrm{ATC}$ ventilation. Increased $\mathrm{ScvO}_{2}$ can be the result of increased oxygen delivery (cardiac output, $\mathrm{CO}$ and arterial oxygen content, $\mathrm{CaO}_{2}$ ) and/or when oxygen consumption is decreased. 15 Unfortunately we are unable to give an exact explanation for this phenomenon as we did not measure $\mathrm{CO}$ and work of breathing (WOB). However, Jiao et al., found in an in vitro investigation that Dräger Evita ${ }^{\circ} \mathrm{XL}$ respirator, the one we used in our study, had the highest expiratory resistance among four newer generation ventilators with active expiratory valve ${ }^{16}$ what can significantly affect WOB. Therefore, it can be that the increase in $\mathrm{ScrO}_{2}$ was in indeed an improvement as a result of the less WOB on T-piece. This hypothesis is also supported by the fact, that there was no sign of inadequate oxygen uptake as indicated by normal lactate, bicarbonate and $\mathrm{pH}$ levels. All 21 patients remained haemodynamically stable throughout as indicated by MAP, $\mathrm{HR}$ and lactate values. However, as there was a 
significant increase of $2 \%$ in $\mathrm{SaO}_{2}$ on T-piece it might have also had some contribution in improved oxygen delivery hence on the observed increase in $\mathrm{ScrO}_{2}$.

\section{Limitations}

The main limitation of this study is that detailed cardio-respiratory monitoring on T-piece such as airway pressure, PEEP, tidal volume, $\mathrm{CO}, \mathrm{WOB}$, was not available it is difficult to explain the observed findings. However, the primary aim of this study was to observe if there was any difference in oxygenation on T-piece. Having found the current results a detailed investigation may be warranted.

\section{Conclusions}

To our best knowledge this is the first study to show that conducting respiratory weaning with Ayre's T-piece significantly improves arterial oxygenation and resulted in higher $\mathrm{ScvO}_{2}$ as compared to CPAP+PS and CPAP+ATC ventilation. Although there are several open questions, our results suggest a potential role of T-piece trials during respiratory weaning in tracheostomized patients.

\section{Key messages}

- Breathing via a T-piece may improve arterial oxygenation in tracheostomized patients during respiratory weaning.

- Weaning on T-piece may result an increase in central venous oxygen saturation.

- During weaning T-piece can serve as an alternative of CPAP with pressure support ventilation.

\section{References}

1. Boles JM, Bion J, Connors A, Herridge M, Marsh B, Melot $\mathrm{C}$ et al. Weaning from mechanical ventilation. Eur Respir J 2007;29:1033-56.

2. Hess D. Ventilator modes used in weaning. Chest 2010;137:1256-8.

3. Ayre P. Anaesthesia for intracranial operations: A new technique. Lancet 1937;229: 561-3.

4. Lawrence JC. PEEP and the Ayre's T-Piece System. Anaesth Intensive Care 1978;6:359.

5. Fabry B, Haberthür C, Zappe D, Guttmann J, Kuhlen R, Stocker R. Breathing pattern and additional work of breathing in spontaneously breathing patients with different ventilatory demands during inspiratory pressure support and automatic tube compensation. Intensive Care Med 1997;23:545-52.

6. Michalopoulos AS, Gregoriades K, Falagas ME. The effect of different arrangements of T-piece parts on oxygenation of patients with tracheostomy. Anesth Analg 2006;103:1054-5.

7. Hoffman LA, Tasota FJ, Delgado E, Zullo TG, Pinsky MR. Effect of tracheal gas insufflation during weaning from prolonged mechanical ventilation: a preliminary study. Am J Crit Care 2003;12:31-9.

8. Moschietto S, Doyen D, Grech L, Dellamonica J, Hyvernat H, Bernardin G. Transthoracic Echocardiography with Doppler Tissue Imaging predicts weaning failure from mechanical ventilation: evolution of the left ventricle relaxation rate during a spontaneous breathing trial is the key factor in weaning outcome. Crit Care 2012;16:R81.

9. Varelmann D, Wrigge H, Zinserling J, Muders T, Hering $\mathrm{R}$, Putensen C. Proportional assist versus pressure support ventilation in patients with acute respiratory failure: cardiorespiratory responses to artificially increased ventilatory demand. Crit Care Med 2005;33:1968-75.

10. Cabello B, Thille AW, Roche-Campo F, Brochard L, Gómez FJ, Mancebo J. Physiological comparison of three spontaneous breathing trials in difficult-to-wean patients. Intensive Care Med 2010;36:1171-9.

11. Hudson MB, Smuder AJ, Nelson WB, Bruells CS, Levine S, Powers SK. Both high level pressure support ventilation and controlled mechanical ventilation induce diaphragm dysfunction and atrophy. Crit Care Med 2012;40:1254-60.

12. Westerdahl E, Lindmark B, Eriksson T, Hedenstierna G, Tenling A. The immediate effects of deep breathing exercises on atelectasis and oxygenation after cardiac surgery. Scand Cardiovasc J 2003;37:363-7.

13. Isgrò S, Zanella A, Giani M, El Aziz El Sayed Deab S, Pesenti A, Patroniti N. Performance of different PEEP valves and helmet outlets at increasing gas flow rates:a bench top study. Minerva Anestesiol 2012 [Epub ahead of print]

14. Villar J. The use of positive end-expiratory pressure in the management of the acute respiratory distress syndrome. Minerva Anestesiol 2005;71:265-72.

15. Bloos F, Reinhart K. Venous oximetry. Intensive Care Med 2005;31:911-3.

16. Jiao GY, Newhart JW. Bench study on active exhalation valve performance. Respir Care 2008;53:1697-702.

Received on November 22, 2012 - Accepted for publication on February 21, 2013.

Corresponding author: A Lovas, University of Szeged, Faculty of Medicine, Department of Anaesthesiology and Intensive Therapy, 6 Semmelweis St, Szeged, 6722, Hungary. E-mail: lovas.andras@med.u-szeged.hu 


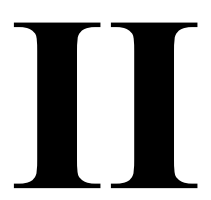





\title{
Lung recruitment can improve oxygenation in patients ventilated in continuous positive airway pressure/pressure support mode
}

\author{
András Lovas, Márton Ferenc Németh, Domonkos Trásy and Zsolt Molnár * \\ Department of Anaesthesiology and Intensive Therapy, Faculty of Medicine, University of Szeged, Szeged, Hungary
}

Background: Recruitment maneuvers are often used in critical care patients with hypoxemic respiratory failure. Although continuous positive airway pressure/pressure support (CPAP/PS) ventilation is a frequently used approach, but whether lung recruitment also improves oxygenation in spontaneously breathing patients has not been investigated yet.

\section{OPEN ACCESS}

Edited by:

Takashi Tagami,

Nippon Medical School, Japan

Reviewed by:

Vsevolod V. Kuzkov,

Northern State Medical University,

Russia

Pieter Roel Tuinman

VU Medical Center, Netherlands

${ }^{*}$ Correspondence:

Zsolt Molnár,

Department of Anaesthesiology and

Intensive Therapy, Faculty of

Medicine, University of Szeged, Semmelweis Utca 6, Szeged 6722

Hungary

zsoltmolna@gmail.com

Specialty section

This article was submitted to Intensive Care Medicine and Anesthesiology,

a section of the journal

Frontiers in Medicine

Received: 13 February 2015 Accepted: 05 April 2015

Published: 21 April 2015

Citation:

Lovas A, Németh MF, Trásy D and Molnár Z (2015) Lung recruitment can improve oxygenation in patients ventilated in continuous positive airway pressure/pressure support mode.

Front. Med. 2:25 doi: 10.3389/fmed.2015.00025 The primary objective was to analyze the effect of recruitment maneuver on oxygenation in patients ventilated in CPAP/PS mode.

Methods: Following baseline measurements PEEP was increased by $5 \mathrm{cmH}_{2} \mathrm{O}$. Recruitment maneuver was applied for $40 \mathrm{~s}$ with $40 \mathrm{cmH}_{2} \mathrm{O}$ of PS. Measurements of the difference in $\mathrm{PaO}_{2} / \mathrm{FiO}_{2}$ and airway parameters measured by the ventilator were recorded immediately after recruitment then 15 and 30 min later. Thirty patients ventilated in CPAP/PS mode with a PEEP $\geq 5 \mathrm{cmH}_{2} \mathrm{O}$ were enrolled in this prospective, observational study if their $\mathrm{PaO}_{2} / \mathrm{FiO}_{2}$ ratio was $<300 \mathrm{mmHg}$ or required an $\mathrm{FiO}_{2}>0.5$.

Results: Following recruitment maneuver patients were considered as non-responders $(\mathrm{NR}, n=15)$ if difference of $\mathrm{PaO}_{2} / \mathrm{FiO}_{2}<20 \%$ and responders $(\mathrm{R}, n=15)$ if difference of $\mathrm{PaO}_{2} / \mathrm{FiO}_{2} \geq 20 \%$. In the NR-group, $\mathrm{PaO}_{2} / \mathrm{FiO}_{2}$ decreased non-significantly from baseline: median [interquartile], $\mathrm{PaO}_{2} / \mathrm{FiO}_{2}=176$ [120-186] vs. after recruitment: 169 [121-182] $\mathrm{mmHg}, P=0.307$ while in the R-group there was significant improvement: 139 [117-164] vs. 230 [211-323] mmHg, $P=0.01$. At the same time points, dead space to tidal volume ratio (Vds/Nte) significantly increased in the NR-group Vds/Nte = 32 [27-37] vs. 36 [25-42]\%, $P=0.013$ but no significant change was observed in the R-group: 26 [22-34] vs. 27 [24-33]\%, $P=0.386$.

Conclusion: Recruitment maneuver improved $\mathrm{PaO}_{2} / \mathrm{FiO}_{2}$ ratio by $\geq 20 \%$ in $50 \%$ of patients ventilated in CPAP/PS mode.

Keywords: capnography, CPAP ventilation, lung compliance, lung recruitment, positive end-expiratory pressure

\section{Introduction}

Hypoxemic respiratory failure is one of the leading causes of the need for mechanical ventilation and can occur in several conditions, most often as a result of heart failure, pneumonia, and sepsis. Its most severe form is acute respiratory distress syndrome (ARDS), which still carries high risk of 
mortality (1). Applying increased level of PEEP (2), prone positioning (3), and lung recruitment (4) are all recommended measures to improve oxygenation and gas exchange in general.

One of the main reasons of hypoxemia, characterized by low partial arterial oxygen tension/fraction of inspired oxygen $\left(\mathrm{PaO}_{2} / \mathrm{FiO}_{2}\right)$, is diffuse atelectasis of the alveoli (5). Therefore, resolving atelectatic lung areas could reduce intrapulmonary shunt and venous admixture and hence improve oxygenation (6). This can be achieved by applying increased intrathoracic pressures for a short period of time and keep the alveoli open by titrating the adequate level of PEEP. This procedure of opening up atelectatic alveoli and keep them open is called as the "open lung concept" (7). However, it is also well known that not every lung responds for recruitment maneuvers (8). Although most recruitment strategies were tested under controlled mechanical ventilation (9), there is also increasing evidence that maintaining spontaneous breathing during mechanical ventilation may provide advantageous ventilation/perfusion ratio and prevents alveolar shearing $(6,10)$. Applying continuous positive airway pressure (CPAP) with or without pressure support (PS) and allowing the patient to breathe spontaneously is an often used ventilation mode, both during noninvasive and invasive ventilation. Although theoretically alveolar recruitment may also have a place in these patients ventilated invasively this has only been investigated during non-invasive ventilation (11). Sophisticated methods of assessing lung recruitment, like computer tomography (CT) scanning, esophageal pressure measurements, etc., are rarely available in the everyday routine in most countries and these are especially difficult to perform in spontaneously breathing patients (12). Nevertheless, one of the benefits of effective recruitment is improved oxygenation after the maneuver. Therefore, the purpose of the current study was to investigate the effects of recruitment on the $\mathrm{PaO}_{2} / \mathrm{FiO}_{2}$ ratio in patients ventilated in CPAP/PS mode suffering from moderate and severe hypoxemic respiratory failure.

\section{Materials and Methods}

\section{Patients}

Following ethics committee approval of the Human Investigation Review Board of University of Szeged, informed consent was obtained from the patients' next of kin. All mechanically ventilated patients with maintained spontaneous breathing, ventilated in CPAP/PS mode with a PEEP $\geq 5 \mathrm{cmH}_{2} \mathrm{O}$, were enrolled in this prospective, observational study if their $\mathrm{PaO}_{2} / \mathrm{FiO}_{2}$ ratio $<300 \mathrm{mmHg}$ or required an $\mathrm{FiO}_{2}>0.5$, regardless of the etiology of respiratory failure $(13,14)$. Exclusion criteria were age $<18$, pregnancy, pulmonectomy/lobectomy, or spontaneous pneumothorax in past-medical history, emphysematous bullae, clinically diagnosed end stage chronic obstructive pulmonary disease, and vasopressor refractory hemodynamic instability.

\section{Measurements and Experimental Protocol}

All patients who were eligible for the study had a radial arterial and an internal jugular or subclavian central venous catheter inserted on admission to the intensive care unit as part of our standard care. Patients were sedated with continuous infusion of propofol and fentanyl reaching a Richmond Agitation Sedation Scale score of -1 to -2 . Electrocardiogram, invasive blood pressure, and $\mathrm{SpO}_{2}$ were continuously monitored by Dräger Infinity Gamma XL Monitor (Telford, PA, USA). Patients were ventilated with Dräger Evita ${ }^{\circledR}$ XL respirators (Lübeck, Germany). The level of PS was adjusted to achieve adequate arterial $\mathrm{pCO}_{2}$ level to maintain $\mathrm{pH} \geq 7.30$. Respiratory parameters, airway pressures, dynamic respiratory compliance, airway resistance, end-tidal carbon dioxide $\left(\mathrm{EtCO}_{2}\right)$, dead space (Vds), and dead space to exhaled tidal volume ratio (Vds/Vte) were all continuously monitored by the respirator and its own volumetric capnography.

Once inclusion criteria were fulfilled respirator settings, cardiorespiratory and airway parameters were recorded at baseline. Then PEEP was increased by $5 \mathrm{cmH}_{2} \mathrm{O}$ and after $5 \mathrm{~min}$ measurements were repeated to investigate the effect of any PEEPinduced recruitment. For alveolar recruitment, PS was increased to $40 \mathrm{cmH}_{2} \mathrm{O}$ for $40 \mathrm{~s}$ to limit the undesirable side effects of volutrauma. After which peak inspiratory pressure was reduced to the initial value as at baseline while maintaining the increased level of PEEP (by $5 \mathrm{cmH}_{2} \mathrm{O}$ ) according to the open lung concept (7). Measurements were repeated immediately after recruitment then 15 and 30 min later with constant respirator settings as at baseline. Arterial blood gas samples were analyzed by a Roche cobas b 221 (Mannheim, Germany) blood gas system at each measurement points and central venous samples were taken at baseline and at the final time point to determine central venous oxygen saturation $\left(\mathrm{ScvO}_{2}\right)$.

Primary outcome parameter was the change in oxygenation $\left(\mathrm{PaO}_{2} / \mathrm{FiO}_{2}\right)$ after the recruitment maneuver. Patients were considered as non-responders (NR) if difference of $\mathrm{PaO}_{2} / \mathrm{FiO}_{2}<20 \%$ and responders ( $\mathrm{R}$ ) if difference of $\mathrm{PaO}_{2} / \mathrm{FiO}_{2} \geq 20 \%$ between baseline and following recruitment measurements.

\section{Statistics}

Based on a preliminary analysis of our data (15), the mean $\mathrm{PaO}_{2} / \mathrm{FiO}_{2}$ ratio before recruitment was $156 \mathrm{mmHg}$ with a SD of $43 \mathrm{mmHg}$. In order the study to have an $80 \%$ power with a $P<0.05$ and to observe an increase in the $\mathrm{PaO}_{2} / \mathrm{FiO}_{2}$ of 10 or $20 \%$ (which corresponds to a $\mathrm{PaO}_{2} / \mathrm{FiO}_{2}$ of 171 and $186 \mathrm{mmHg}$, respectively) after recruitment, the required minimal sample size was calculated to be 51 or 13 . Therefore, we decided that a sample size of 30 should be feasible and provide adequate statistical power.

All data in the tables are presented as median [interquartile range]. Figures are presented as boxplots: 5th-95th percentile, interquartile range, and median. After testing for normality with Shapiro-Wilk test data were analyzed between groups with Mann-Whitney $U$ test or Kruskal-Wallis test as suitable. Matched pairs were investigated with Wilcoxon signed rank test and relationship was analyzed with Spearman's correlation coefficient. For evaluating goodness of fit and independence, Pearson's chi-square test was used. The " $P$ " value was considered significant if $<0.05$. For statistical analysis, IBM SPSS Statistics Version 20 (Armonk, NY, USA) software was used.

\section{Results}

Over the study period 30 patients were enrolled, of whom 15 (50\%) patients turned out to be NR and 15 (50\%) responders. 
TABLE 1 | Demographic data

\begin{tabular}{lccc}
\hline & $\begin{array}{c}\text { Non-responders } \\
(\boldsymbol{n}=\mathbf{1 5})\end{array}$ & $\begin{array}{c}\text { Responders } \\
(\boldsymbol{n}=\mathbf{1 5})\end{array}$ & $\boldsymbol{P}$ \\
\hline Age (years) & $63[55-58]$ & $74[59-76]$ & 0.045 \\
Male/female $(\mathrm{N})$ & $11 / 4$ & $9 / 6$ & \\
Body-mass index $\left(\mathrm{kg} / \mathrm{m}^{2}\right)$ & $27[24-31]$ & $29[25-34]$ & 0.389 \\
APACHE II score & $21[18-25]$ & $23[19-33]$ & 0.851 \\
Baseline PEEP $\left(\mathrm{cmH}_{2} \mathrm{O}\right)$ & $10[8-12]$ & $10[10-12]$ & 0.389 \\
Baseline FiO ${ }_{2}(\%)$ & $60[50-62]$ & $60[60-80]$ & 0.126 \\
Baseline PS $\left(\mathrm{cmH} \mathrm{H}_{2} \mathrm{O}\right)$ & $12[8-16]$ & $10[10-16]$ & 0.935 \\
Ventilated days $(\mathrm{N})$ & $4[2-6]$ & $2[1-4]$ & 0.202 \\
Lung injury score & $2.3[1.7-2.7]$ & $2.3[2.0-2.8]$ & 0.461 \\
Orotracheal tube ID $(\mathrm{mm})$ & $8[8-8.5]$ & $8[8-8]$ & 0.567 \\
Cause of admission $(\%)$ & & & \\
Heart failure & $4(13)$ & $6(20)$ & \\
Ischemic heart disease & $2(8)$ & $7(24)$ & \\
Pneumonia & $3(10)$ & $1(3)$ & \\
Sepsis & $3(10)$ & 0 & \\
Pulmonary contusion & $1(3)$ & 0 & \\
Stroke & $1(3)$ & $1(3)$ & \\
Other & $1(3)$ & & \\
\hline
\end{tabular}

APACHE II, acute physiology and chronic health evaluation II; PEEP, positive end expiratory pressure; PS, pressure support; ID, internal diameter.

There was no significant difference between groups in baseline respirator settings and demographic characteristics except of age. Out of the 19 patients with admission diagnosis of cardiac origin 13 (68\%) were responders (Table 1). Serious adverse effects of recruitment maneuver like pneumothorax and worsening hemodynamic instability were not detected.

There was a non-significant decrease in $\mathrm{PaO}_{2} / \mathrm{FiO}_{2}$ from baseline to $30 \mathrm{~min}$ following recruitment in the NR-group. In the $\mathrm{R}$ group, $\mathrm{PaO}_{2} / \mathrm{FiO}_{2}$ significantly improved after the recruitment maneuver as compared to baseline results and remained elevated throughout the observation period. There was significant improvement in $\mathrm{SaO}_{2}$ among responders, while there was no significant change in the NR-group. Bicarbonate and base excess levels showed significant difference between groups at all time points. Hemodynamic parameters and $\mathrm{ScvO}_{2}$ did not show any significant change over time (Table 2; Figure 1).

There was no significant change in tidal volume, Vte indexed for predicted bodyweight, respiratory rate, and minute ventilation between groups and throughout the study as compared to baseline parameters. In the NR-group dynamic compliance, a parameter indicated on the ventilator dropped non-significantly after the recruitment maneuver but there was a significant increase in $\mathrm{Vds} /$ Vte following recruitment and $15 \mathrm{~min}$ later as compared to baseline in the same group. There was no other significant change in the examined respiratory and airway parameters in the NR- and R-group (Table 3).

Improvement in oxygenation was detected in $74 \%$ of all patients, and in $26 \%$ arterial oxygenation did not improve or even deteriorated. Testing in a contingency table the change in $\mathrm{PaO}_{2} / \mathrm{FiO}_{2}$ and dynamic compliance after the recruitment maneuver is shown in Figure 2. Improvement $(\geq 0)$ or deterioration $(<0)$ of dynamic compliance gave high sensitivity and specificity with a positive predictive value of 0.89 to differentiate patients with worsening as compared to those with improved $\mathrm{PaO}_{2} / \mathrm{FiO}_{2}$.

\section{Discussion}

The most important finding of this study is that recruitment maneuver improved oxygenation by more than $20 \%$ in half of the patients with moderate and severe hypoxemic respiratory failure ventilated in CPAP/PS mode. We also found that patients in whom hypoxemia was due to cardiac origin seemed to benefit the most, as nearly $70 \%$ of these patients were found to be responders.

Patients, according to the change in the $\mathrm{PaO}_{2} / \mathrm{FiO}_{2}$ ratio after recruitment, were divided to non-responder and responder groups. Regarding the demographic data, it is an interesting finding that patients in the NR-group were significantly younger than those in the R-group. There were also more patients with ischemic heart disease and heart failure in the R-group, while there were only four patients with heart failure in the NR-group. One of the possible explanations is that although lung compliance decreases with age in general but success of recruitment depends on other factors like co-morbidities and it may be more successful in patients with heart disease as compared to patients with pneumonia. The beneficial effects of PEEP-induced alveolar recruitment with improved compliance and oxygenation are well known phenomenon in patients with ischemic heart disease (16). PEEP can also decrease intrapulmonary shunt such as hypoxic pulmonary vasoconstriction with a reduced pulmonary artery pressure among patients with heart failure (17). Therefore, it is not the age per se but the accompanying higher number of patients with heart condition that caused the observed difference in the current study. Our results draw the attention of the importance of the etiology of acute lung injury and co-morbidities, at least as far as improvement in oxygenation is concerned after the recruitment maneuver. These results are also in accord with those reported in patients on controlled mechanical ventilation (18) but it also contradicts those in which etiology did not seem to matter (19). However, in this recent study by Grasso et al., the sample size was small (11/group) and none of the patients were admitted due to acute heart failure. Nevertheless, the success of recruitment as far as oxygenation is concerned in spontaneously breathing patients having developed hypoxemic respiratory failure due to acute heart failure is an important finding and should be investigated further.

Although it is not the most accurate way to assess lung recruitment, but measuring changes in arterial oxygenation is one of the commonly used methods to detect the efficacy of recruitment $(20,21)$. Furthermore, there is no consensus on how to define responders and $\mathrm{NR}$ based on the $\mathrm{PaO}_{2} / \mathrm{FiO}_{2}$ values, which vary between 30 and $50 \%$ in the literature $(19,22)$. Due to the lack of well-defined values, we have chosen an arbitrary threshold of difference in $\mathrm{PaO}_{2} / \mathrm{FiO}_{2} \geq 20 \%$ to define as responders and $<20 \%$ as NR following recruitment. Nevertheless, we detected an improvement of oxygenation in $74 \%$ of all patients, and in $26 \%$ arterial oxygenation did not improve or even deteriorated. Taking the $20 \%$ improvement in oxygenation as a clinically significant change, $50 \%$ of patients still responded, which is similar to that of reported in recently published studies $(23,24)$. However, it is important to note that the ratio of responders is highly dependent on the defined threshold. Furthermore, the 
TABLE 2 | Hemodynamic variables and blood gas results.

\begin{tabular}{|c|c|c|c|c|c|c|}
\hline & \multirow[t]{2}{*}{ Group } & \multicolumn{5}{|c|}{ Time point } \\
\hline & & Baseline & $\begin{array}{c}\text { PEEP } \\
\text { increment }\end{array}$ & After RM & $\begin{array}{c}15 \mathrm{~min} \\
\text { following } \mathrm{RM}\end{array}$ & $\begin{array}{c}30 \mathrm{~min} \\
\text { following } R M\end{array}$ \\
\hline \multirow{2}{*}{ Heart rate $(1 / \mathrm{min})$} & $N R$ & 88 [64-99] & 89 [68-102] & 87 [66-100] & 91 [67-99] & 90 [67-99] \\
\hline & $\mathrm{R}$ & 95 [70-100] & 95 [72-115] & 93 [70-106] & 92 [70-101] & 99 [70-119] \\
\hline \multirow[t]{2}{*}{ MAP (mmHg) } & $N R$ & 75 [68-92] & 80 [70-83] & 79 [68-88] & 79 [69-83] & 80 [70-86] \\
\hline & $\mathrm{R}$ & 75 [69-88] & $75[71-87]$ & 78 [66-87] & 76 [68-85] & 74 [69-86] \\
\hline \multirow{2}{*}{$\mathrm{SaO}_{2}(\%)$} & $N R$ & 96 [93-99] & 97 [94-99] & 97 [94-99] & 97 [95-98] & 97 [95-99] \\
\hline & $\mathrm{R}$ & 95 [94-97] & $96[95-98]^{\mathrm{a}}$ & $98[96-99]^{\mathrm{a}}$ & $98[96-99]^{a}$ & $97[96-99]^{\mathrm{a}}$ \\
\hline \multirow[t]{2}{*}{$\mathrm{PaCO}_{2}(\mathrm{mmHg})$} & $N R$ & 47 [44-50] & 50 [44-52] & $48[43-50]$ & 48 [45-53] & $48[43-52]$ \\
\hline & $\mathrm{R}$ & 39 [37-49] & $41[37-50]$ & $42[37-51]$ & $40[37-52]$ & 39 [37-53] \\
\hline \multirow[t]{2}{*}{$\mathrm{ScvO}_{2}(\%)$} & NR & 74 [70-82] & & & & 77 [69-83] \\
\hline & $\mathrm{R}$ & 76 [69-79] & & & & 77 [72-81] \\
\hline \multirow[t]{2}{*}{$\mathrm{pH}$} & $N R$ & 7.4 [7.3-7.4] & 7.4 [7.3-7.4] & $7.4[7.3-7.4]$ & 7.4 [7.3-7.4] & $7.4[7.3-7.4]$ \\
\hline & $\mathrm{R}$ & 7.4 [7.3-7.4] & $7.4[7.3-7.4]$ & $7.4[7.3-7.4]$ & $7.4[7.3-7.4]$ & 7.4 [7.3-7.4] \\
\hline & $\mathrm{R}$ & $23[20-28]^{b}$ & $23[21-27]^{b}$ & $23[21-28]^{b}$ & $23[21-28]^{b}$ & $23[20-28]^{b}$ \\
\hline \multirow[t]{2}{*}{$\mathrm{BE}$} & NR & $2.7[-0.3$ to 4.5$]$ & $3.2[-0.7$ to 5.1$]$ & $2.9[-0.6$ to 5.0$]$ & $3.2[-1.3$ to 5.3$]$ & $3.0[-2.4$ to 5.0$]$ \\
\hline & $\mathrm{R}$ & $-1.4[-4.2 \text { to } 2.5]^{b}$ & $-1.6[-4.2 \text { to } 2.5]^{\mathrm{b}}$ & $-1.8[-4.2 \text { to } 2.1]^{\mathrm{b}}$ & $-1.9[-4.2 \text { to } 1.9]^{\mathrm{b}}$ & $-1.9[-4.2 \text { to } 1.8]^{b}$ \\
\hline \multirow[t]{2}{*}{ Lactate (mmol/L) } & NR & $0.9[0.7-1.1]$ & 0.9 [0.7-1.0] & $0.9[0.7-1.1]$ & 0.9 [0.6-1.0] & 0.9 [0.6-1.0] \\
\hline & $\mathrm{R}$ & $1.1[0.8-1.6]$ & $1.1[0.8-1.5]$ & $1.1[0.8-1.5]$ & $1.1[0.9-1.5]$ & $1.0[0.7-1.5]$ \\
\hline
\end{tabular}

PEEP, positive end-expiratory pressure; $R M$, recruitment maneuver; NR, non-responder; $R$, responder; $M A P$, mean arterial pressure; $S c v \mathrm{O}_{2}$, central venous oxygen saturation; $B E$, base excess.

a Significant difference as compared to baseline measurements, $\mathrm{P}<0.05$.

${ }^{b}$ Significant difference between groups, $\mathrm{P}<0.05$.

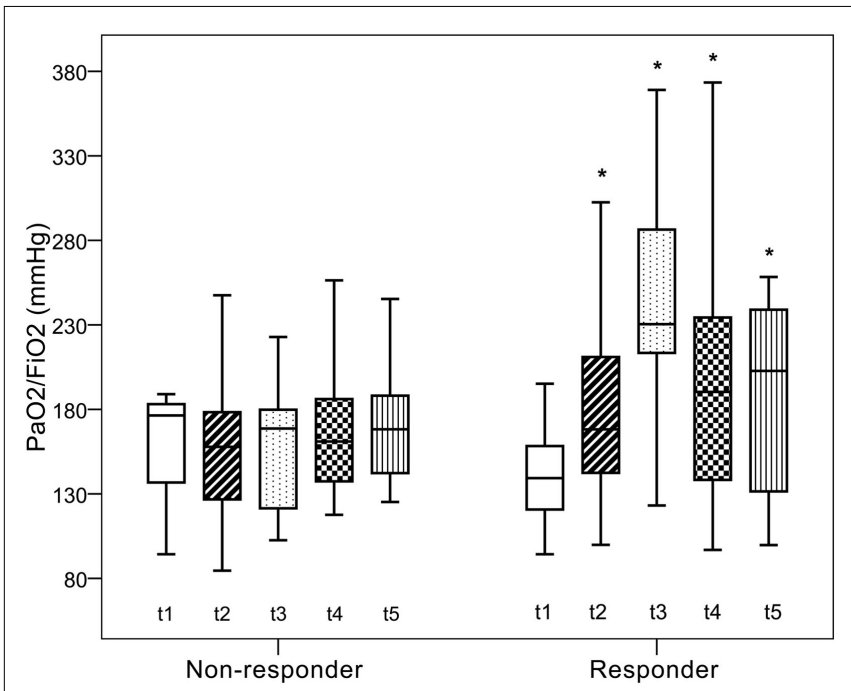

FIGURE 1 | Changes in $\mathbf{P a O}_{2} / \mathbf{F i O}_{2}$. $t_{0}$, baseline measurements; $t_{1}$ increasing PEEP by $5 \mathrm{cmH}_{2} \mathrm{O} ; t_{2}$, after recruitment; $t_{3}$ and $t_{4}, 15$ and $30 \mathrm{~min}$ after recruitment. *Significant difference as compared to baseline measurements, $P<0.05$.

improvement in arterial oxygenation among responders lasted longer than in studies where controlled ventilation was applied. In the investigation by Oczenski et al., after the initial improvement, $\mathrm{PaO}_{2} / \mathrm{FiO}_{2}$ returned to the baseline values after $30 \mathrm{~min}$ (25) while in our trial the significant improvement in oxygenation persisted throughout, suggesting that the effects of recruitment may last longer in spontaneous assisted modes as compared to controlled modes of ventilation in hypoxemic respiratory failure. Although the sample size is too small for an outcome study, which holds true for all of the above mentioned investigations, but our data suggest that CPAP/PS ventilation and lung recruitment may have benefits in patients suffering from moderate to severe acute lung injury, especially due to acute heart failure, which should be investigated further.

It may also be important to note, that prior to intervention patients were ventilated for a median of 4 days in the NR-group while it was only 2 days in the R-group. Although it was not statistically significant, but these results are similar to that of reported by Grasso et al., where the length of mechanical ventilation was significantly shorter in those patients who responded for recruitment maneuvers (19).

It is well known that not every lung responds for recruitment and unnecessary maneuvers may lead to adverse effects $(8,26)$. Several methods had been evaluated of which chest CT scan remains the gold standard warranting the direct visualization of the recruitable lung tissue (8). However, this method requires the transport of the critically ill patients to the CT scanner and exposes them to radiation (27). Other bed-side measurements to assess recruitability are pressure-volume curve assessment and end-expiratory lung volume/functional residual capacity ratio measurement $(28,29)$. Unfortunately, due to financial and ethical reasons, these methods were not applied in our study therefore we only have limited proof on the change in lung volume after the recruitment.

We did not observe any significant change neither in the $\mathrm{PaCO}_{2}$ nor in any other blood gas variables throughout the study. However, there was a significant difference in bicarbonate and base excess levels between groups this observation had no effect on the investigation of recruitment. One of the potential alternatives for 
TABLE 3 | Respiratory and airway parameters complemented with arterial to end-tidal $\mathrm{CO}_{2}$ results

\begin{tabular}{|c|c|c|c|c|c|c|}
\hline & \multirow[t]{2}{*}{ Group } & \multicolumn{5}{|c|}{ Time point } \\
\hline & & Baseline & $\begin{array}{c}\text { PEEP } \\
\text { increment }\end{array}$ & After RM & $\begin{array}{c}15 \mathrm{~min} \\
\text { following } \mathrm{RM}\end{array}$ & $\begin{array}{c}30 \mathrm{~min} \\
\text { following } \mathrm{RM}\end{array}$ \\
\hline \multirow[t]{2}{*}{ Vte $(m L)$} & $N R$ & 473 [398-612] & 479 [397-588] & 447 [393-615] & 506 [378-597] & 471 [453-663] \\
\hline & $\mathrm{R}$ & 513 [406-667] & 489 [385-702] & 492 [398-602] & 510 [354-698] & $520[402-741]$ \\
\hline \multirow[t]{2}{*}{ Vte/PBW (mL/kg) } & NR & 8 [6-8] & $7[6-9]$ & $7[5-8]$ & $7[6-9]$ & $7[6-9]$ \\
\hline & $\mathrm{R}$ & 7 [7-9] & 7 [6-10] & 7 [6-10] & $8[6-10]$ & $8[7-10]$ \\
\hline \multirow[t]{2}{*}{$\mathrm{RR}(1 / \mathrm{min})$} & NR & 17 [13-22] & 18 [13-20] & 18 [13-20] & 18 [13-20] & 17 [14-22] \\
\hline & $\mathrm{R}$ & $19[13-24]$ & 19 [14-26] & $17[14-26]$ & $19[15-24]$ & $18[14-24]$ \\
\hline \multirow[t]{2}{*}{$\mathrm{MV}(\mathrm{mL})$} & $N R$ & $7896[7011-11,016]$ & $8040[6300-11,020]$ & 7524 [7152-9825] & 7809 [6230-10,380] & 8208 [7260-10,296] \\
\hline & $\mathrm{R}$ & $9744[8037-11,687]$ & $9741[8220-10,875]$ & 9798 [7700-11,808] & $10,101[8328-11,328]$ & $10,116[8788-11,625]$ \\
\hline \multirow[t]{2}{*}{$R_{\mathrm{aw}}\left(\mathrm{cmH}_{2} \mathrm{O} / \mathrm{L} / \mathrm{s}\right)$} & NR & $13[9-14]$ & $13[9-18]$ & $14[10-17]$ & $13[9-18]$ & 14 [9-18] \\
\hline & $\mathrm{R}$ & $11[9-16]$ & $11[9-16]$ & $11[9-16]$ & $11[9-15]$ & $11[9-15]$ \\
\hline \multirow[t]{2}{*}{$C_{\mathrm{rs}}\left(\mathrm{mL} / \mathrm{cmH}_{2} \mathrm{O}\right)$} & $N R$ & 68 [47-83] & 65 [41-85] & 64 [42-75] & 69 [43-95] & 68 [46-85] \\
\hline & $\mathrm{R}$ & 52 [34-98] & 53 [31-106] & 56 [36-90] & 58 [39-98] & 58 [39-99] \\
\hline & $\mathrm{R}$ & $36[30-47]$ & 37 [31-47] & 39 [31-47] & 38 [30-48] & 39 [30-48] \\
\hline \multirow[t]{2}{*}{$\mathrm{P}_{(\mathrm{a}-\mathrm{ET})} \mathrm{CO}_{2}(\mathrm{mmHg})$} & NR & 7 [4-13] & 8 [4-10] & $8[5-13]$ & $7[4-11]$ & $7[4-13]$ \\
\hline & $\mathrm{R}$ & 5 [1-9] & 6 [2-9] & $6[3-11]$ & $5[1-10]$ & $6[1-9]$ \\
\hline \multirow[t]{2}{*}{ Vds (mL) } & $N R$ & 146 [128-191] & 148 [135-201] & 153 [133-198] & 150 [127-198] & 150 [127-198] \\
\hline & $\mathrm{R}$ & $153[118-172]$ & 166 [126-180] & 144 [118-180] & $153[125-177]$ & 158 [125-183] \\
\hline \multirow[t]{2}{*}{ Vds/Nte (\%) } & NR & 32 [27-37] & 35 [30-42] & $36[25-42]^{a}$ & $35[29-41]^{\mathrm{a}}$ & 32 [29-40] \\
\hline & $\mathrm{R}$ & 26 [22-34] & 28 [24-38] & 27 [24-33] & 27 [24-34] & 28 [25-36] \\
\hline
\end{tabular}

PEEP, positive end-expiratory pressure; RM, recruitment maneuver; NR, non-responder; $R$, responder; Vte, exhaled tidal volume; Vte/PBW, exhaled tidal volume indexed to predicted body weight; $R R$, respiratory rate; $M V$, minute ventilation; $\mathrm{R}_{a w}$, airway resistance; $\mathrm{C}_{r s}$, dynamic compliance; $\mathrm{EtCO}_{2}$, end-tidal $\mathrm{CO}_{2} ; P_{(a-E)} \mathrm{CO}_{2}$, arterial minus end-tidal $C \mathrm{O}_{2} ;$ Vds, dead space; Vds/Vte, dead space to exhaled tidal volume ratio.

asignificant difference as compared to baseline measurements, $\mathrm{P}<0.05$

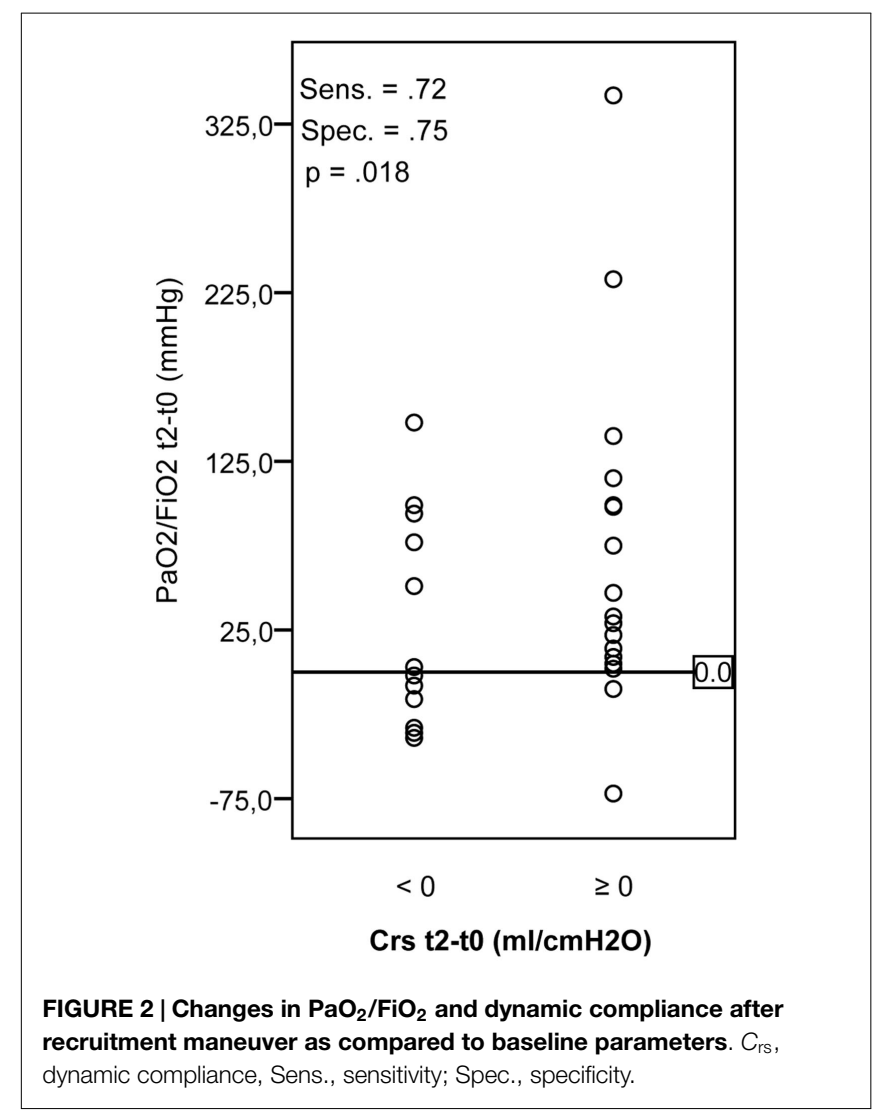

assessing alveolar recruitment may be the change in the difference between the arterial and end-tidal $\mathrm{CO}_{2}\left(\mathrm{P}_{\mathrm{a}-\mathrm{ET}} \mathrm{CO}_{2}\right)(30)$. In our study, $\mathrm{P}_{\mathrm{a}-\mathrm{ET}} \mathrm{CO}_{2}$ although did not change significantly over time in neither of the groups but in the R-group its value was lower than in the NR-group. Therefore, it may be a promising parameter but its relevance requires further studies.

Another important parameter is compliance, which is determined by volume/pressure relationships. Theoretically, in recruitable patients increasing pressures will increase volume hence compliance should improve or remain unchanged. While in non-recruitable patients increased pressures during recruitment can lead to the overdistension without gaining lung volumes, hence result in a consecutive fall in respiratory compliance (31). Although, in a recent study by Oczenski et al., in patients with ARDS who were ventilated in controlled mode and underwent recruitment after a PEEP trial there was no significant change in compliance $3 \mathrm{~min}$ after the maneuver what was accompanied by a significant improvement in oxygenation (25). This approach cannot be evaluated in our study as the value of the ventilator indicated compliance in spontaneously breathing patients has not been validated yet.

Finally, hemodynamic changes during the recruitment maneuver have been widely investigated $(32,33)$. Although we did not apply advanced hemodynamic monitoring in this study but as far as heart rate, mean arterial pressure, lactate, and $\mathrm{ScvO}_{2}$ are concerned there was no significant change after the recruitment procedure as compared to baseline therefore it is likely that patients remained hemodynamically stable, suggesting that performing 
recruitment maneuver in CPAP/PS ventilation is a safe strategy in patients with severe acute respiratory failure.

\section{Limitations}

There are several limitations of our study. In the absence of lung CT scans, recruitment and the degree of the recruited lung area cannot be estimated. Although the investigation of Gattinoni et al. still remains the reference method to assess lung recruitment (8) we considered it difficult to be accepted ethically because of the potential dangers of transport and radiation. Furthermore, esophageal and herewith transpulmonary pressures were not monitored therefore we could not conclude if pleural pressure was swinging in spontaneously breathing patients hereby producing different recruitment effects during the time course of the maneuver. Finally, neither the sample size, which was too small, nor the protocol (with one single recruitment maneuver only) allowed us to draw any conclusion regarding hard clinical end-points such as ventilator free days, length of stay or outcome. However, based on the current findings, a study designed to answer these questions is certainly warranted. Nevertheless, the significant tendency what we observed has never been reported before and these preliminary results may provide important information for those who are interested in applying spontaneous assisted/supported modes of ventilation for patients with severe acute respiratory failure.

\section{References}

1. Eastwood G, Bellomo R, Bailey M, Taori G, Pilcher D, Young P, et al. Arterial oxygen tension and mortality in mechanically ventilated patients. Intensive Care Med (2012) 38:91-8. doi:10.1007/s00134-011-2419-6

2. Briel M, Meade M, Mercat A, Brower RG, Talmor D, Walter SD et al. Higher vs lower positive end-expiratory pressure in patients with acute lung injury and acute respiratory distress syndrome: systematic review and meta-analysis. JAMA (2010) 303:865-73. doi:10.1001/jama.2010. 218

3. Guérin C, Reignier J, Richard JC, Beuret P, Gacouin A, Boulain T, et al. Prone positioning in severe acute respiratory distress syndrome. N Engl J Med (2013) 368:2159-68. doi:10.1056/NEJMoa1214103

4. Suzumura EA, Figueiró M, Normilio-Silva K, Laranjeira L, Oliveira C, Buehler AM, et al. Effects of alveolar recruitment maneuvers on clinical outcomes in patients with acute respiratory distress syndrome: a systematic review and meta-analysis. Intensive Care Med (2014) 40:1227-40. doi:10.1007/ s00134-014-3413-6

5. Cortés I, Peñuelas O, Esteban A. Acute respiratory distress syndrome: evaluation and management. Minerva Anestesiol (2012) 78:343-57.

6. Vimlati L, Kawati R, Hedenstierna G, Larsson A, Lichtwarck-Aschoff M. Spontaneous breathing improves shunt fraction and oxygenation in comparison with controlled ventilation at a similar amount of lung collapse. Anesth Analg (2011) 113:1089-95. doi:10.1213/ANE.0b013e31822ceef8

7. Lachman B. Open up the lung and keep the lung open. Intensive Care Med (1992) 18:319-21. doi:10.1007/BF01694358

8. Gattinoni L, Caironi P, Cressoni M, Chiumello D, Ranieri VM, Quintel M, et al. Lung recruitment in patients with the acute respiratory distress syndrome. $N$ Engl J Med (2006) 354:1775-86. doi:10.1056/NEJMoa052052

9. Sassoon CS, Zhu E, Caiozzo VJ. Assist-control mechanical ventilation attenuates ventilator-induced diaphragmatic dysfunction. Am J Respir Crit Care Med (2004) 170:626-32. doi:10.1164/rccm.200401-042OC

10. Putensen C, Muders T, Varelmann D, Wrigge H. The impact of spontaneous breathing during mechanical ventilation. Curr Opin Crit Care (2006) 12:13-8. doi:10.1097/01.ccx.0000198994.37319.60

\section{Conclusion}

Alveolar recruitment maneuver can improve oxygenation in patients suffering from moderate and severe acute hypoxemic respiratory failure and ventilated in CPAP/PS mode as indicated by the significant improvement in oxygenation after recruitment in $74 \%$ of all patients. The decrease in dynamic compliance as displayed on the ventilator after the recruitment maneuver proved to be a simple bed-side indicator of failure in improving oxygenation in spontaneously breathing patients.

\section{Author Note}

The results of this investigation were presented as a poster at the 35th International Symposium on Intensive Care and Emergency Medicine.

\section{Author Contributions}

$\mathrm{ZM}$ and $\mathrm{AL}$ designed the trial, interpreted the results, and drafted the manuscript. MN gave substantial contributions to the conception and design of the study. AL carried out the statistical analysis. $\mathrm{AL}, \mathrm{MN}$, and DT participated in coordination and have made substantial contributions to analysis of data. AL, MN, and DT contributed with data collection and ZM, AL, MN and DT assisted in the critical revision of the manuscript. All authors have read and approved the final version of the manuscript.

11. Cammarota G, Vaschetto R, Turucz E, Dellapiazza F, Colombo D, Blando $\mathrm{C}$, et al. Influence of lung collapse distribution on the physiologic response to recruitment maneuvers during noninvasive continuous positive airway pressure. Intensive Care Med (2011) 37:1095-102. doi:10.1007/s00134-0112239-8

12. Brochard L, Martin GS, Blanch L, Pelosi P, Belda FJ, Jubran A, et al. Clinical review: respiratory monitoring in the ICU - a consensus of 16. Crit Care (2012) 16:219. doi:10.1186/cc11146

13. Murray JF, Matthay MA, Luce JM, Flick MR. An expanded definition of the adult respiratory distress syndrome. Am Rev Respir Dis (1988) 138:720-3. doi:10.1164/ajrccm/138.3.720

14. Ferguson ND, Fan E, Camporota L, Antonelli M, Anzueto A, Beale R, et al. The Berlin definition of ARDS: an expanded rationale, justification, and supplementary material. Intensive Care Med (2012) 38:1573-82. doi:10.1007/ s00134-012-2682-1

15. Lovas A, Trasy D, Nemeth M, Laszlo I, Molnar Z. Effect of lung recruitment on oxygenation in patients with acute lung injury ventilated in CPAP/pressure support mode. Crit Care (2015) 19:226. doi:10.1186/cc14306

16. Wiesen J, Ornstein M, Tonelli AR, Menon V, Ashton RW. State of the evidence: mechanical ventilation with PEEP in patients with cardiogenic shock. Heart (2013) 99:1812-7. doi:10.1136/heartjnl-2013-303642

17. Pinsky MR. Cardiovascular issues in respiratory care. Chest (2005) 128:592S-7S. doi:10.1378/chest.128.5_suppl_2.592S

18. Rocco PR, Pelosi P. Pulmonary and extrapulmonary acute respiratory distress syndrome: myth or reality? Curr Opin Crit Care (2008) 14:50-5. doi:10.1097/ MCC.0b013e3282f2405b

19. Grasso S, Mascia L, Del Turco M, Malacarne P, Giunta F, Brochard L, et al. Effects of recruiting maneuvers in patients with acute respiratory distress syndrome ventilated with protective ventilatory strategy. Anesthesiology (2002) 96:795-802. doi:10.1097/00000542-200204000-00005

20. Esan A, Hess DR, Raoof S, George L, Sessler CN. Severe hypoxemic respiratory failure: part 1 - ventilatory strategies. Chest (2010) 137:1203-16. doi:10.1378/ chest.09-2415

21. Schreiter D, Reske A, Stichert B, Seiwerts M, Bohm SH, Kloeppel R, et al. Alveolar recruitment in combination with sufficient positive end-expiratory 
pressure increases oxygenation and lung aeration in patients with severe ches trauma. Crit Care Med (2004) 32:968-75. doi:10.1097/01.CCM.0000120050. 85798.38

22. Reutershan J, Schmitt A, Dietz K, Unertl K, Fretschner R. Alveolar recruitmen during prone position: time matters. Clin Sci (Lond) (2006) 110:655-63. doi:10. 1042/CS20050337

23. Di Marco F, Devaquet J, Lyazidi A, Galia F, da Costa NP, Fumagalli R, et al Positive end-expiratory pressure-induced functional recruitment in patients with acute respiratory distress syndrome. Crit Care Med (2010) 38:127-32. doi:10.1097/CCM.0b013e3181b4a7e7

24. Huh JW, Hong SB, Lim CM, Koh Y. Effect of the alveolar recruitment manoeuvre on haemodynamic parameters in patients with acute respiratory distress syndrome: relationship with oxygenation. Respirology (2010) 15:1220-5. doi:10 1111/j.1440-1843.2010.01852.x

25. Oczenski W, Hörmann C, Keller C, Lorenzl N, Kepka A, Schwarz S. Recruitment maneuvers after a positive end-expiratory pressure trial do not induce sustained effects in early adult respiratory distress syndrome. Anesthesiology (2004) 101:620-5. doi:10.1097/00000542-200409000-00010

26. Dueck R. Alveolar recruitment versus hyperinflation: a balancing act. Curr Opin Anaesthesiol (2006) 19:650-4. doi:10.1097/ACO.0b013e328011015d

27. Waydhas C. Intrahospital transport of critically ill patients. Crit Care (1999) 3:R83-9. doi:10.1186/cc362

28. Patroniti N, Bellani G, Cortinovis B, Foti G, Maggioni E, Manfio A, et al. Role of absolute lung volume to assess alveolar recruitment in acute respiratory distress syndrome patients. Crit Care Med (2010) 38:1300-7. doi:10.1097/CCM 0b013e3181d8cb51

29. Dellamonica J, Lerolle N, Sargentini C, Beduneau G, Di Marco F, Mercat A, et al. PEEP-induced changes in lung volume in acute respiratory distress syndrome. Two methods to estimate alveolar recruitment. Intensive Care Med (2011) 37:1595-604. doi:10.1007/s00134-011-2333-y

30. Blanch L, Fernández R, Benito S, Mancebo J, Net A. Effect of PEEP on the arterial minus end-tidal carbon dioxide gradient. Chest (1978) 92:451-4. doi:10. 1378/chest.92.3.451

31. Schumann S, Vimlati L, Kawati R, Guttmann J, Lichtwarck-Aschoff M. Analysis of dynamic intratidal compliance in a lung collapse model. Anesthesiology (2011) 114:1111-7. doi:10.1097/ALN.0b013e31820ad41b

32. Toth I, Leiner T, Mikor A, Szakmany T, Bogar L, Molnar Z. Hemodynamic and respiratory changes during lung recruitment and descending optimal positive end-expiratory pressure titration in patients with acute respiratory distress syndrome. Crit Care Med (2007) 35:787-93. doi:10.1097/01.CCM.0000257330. 54882.BE

33. Villagrá A, Ochagavía A, Vatua S, Murias G, Del Mar Fernández M, Lopez Aguilar J, et al. Recruitment maneuvers during lung protective ventilation in acute respiratory distress syndrome. Am J Respir Crit Care Med (2002) 165:165-70. doi:10.1164/ajrccm.165.2.2104092

Conflict of Interest Statement: The authors declare that the research was conducted in the absence of any commercial or financial relationships that could be construed as a potential conflict of interest.

Copyright (C) 2015 Lovas, Németh, Trásy and Molnár. This is an open-access article distributed under the terms of the Creative Commons Attribution License (CC BY). The use, distribution or reproduction in other forums is permitted, provided the original author(s) or licensor are credited and that the original publication in this journal is cited, in accordance with accepted academic practice. No use, distribution or reproduction is permitted which does not comply with these terms. 

III 



\title{
Review Article
}

\section{Haemodynamic Effects of Lung Recruitment Manoeuvres}

\author{
András Lovas ${ }^{1}$ and Tamás Szakmány ${ }^{2,3}$ \\ ${ }^{1}$ Department of Anaesthesiology and Intensive Therapy, University of Szeged, Semmelweis Utca 6, Szeged 6725, Hungary \\ ${ }^{2}$ Department of Anaesthesia, Intensive Care and Pain Medicine, Cardiff University, Institute of Infection and Immunology, \\ Heath Park Campus, Cardiff CF14 4XN, UK \\ ${ }^{3}$ Aneurin Bevan University Health Board, Critical Care Directorate, Royal Gwent Hospital, Cardiff Road, Newport NP20 5UB, UK \\ Correspondence should be addressed to András Lovas; lovas.andras@med.u-szeged.hu
}

Received 21 July 2015; Revised 29 September 2015; Accepted 12 October 2015

Academic Editor: Xavier Monnet

Copyright ( 2015 A. Lovas and T. Szakmány. This is an open access article distributed under the Creative Commons Attribution License, which permits unrestricted use, distribution, and reproduction in any medium, provided the original work is properly cited.

\begin{abstract}
Atelectasis caused by lung injury leads to increased intrapulmonary shunt, venous admixture, and hypoxaemia. Lung recruitment manoeuvres aim to quickly reverse this scenario by applying increased airway pressures for a short period of time which meant to open the collapsed alveoli. Although the procedure can improve oxygenation, but due to the heart-lung and right and left ventricle interactions elevated intrathoracic pressures can inflict serious effects on the cardiovascular system. The purpose of this paper is to give an overview on the pathophysiological background of the heart-lung interactions and the best way to monitor these changes during lung recruitment.
\end{abstract}

\section{Introduction}

Patients admitted to the intensive care unit are often affected by acute respiratory distress syndrome (ARDS). ARDS is a life-threatening condition precipitated by disorders frequently resulting in critical care admissions like trauma, severe burns, sepsis, pancreatitis, and pneumonia [1]. All of these disorders, either causing direct (pulmonary) or indirect (extrapulmonary) tissue damage, are featured by a systemic inflammatory response. The released cytokines like interleukin- (IL-) 1, IL-6, IL-8, and tumor necrosis factor activate neutrophils in the lung throughout the inflammatory cascade [2]. The activated immune cells excrete injurious substances such as free oxygen radicals and proteolytic enzymes leading to alveolar endothelium and epithelium destruction. The latter pathophysiological mechanism induces impaired permeability in the lung resulting in alveolar immerging by the protein-rich oedema fluid [3]. Surfactant, which has a major role in modulating the surface tension of alveoli, is also washed out. Furthermore, the surfactant production is also decreased due to the dysfunction of type II epithelial cells. As a consequence, pulmonary atelectasis develops due to alveolar collapse [4].
Pulmonary atelectasis is accompanied by arterial hypoxaemia due to increased intrapulmonary shunt [5]. As severe acute hypoxaemia is a potential danger for all vital organs, its resolution is of pivotal importance. There are several interventions, which may help improve oxygenation. In the most severe circumstances, extracorporeal membrane oxygenation [6], high frequency oscillatory ventilation [7], and prone positioning [8] have been shown to reverse persistent hypoxaemia. Some of these interventions require special equipment, demand extra manpower, and may be time consuming to commence. In less severe cases of acute hypoxaemia, especially when this is primarily caused by atelectasis, the collapsed lung areas can be opened up with the help of transient increment in transpulmonary pressure (TP) within a short time, hence decreasing shunt fraction and improving arterial oxygenation [9]. This procedure is called the lung recruitment manoeuvre. It can be accompanied by the titration of the "optimal" PEEP, a process which is called on a broader term the "open lung concept" described by Lachmann in 1992 [10].

Several applications of recruitment manoeuvres have been described so far. Although these may differ in certain details but by-and-large the most common feature is in all of them that they apply peak airway pressures of $40-60 \mathrm{~cm} \mathrm{H}_{2} \mathrm{O}$ 
for a short period of time, usually not exceeding 40120 seconds [9]. Although survival benefit has not been demonstrated with any of the recruitment manoeuvres, the intervention is frequently administered in atelectasis induced hypoxaemia [11]. It is beyond the scope of this paper to review the available recruitment techniques; therefore we will only concentrate on the heart-lung interactions, haemodynamic effects, and the monitoring alternatives.

The anatomical proximity of the lungs and heart within the chest means that transiently increased intrathoracic pressures have major effect on systemic cardiovascular function. Undesired side effects of the recruitment process mainly arise from the increased airway pressures which can cause overdistension of alveoli in well-ventilated lung areas, marked increase in ventilation-perfusion mismatch, barotrauma, pneumothorax, and new air leak around an existing chest tube [12]. These effects may be even more pronounced in patients with ARDS in whom haemodynamic instability is a common feature [13]. It has strong pathophysiological rationale supported by clinical data that routine ICU monitoring, such as invasive blood pressure and central venous pressure monitoring, may not be adequate to follow haemodynamic changes encountered during lung recruitment [14].

\section{Effects on Right Heart and Pulmonary Circulation}

Distending lung volume evoked by applied raised airway pressure leads to an increase in TP. TP can be estimated from the difference between alveolar and intrathoracic pressures. The transmission of TP to the pleural space impedes venous return and the filling of the right ventricle. Meanwhile, the increased TP is transposed to vessels interlacing the lung tissue hereby elevating pulmonary vascular resistance (PVR) and right ventricular afterload.

\subsection{Systemic Venous Return and Right Ventricle Preload. The increase of intrathoracic pressure compresses the right atrium and caval veins carrying the systemic venous return to the heart. The generated retrograde pressure results in elevation in the central venous pressure (CVP) and could impede right ventricular filling. Due to this mechanism the assessment of cardiac preload by CVP during lung recruitment manoeuvre is misleading, as the transmission of the intrathoracic pres- sure to the intravascular compartment [14] does not represent the true preload component. Restricted right ventricular preload is a dominant but not solitary mechanism in the fall of the right ventricular ejection fraction.}

\subsection{Right Ventricular Afterload. Right ventricular afterload} represents the resistance, quantified by the pulmonary artery pressure, which the right ventricle should overcome to eject the blood through the pulmonary valve. During the lung recruitment manoeuvre, the interposed TP further increases the area where the intraluminal pressure of the juxta-alveolar capillaries is lower than the intra-alveolar pressure. This results in a significant increase in the pulmonary vascular resistance, parallel to an increase in the pulmonary artery pressure. Thus right ventricular afterload is augmented by transitionally elevated TP.

Hypoxic pulmonary vasoconstriction, which developed to attenuate the ventilation-perfusion mismatch caused by alveolar hypoventilation, is another important determinant of the right ventricular afterload [15]. During significant hypoxaemia, the atelectatic lung regions are served with only marginal circulation. The hypoxic pulmonary vasoconstriction contributes to the overall pulmonary vascular resistance; however there is only limited data about its role and the changes occurring during lung recruitment.

These mechanisms can impair right ventricular function and decrease right ventricular stroke volume. Iannuzzi et al. [16] found that pressure controlled ventilation (PCV) with peak inspiratory pressure of $45 \mathrm{~cm} \mathrm{H}_{2} \mathrm{O}$ for 2 minutes generated a higher grade of lung opening and resulted in a major and significant increase in $\mathrm{PaO}_{2} / \mathrm{FiO}_{2}$ ratio compared to sustained inflation (SI) (Figure 1). They found that hypoxic pulmonary vasoconstriction and pulmonary vascular resistance index (PVRI) were also reduced, with smaller degree of hyperinflation in the PCV group (Figure 1).

On the other hand, Reis Miranda et al. could not detect any significant impairment in right heart function comparing conventional mechanical ventilation to the open lung concept in patients after cardiac surgery [17]. This disagreement between the two observations may arise from the different methods applied, especially the different timing of measurements. Whereas Iannuzzi et al. investigated the immediate effects [16], in the other study cardiovascular measurements were taken every 30 minutes for 3 hours [17].

Similar results were reported by Celebi et al. [18] where pulmonary and haemodynamic effects of two different recruitment manoeuvres were investigated in patients after open heart surgery. During the study period, there was no significant change of PVR between the groups, measured after 15 minutes. One may suggest from these observations that the effect of the recruitment manoeuvre on the right ventricular afterload is transient, lasting for seconds only. Relieving high airway pressures after recruitment helps in the normalization of haemodynamic changes in the pulmonary circulation.

Apart from the different methods employed in the studies, controversial results may arise from the different patient inclusion criteria. In the study of Iannuzzi et al., patients with primary ARDS due to hospital acquired bacterial pneumonia were recruited [16], whilst Reis Miranda et al. investigated patients following cardiac surgery without significant lung injury [17]. It has been demonstrated in a murine model of acute lung injury induced by Escherichia coli lipopolysaccharide that dynamic inflation applied during lung recruitment produced increased right ventricular pressure and total PVR. It also resulted in sustained inflammation and vascular dysfunction whilst no similar changes were reported in healthy lungs [19].

2.3. Right Ventricular Ejection Fraction. The primary role of the right ventricle is to receive systemic venous blood and to forward it via a high volume and low-pressure system, the pulmonary circulation, to the left heart chambers [20]. Right ventricular ejection fraction is affected by preload, 


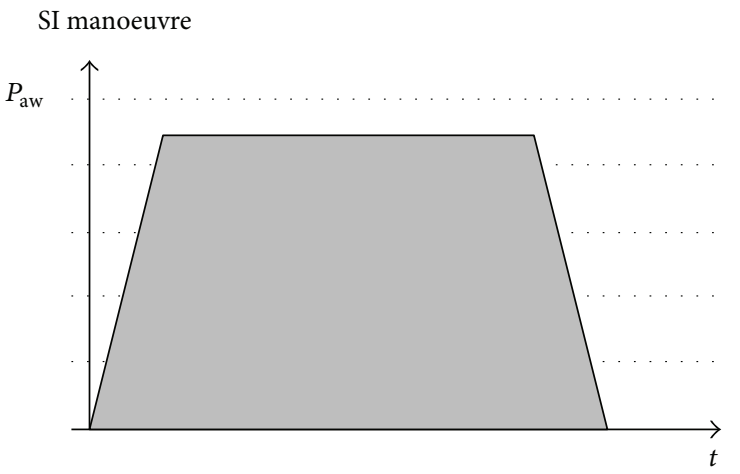

(a)

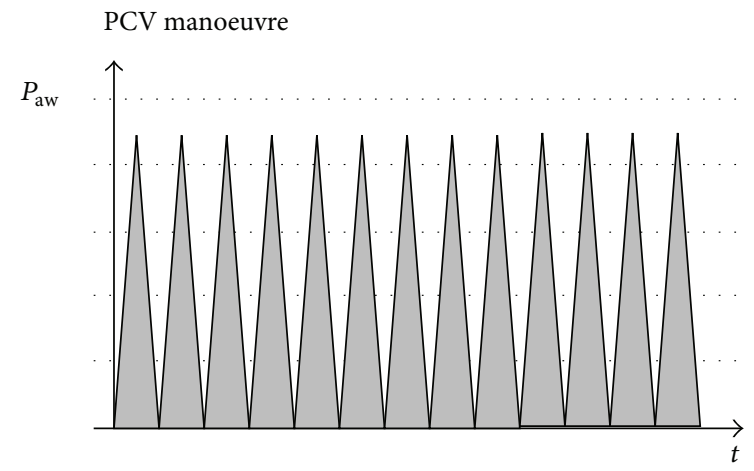

(b)

\begin{tabular}{lcc}
\hline & SI manoeuvre & PCV manoeuvre \\
\hline Lung opening & $\uparrow$ & $\uparrow \uparrow \uparrow$ \\
$\mathrm{PaO}_{2} / \mathrm{FiO}_{2}$ & $\uparrow$ & $\uparrow \uparrow \uparrow$ \\
$\mathrm{CI}$ & $\downarrow \downarrow$ & $\leftrightarrow$ \\
PVRI & $\uparrow \uparrow$ & $\downarrow \downarrow$ \\
RWSVI & $\downarrow$ & $\downarrow \downarrow$ \\
EI & $\uparrow \uparrow$ & $\uparrow$ \\
\hline
\end{tabular}

(c)

FIgURE 1: Pressure-time product (a-b) and main characteristics (c) of sustained inflation (SI) and pressure control ventilation (PCV) recruitment manoeuvres. $P_{\text {aw }}$, airway pressure; $t$, time; CI, cardiac index; PVRI, pulmonary vascular resistance index; RWSVI, right ventricle stroke work index; EI, eccentricity index.

contractility, and afterload. During the recruitment manoeuvre, the raised intrathoracic and right atrial pressures, as discussed previously, could affect both venous return and afterload significantly [18] (Figures 2 and 3). Both mechanisms can result in impaired right ventricular contractility.

Right ventricular ejection fraction is inversely related to the ventricle's afterload. In the study by Reis Miranda et al. [17], PVRI and right ventricular ejection fraction showed no significant changes following recruitment within the first 3 hours, neither within nor between groups at any measurement points. However, if immediate effects on right ventricular function were investigated, then significant increase in right ventricular stroke work index was reported during the recruitment manoeuvre and 2 minutes following the intervention [21]. These results call for further attention to the immediate effects of the recruitment manoeuvre on right heart function. There is also lack of data, whether it has any clinically relevant long-term effects.

2.4. Ventricular Interdependence. It is important to note that the end-diastolic right ventricular volume has a direct effect on the left ventricle, which holds true vice versa. This is called the ventricular diastolic interdependence [22]. The two chambers are coupled within a common pericardial sac and share joint intraventricular septa as a traverse wall. Thus, their volumes are limited by the pericardium; hence any change in the right ventricular end-diastolic volume has an effect on the left ventricular end-diastolic volume (Figure 4).

During sigh recruitment, the right ventricle can have a marked effect on the adjacent heart chamber. When lung recruitment manoeuvre is applied by a sustained inspiration, left ventricular end-diastolic area can be reduced by as much as $45 \%$ [23]. PVR is also increasing with the transposed intrathoracic pressure, leading to an acute right ventricular pressure overload with dilation, leftward septal shift, and left ventricular collapse resulting in low cardiac output $(\mathrm{CO})$ and marked systemic haemodynamic changes (Figure 4). These changes are transient and only seen during the manoeuvre, with almost instant normalisation of haemodynamics once the intrathoracic pressure returns to the baseline [16].

There is a special scenario when this interdependence is questioned and this is the postoperative period after cardiac surgery when the pericardial sac is kept open [17]. Theoretically, due to the missing pericardial sac, interaction between the two adjacent ventricles should be impaired and in these patients the diastolic interdependence is not fully present. However, in an animal experiment on dogs, it was found that artificially increasing the pulmonary artery resistance and the right ventricular load had a profound effect on the left ventricular filling dynamics. This was explained by the prolonged relaxation and altered pressure-volume chamber relations [24]. 


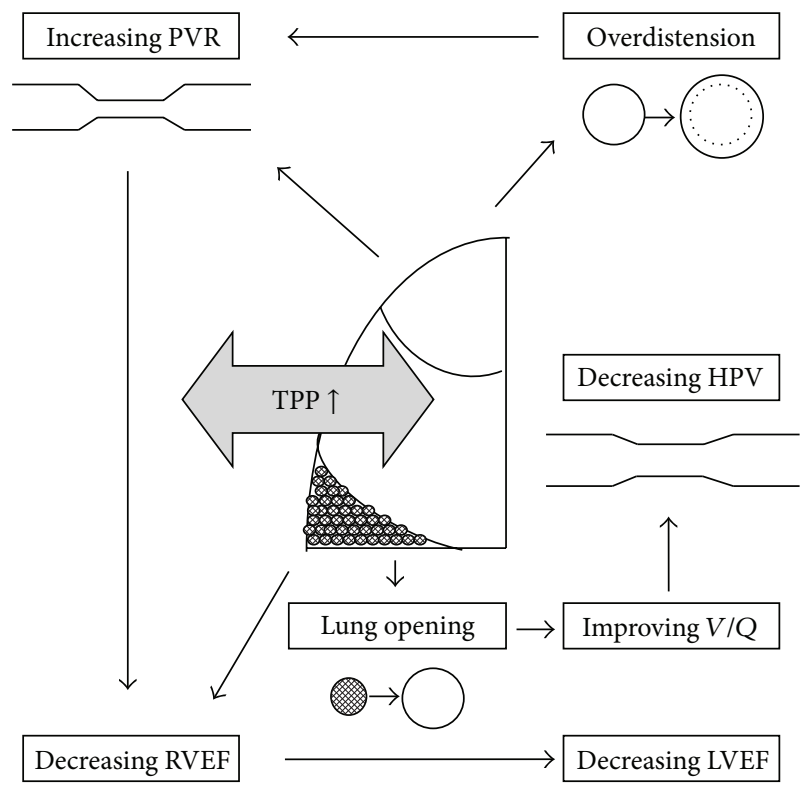

FIGURE 2: The effects of increased transpulmonary pressure (TPP). PVR, pulmonary vascular resistance; RVEF, right ventricular ejection fraction; LVEF, left ventricular ejection fraction; $V / Q$, ventilation/perfusion; HPV, hypoxic pulmonary vasoconstriction.

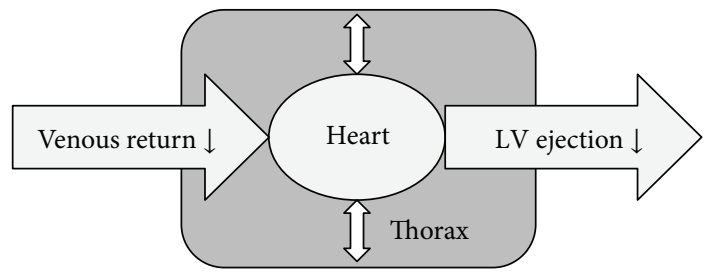

FiguRe 3: Pressure chamber (heart) in a pressure chamber (thorax). LV ejection; left ventricular ejection.

\section{Effects on Left Heart and Systemic Circulation}

The cardiopulmonary system is described by Pinsky as a pressure chamber inside a pressure chamber [25]. Any increment in the intrathoracic pressure increases the right atrial pressure and decreases the venous return and the transmural left ventricular systolic pressure, hence attenuating the left ventricular ejection fraction (Figure 3 ). If haemodynamic changes are solely monitored by mean arterial pressure (MAP) during lung recruitment manoeuvre, one can theoretically miss relevant alterations in the systemic circulation. Recent investigations concluded that simple haemodynamic parameters like MAP or heart rate did not show any significant change during and after various recruitment interventions [17, 21, 26]. However, applying advanced invasive haemodynamic monitoring, relevant changes in the systemic circulation can be observed [14].

3.1. Left Ventricle Preload and Afterload. As described above, ventricular interdependence plays a significant role during lung recruitment manoeuvre in determining the left ventricular preload. The increased TP compresses the right atrium and increases the CVP by the transmission of pressure to the intraluminal compartment of the caval veins. Echocardiographic investigations identify this mechanism as partial cause of the impaired left ventricular preload and consecutive decrease of CO [16].

Left ventricular afterload is defined as the pressure of the wall in the left ventricle during ejection. Following Laplace's law, if there is no significant alteration in the systolic arterial pressure, as seen throughout most of the studies investigating recruitment manoeuvre, left ventricle afterload decreases along with the fall of the transmural pressure of the left ventricle [27]. Measuring these pressure fluctuations requires sophisticated methods at the bedside; therefore correlation between left ventricle afterload and lung recruitment has not been investigated thoroughly in human subjects.

\subsection{Cardiac Output and Left Ventricular End-Diastolic Vol-} ume. The increased availability of sophisticated continuous $\mathrm{CO}$ monitoring using pulse pressure analysis like pulse contour cardiac output (PiCCO), lithium dilution cardiac output (LiDCO), or FloTrac/Vigileo techniques and Doppler cardiac output devices enabled the clinicians to follow alterations in the systemic haemodynamics during each cardiac cycle [28]. Utilising these advanced monitoring techniques, profound and significant decrease in $\mathrm{CO}$ was observed during lung recruitment manoeuvres $[14,16,23]$. This decline in left ventricular performance can be explained by interconnected fluctuations within the "chamber in the chamber" system discussed previously [25]. Increased intrathoracic pressure, decreased right ventricular filling, and increased right ventricular outflow impedance with leftward intraventricular septal shift are all precipitating reduced CO (Figure 2). However, rapid recovery of the baseline $\mathrm{CO}$ was described when the effects were measured in a temporal study, so the depression is only transient correlating with the temporarily increased TP [29].

The absolute reduction in $\mathrm{CO}$ is influenced by the technique of the lung recruitment and also by the nature of the lung injury. As discussed previously, sustained inflation manoeuvre can significantly change left ventricle eccentricity index (Figure 4) indicating a significant reduction in left ventricular end-diastolic volume compared to PCV-recruitment, which was accompanied by a less profound effect.

The importance of the underlying pathology of the lung injury has been emphasised by Lim et al. [29]. They investigated three different types of lung injury models during recruitment: oleic acid injury depicting acute surfactant loss, ventilator-induced lung injury, and finally an injury caused by infection. Animals in all three models underwent a PCV, a sigh, and a PEEP incremental recruitment. Regardless of the way the manoeuvres were executed, a significant but interim drop of $\mathrm{CO}$ was observed in each model. However, in the pneumonia model, the $\mathrm{CO}$ decreased to a greater extent and the recovery of systemic haemodynamics also showed a moderate pattern as compared to the other two. It is possible that, in septic shock induced inflammatory response, 


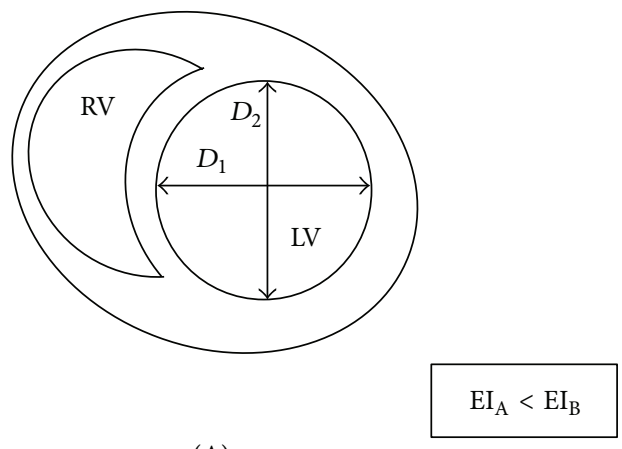

(A)

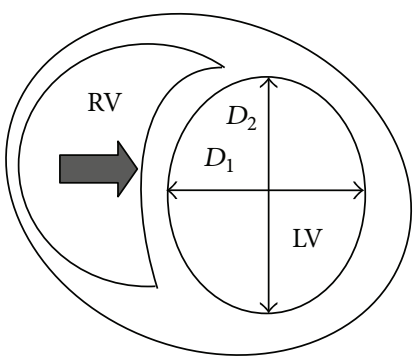

(B)

FIGURE 4: Ventricular interdependence before (A) and during alveolar recruitment manoeuvre (B). $D_{1}$, midmitral diameter; $D_{2}$, diameter orthogonal to $D_{1}$. Eccentricity index (EI) is calculated as $D_{2} / D_{1}$. RV, right ventricle; LV, left ventricle.

a more profound depression of myocardial function and compensatory vasomotor reflexes takes place [30]. Out of the three recruitment techniques, the sigh manoeuvre resulted in the most significant reduction in $\mathrm{CO}$ in accordance with previous investigations $[16,29]$.

One of the available methods to prevent the undesired decrease in $\mathrm{CO}$ during lung recruitment is the selective lung opening technique described by Hansen et al. in an elegant animal model [31]. In their experiment, pigs were randomized into two groups of lung recruitment manoeuvres (by applying $40 \mathrm{~cm} \mathrm{H}_{2} \mathrm{O}$ airway pressure for 30 seconds), either a selective lung recruitment manoeuvre such as using the inner lumen of the bronchial blocker followed by a whole lung recruitment manoeuvre or vice versa. Whilst there was no significant difference in the improvement of oxygenation and the end-expiratory lung volume between the two groups, there were no circulatory changes during the selective technique. On the other hand, the whole lung recruitment caused a significant drop in $\mathrm{CO}$ and left ventricular enddiastolic volume. This suggests that selective lung recruitment technique might be advantageous in patients with lobar atelectasis prone to haemodynamic instability. However, this new method requires further investigations in humans.

3.3. Alterations in Heart Rate. Along with stroke volume, heart rate is the other determinant of CO. Through the recruitment manoeuvre, one may expect the development of reflex tachycardia along the drop in CO. Many investigations failed to observe such an increase in heart rate; principally no significant alteration of pulse rate was found $[14,16-$ $18,21,26]$. However, in the investigation of Nielsen et al., the significant reduction in heart rate was suspected as the major component of the declining $\mathrm{CO}$ during the sigh manoeuvre [23]. One of the explanations is that the inflated lung tissue can activate vagal tone causing bradycardia [32]. Another assumption is that the sigh manoeuvre may precipitate a similar pattern in intrathoracic pressure as the Valsalva manoeuvre, hence producing reduction in heart rate. As opposed to the previous findings, Lim et al. reported an increased heart rate, perhaps reflecting just a sympathetic response to the lengthy recruitment procedure they used [33].
3.4. The Effect of Volemic State on Left Heart Function. One of the main patient exclusion criteria in the lung recruitment studies is haemodynamic instability and/or signs of intravascular volume depletion [14, 18, 23, 26, 33]. Hypovolaemia can amplify the undesirable haemodynamic effects of lung recruitment manoeuvre as demonstrated by Nielsen et al. [34]. In their animal experiment, the impact of recruitment manoeuvre on central haemodynamics was investigated in pigs with different volemic states. The animals were randomized to a 10 -second-long recruitment followed by lung opening lasting 30 seconds by applying $40 \mathrm{~cm} \mathrm{H}_{2} \mathrm{O}$ airway pressure or vice versa, performed under hypo-, normo-, and hypervolemia. Volemic states were controlled either by removing $15 \%$ of the estimated blood volume or by infusion of a volume equal to $15 \%$ of the estimated blood volume with 3\% dextran in Ringer's solution. The study focused on the immediate circulatory effects. They found a significant reduction in left ventricular end-diastolic volume, which could explain the depleted $\mathrm{CO}$ during lung recruitment manoeuvre in pigs with acute lung injury. As expected, the impact of this effect was significantly exaggerated by hypovolaemia. On the other hand, hypervolemic conditions prevented the reduction of $\mathrm{CO}$ during the extended sigh manoeuvre.

Fougères et al. suggested that some microvessels of the lungs may be collapsed by PEEP and were recruitable by the increased left ventricular preload [35]. In their recent investigation in patients with ARDS, recruitment was accomplished by increasing PEEP for reaching a plateau pressure of $30 \mathrm{~cm} \mathrm{H}_{2} \mathrm{O}$. During the manoeuvre, $\mathrm{CO}$ was decreased along with increasing right ventricular afterload. Importantly, passive leg raising restored the $\mathrm{CO}$ and reduced the PVR. These important observations reinforce the need of appropriate intravascular volume assessment prior to the alveolar opening procedure.

\section{Recruitment in Spontaneously Breathing Patients}

There is some evidence that patients on continuous positive airway pressure and pressure support ventilation may 
benefit from recruitment manoeuvres, resulting in fast and significant improvement in oxygenation [26]. However, there are very few publications in this topic as most studies on recruitment were performed in patients receiving controlled mechanical ventilation. Although it is well known that spontaneous ventilation and spontaneous breathing efforts significantly interfere with heart-lung interactions, apart from routine parameters such as blood pressure and heart rate, we have no detailed haemodynamic information in this patient group. As the changes are markedly different from that observed during controlled ventilation, this can be a potential field for further research.

\section{Conclusions}

Applying recruitment technique is a simple procedure to perform at the bedside but it is not free of certain risks. Increased airway and intrathoracic pressures can inflict deleterious haemodynamic effects due to the anatomical proximity of the lungs and heart within the thoracic cavity. Therefore, detailed understanding of the physiology and pathophysiology of these changes is necessary to perform lung recruitment safely. The evidence suggests that those patients who are at risk of overt hypovolaemia or whose lung injury is secondary to a primary lung infection, hence developing significant localised inflammatory changes, are more likely to benefit from advanced haemodynamic monitoring by devices that enable continuous and reliable evaluation of cardiac output during lung recruitment so that the treating clinician can maintain circulatory homeostasis.

\section{Conflict of Interests}

The authors declare that there is no conflict of interests regarding the publication of this paper.

\section{References}

[1] I. Cortés, O. Peñuelas, and A. Esteban, "Acute respiratory distress syndrome: evaluation and management," Minerva Anestesiologica, vol. 78, no. 3, pp. 343-357, 2012.

[2] W. L. Lee and G. P. Downey, "Neutrophil activation and acute lung injury," Current Opinion in Critical Care, vol. 7, no. 1, pp. $1-7,2001$.

[3] S. Han and R. K. Mallampalli, "The acute respiratory distress syndrome: from mechanism to translation," The Journal of Immunology, vol. 194, no. 3, pp. 855-860, 2015.

[4] L. B. Ware and M. A. Matthay, "The acute respiratory distress syndrome," The New England Journal of Medicine, vol. 342, no. 18, pp. 1334-1349, 2000.

[5] P. Pelosi and M. G. de Abreu, "Acute respiratory distress syndrome: we can't miss regional lung perfusion!," BMC Anesthesiology, vol. 15, article 35, 2015.

[6] A. Leligdowicz and E. Fan, "Extracorporeal life support for severe acute respiratory distress syndrome," Current Opinion in Critical Care, vol. 21, no. 1, pp. 13-19, 2015.

[7] N. D. Ferguson, D. J. Cook, G. H. Guyatt et al., "High-frequency oscillation in early acute respiratory distress syndrome," The
New England Journal of Medicine, vol. 368, no. 9, pp. 795-805, 2013.

[8] C. Guérin, J. Reignier, J.-C. Richard et al., "Prone positioning in severe acute respiratory distress syndrome," The New England Journal of Medicine, vol. 368, no. 23, pp. 2159-2168, 2013.

[9] J. C. Keenan, P. Formenti, and J. J. Marini, "Lung recruitment in acute respiratory distress syndrome: what is the best strategy?" Current Opinion in Critical Care, vol. 20, no. 1, pp. 63-68, 2014.

[10] B. Lachmann, "Open up the lung and keep the lung open," Intensive Care Medicine, vol. 18, no. 6, pp. 319-321, 1992.

[11] R. M. Kacmarek and J. Villar, "Management of refractory hypoxemia in ARDS," Minerva Anestesiologica, vol. 79, no. 10, pp. 1173-1179, 2013.

[12] E. Fan, W. Checkley, T. E. Stewart et al., "Complications from recruitment maneuvers in patients with acute lung injury: secondary analysis from the lung open ventilation study," Respiratory Care, vol. 57, no. 11, pp. 1842-1849, 2012.

[13] B. M. Fuller, N. M. Mohr, T. J. Graetz et al., "The impact of cardiac dysfunction on acute respiratory distress syndrome and mortality in mechanically ventilated patients with severe sepsis and septic shock: an observational study," Journal of Critical Care, vol. 30, no. 1, pp. 65-70, 2015.

[14] I. Toth, T. Leiner, A. Mikor, T. Szakmany, L. Bogar, and Z. Molnar, "Hemodynamic and respiratory changes during lung recruitment and descending optimal positive end-expiratory pressure titration in patients with acute respiratory distress syndrome," Critical Care Medicine, vol. 35, no. 3, pp. 787-793, 2007.

[15] C. H. Orchard, R. Sanchea de Leon, and M. K. Sykes, "The relationship between hypoxic pulmonary vasoconstriction and arterial oxygen tension in the intact dog," The Journal of Physiology, vol. 338, pp. 61-74, 1983.

[16] M. Iannuzzi, A. de Sio, E. de Robertis, O. Piazza, G. Servillo, and R. Tufano, "Different patterns of lung recruitment maneuvers in primary acute respiratory distress syndrome: effects on oxygenation and central hemodynamics," Minerva Anestesiologica, vol. 76, no. 9, pp. 692-698, 2010.

[17] D. Reis Miranda, D. Gommers, A. Struijs et al., "The open lung concept: effects on right ventricular afterload after cardiac surgery," British Journal of Anaesthesia, vol. 93, no. 3, pp. 327332, 2004

[18] S. Celebi, Ö. Köner, F. Menda, K. Korkut, K. Suzer, and N. Cakar, "The pulmonary and hemodynamic effects of two different recruitment maneuvers after cardiac surgery," Anesthesia and Analgesia, vol. 104, no. 2, pp. 384-390, 2007.

[19] A. M. Dessap, G. Voiriot, T. Zhou et al., "Conflicting physiological and genomic cardiopulmonary effects of recruitment maneuvers in murine acute lung injury," American Journal of Respiratory Cell and Molecular Biology, vol. 46, no. 4, pp. 541550, 2012.

[20] F. Haddad, S. A. Hunt, D. N. Rosenthal, and D. J. Murphy, "Right ventricular function in cardiovascular disease, part I: anatomy, physiology, aging, and functional assessment of the right ventricle," Circulation, vol. 117, no. 11, pp. 1436-1448, 2008.

[21] J. W. Huh, S.-B. Hong, C.-M. Lim, and Y. Koh, "Effect of the alveolar recruitment manoeuvre on haemodynamic parameters in patients with acute respiratory distress syndrome: relationship with oxygenation," Respirology, vol. 15, no. 8, pp. 1220-1225, 2010.

[22] J. S. Janicki and K. T. Weber, "The pericardium and ventricular interaction, distensibility, and function," The American Journal of Physiology, vol. 238, no. 4, pp. H494-H503, 1980. 
[23] J. Nielsen, M. Østergaard, J. Kjaergaard et al., "Lung recruitment maneuver depresses central hemodynamics in patients following cardiac surgery," Intensive Care Medicine, vol. 31, no. 9, pp. 1189-1194, 2005.

[24] J. I. Fragata and J. C. Areias, "Acute loads applied to the right ventricle: effect on left ventricular filling dynamics in the presence of an open pericardium," Pediatric Cardiology, vol. 17, no. 2, pp. 77-81, 1996.

[25] M. R. Pinsky, "Recent advances in the clinical application of heart-lung interactions," Current Opinion in Critical Care, vol. 8, no. 1, pp. 26-31, 2002.

[26] A. Lovas, M. F. Németh, D. Trásy, and Z. Molnár, "Lung recruitment can improve oxygenation in patients ventilated in continuous positive airway pressure/pressure support mode," Frontiers in Medicine, vol. 2, article 25, 2015.

[27] C. Katzenberg, M. Olajos, E. Morkin, and S. Goldman, "Effects of changes in airway pressure on the left ventricle and left atrium of dogs," Cardiovascular Research, vol. 20, no. 11, pp. 853-862, 1986.

[28] J. A. Alhashemi, M. Cecconi, and C. K. Hofer, "Cardiac output monitoring: an integrative perspective," Critical Care, vol. 15, no. 2, article 214, 2011.

[29] S.-C. Lim, A. B. Adams, D. A. Simonson et al., "Transient hemodynamic effects of recruitment maneuvers in three experimental models of acute lung injury," Critical Care Medicine, vol. 32, no. 12, pp. 2378-2384, 2004.

[30] K. R. Walley, "Deeper understanding of mechanisms contributing to sepsis-induced myocardial dysfunction," Critical Care, vol. 18, no. 3, article 137, 2014.

[31] L. K. Hansen, E. Sloth, J. Nielsen et al., "Selective recruitment maneuvers for lobar atelectasis: effects on lung function and central hemodynamics: an experimental study in pigs," Anesthesia \& Analgesia, vol. 102, no. 5, pp. 1504-1510, 2006.

[32] J. A. Campagna and C. Carter, "Clinical relevance of the BezoldJarisch reflex," Anesthesiology, vol. 98, no. 5, pp. 1250-1260, 2003.

[33] C.-M. Lim, Y. Koh, W. Park et al., "Mechanistic scheme and effect of 'extended sigh' as a recruitment maneuver in patients with acute respiratory distress syndrome: a preliminary study," Critical Care Medicine, vol. 29, no. 6, pp. 1255-1260, 2001.

[34] J. Nielsen, M. Nilsson, F. Fredén et al., "Central hemodynamics during lung recruitment maneuvers at hypovolemia, normovolemia and hypervolemia. a study by echocardiography and continuous pulmonary artery flow measurements in lunginjured pigs," Intensive Care Medicine, vol. 32, no. 4, pp. 585-594, 2006.

[35] E. Fougères, J.-L. Teboul, C. Richard, D. Osman, D. Chemla, and $\mathrm{X}$. Monnet, "Hemodynamic impact of a positive end-expiratory pressure setting in acute respiratory distress syndrome: importance of the volume status," Critical Care Medicine, vol. 38, no. 3, pp. 802-807, 2010. 
